\title{
The National Energy Modeling System:
}

\section{An Overview 1998}

\section{February 1998}

Energy Information Administration

Office of Integrated Analysis and Forecasting

U.S. Department of Energy

Washington, DC 20585

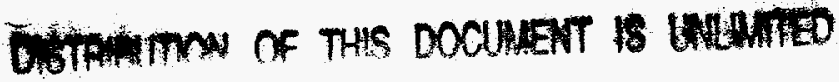

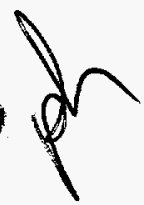

This report was prepared by the Energy Information Administration, the independent statistical and analytical agency within the U.S. Department of Energy. The information contained herein should be attributed to the Energy Information Administration and should not be construed as advocating or reflecting any policy position of the Department of Energy or any other organization. 


\section{PREFACE}

The National Energy Modeling System: An Overview provides a summary description of the National Energy Modeling System (NEMS), which was used to generate the forecasts of energy production, demand, imports, and prices through the year 2020 for the Annual Energy Outlook 1998 (AEO98), (DOE/EIA-0383(98)), released in December 1997. AEO98 presents national forecasts of energy markets for five cases-a reference case and four additional cases that assume higher and lower economic growth and higher and lower world oil prices than in the reference case. The Overview presents a brief description of the methodology and scope of each of the component modules of NEMS. The model documentation reports listed in the appendix of this document provide further details.

The Overview was prepared by the Energy Information Administration (EIA), Office of Integrated Analysis and Forecasting under the direction of Mary J. Hutzler (mhutzler@eia.doe.gov, 202/586-2222), Director of the Office of Integrated Analysis and Forecasting; Arthur T. Andersen (aanderse@eia.doe.gov, 202/586-1441), Director of the Energy Demand and Integration Division; Scott Sitzer (ssitzer@eia.doe.gov, 202/586-2308), Director of the Energy Supply and Conversion Division; and Andy S. Kydes (akydes@eia.doe.gov, 202/586-2222), Senior Modeling Analyst. Detailed questions concerning NEMS may be addressed to the following analysts:

AEO98 ........................... Susan H. Holte (sholte@eia.doe.gov, 202/586-4838)

Integrating Module/Carbon Emissions ........... Daniel H. Skelly (dskelly@eia.doe.gov, 202/586-1722)

Macroeconomic Activity Module ............. Kay A. Smith (ksmith@eia.doe.gov, 202/586-1455)

International Energy Module ............... G. Daniel Butler (gbutler@eia.doe.gov, 202/586-9503)

Residential Demand Module ............... John Cymbalsky (jcymbals@eia.doe.gov, 202/586-4815)

Commercial Demand Module ............... Erin Boedecker (eboedeck@eia.doe.gov, 202/586-4791)

Industrial Demand Module ................ T. Crawford Honeycutt (choneycu@eia.doe.gov, 202/586-1420)

Transportation Demand Module ............. David Chien (dchien@eia.doe.gov, 202/586-3994)

Electricity Market Module ................. Jeffrey Jones (jjones@eia.doe.gov, 202/586-2038)

Renewable Fuels Module ................... Thomas Petersik (tpetersi@eia.doe.gov, 202/586-6582)

Oil and Gas Supply Module ................ Ted McCallister (tmccalli@eia.doe.gov, 202/586-4820)

Natural Gas Transmission and

Distribution Module ................... Joseph Benneche (jbennech@eia.doe.gov, 202/586-6132)

Petroleum Market Module ................. Thomas White (twhite@eia.doe.gov, 202/586-1393)

Coal Market Module .................. Richard Newcombe (rnewcomb@eia.doe.gov, 202/586-2415)

AEO98 is available on the EIA CD-ROM and the EIA Home Page on the Internet (http://www.eia.doe.gov/oiaf/aeo98/homepage.html) including text, forecast tables, and graphics. To download the tables, go to the EIA FTP site (ftp://ftp.eia.doe.gov/pub/forecasting/aeo98/aeo98tables). To downlciad the entire report in Portable Document Format (PDF), go to ftp:/ / ftp.eia.doe.gov/pub/forecasting/aeo98/reports/0383(98).pdf. Assumptions underlying the projections, tables of regional projections and other underlying details of the reference case, model documentation reports, and The National Energy Modeling System: An Overview are also available on the CDROM and the Home Page.

For ordering information and for questions on energy statistics, please contact EIA's National Energy Information Center.

National Energy Information Center, EI-30

Energy Information Administration

Forrestal Building

Washington, DC 20585

Telephone: 202/586-8800

FAX: 202/586-0727

TTY: 202/586-1181

9 a.m. to 4 p.m., eastern time, M-F

E-mail: infoctr@eia.doe.gov

World Wide Web Site: $h t t p: / / w w w . e i a . a ̈ o e . g o v$

FTP Site: ftp://ftp.eia.doe.gov 


\section{DISCLAIMER}

This report was prepared as an account of work sponsored by an agency of the United States Government. Neither the United States Government nor any agency thereof, nor any of their employees, makes any warranty, express or implied, or assumes any legal liability or responsibility for the accuracy, completeness, or usefulness of any information, apparatus, product, or process disclosed, or represents that its use would not infringe privately owned rights. Reference herein to any specific commercial product, process, or service by trade name, trademark, manufacturer, or otherwise does not necessarily constitute or imply its endorsement, recommendation, or favoring by the United States Government or any agency thereof. The views and opinions of authors expressed herein do not necessarily state or reflect those of the United States Government or any agency thereof. 


\section{DISCLAIMER}

Portions of this document may be illegible electronic image products. Images are produced from the best available original document. 
Introduction

Overview of NEMS

Carbon Emissions

Macroeconomic Activity Module

International Energy Module

Residential Demand Module

Commercial Demand Module

Industrial Demand Module

Transportation Demand Module

Electricity Market Module

Renewable Fuels Module

Oil and Gas Supply Module

Natural Gas Transmission and Distribution Module 55

Petroleum Market Module 59

Coal Market Module

Appendix

Bibliography 
Figures

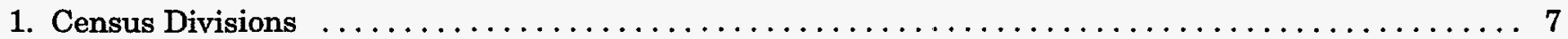

2. National Energy Modeling System $\ldots \ldots \ldots \ldots \ldots \ldots \ldots \ldots \ldots \ldots \ldots \ldots \ldots \ldots \ldots \ldots \ldots \ldots$

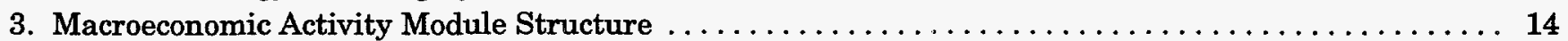

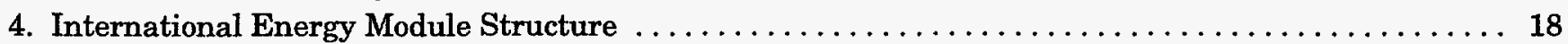

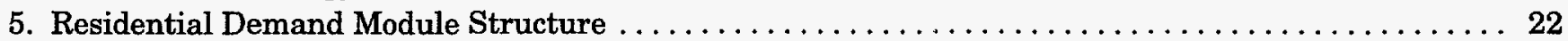

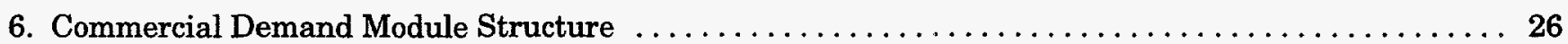

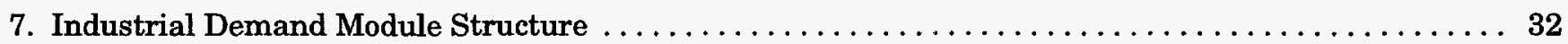

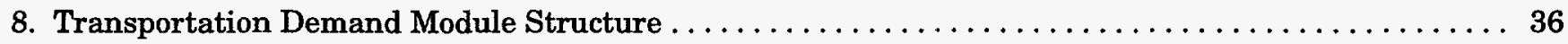

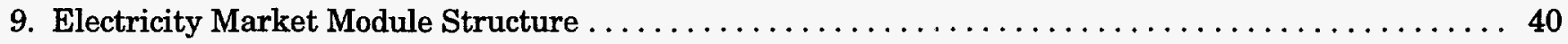

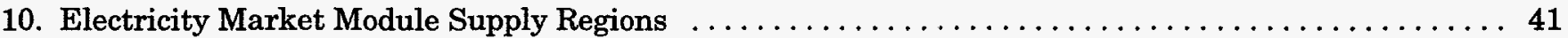

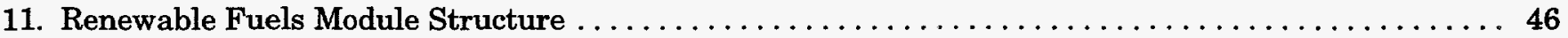

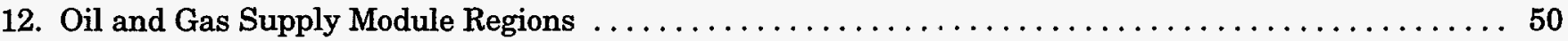

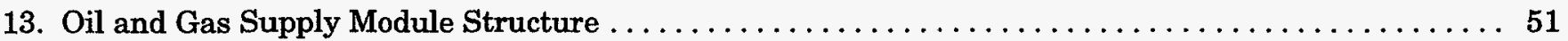

14. Foreign Natural Gas Trade via Pipeline and Liquefied Natural Gas Terminals . . . . . . . . . . . . 53

15. Natural Gas Transmission and Distribution Module Network $\ldots \ldots \ldots \ldots \ldots \ldots \ldots \ldots \ldots \ldots$

16. Natural Gas Transmission and Distribution Module Structure . . . . . . . . . . . . . . . . . 57

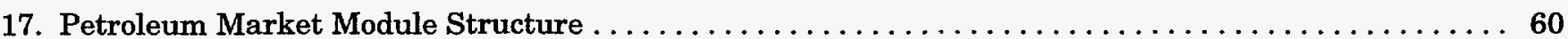

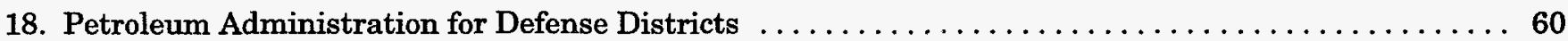

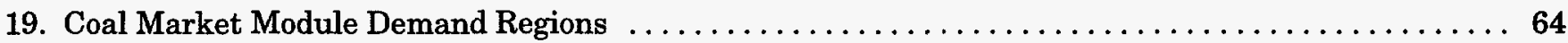

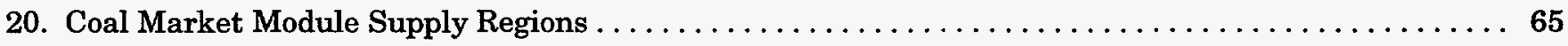

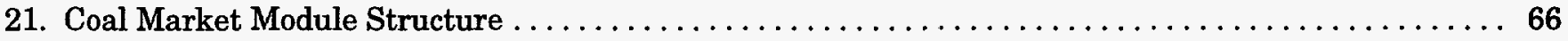


The National Energy Modeling System (NEMS) is a computer-based, energy-economy modeling system of U.S. energy markets for the midterm period through 2020. NEMS projects the production, imports, conversion, consumption, and prices of energy, subject to assumptions on macroeconomic and financial factors, world energy markets, resource availability and costs, behavioral and technological choice criteria, cost and performance characteristics of energy technologies, and demographics. NEMS was designed and implemented by the Energy Information Administration (EIA) of the U.S. Department of Energy (DOE).

The National Energy Modeling System: An Overview presents an overview of the structure and methodology of NEMS and each of its components. This chapter provides a description of the design and objectives of the system, followed by a chapter on the overall modeling structure and solution algorithm. The remainder of the report summarizes the methodology and scope of the component modules of NEMS. The model descriptions are intended for readers familiar with terminology from economics, operations research, and energy modeling. More detailed model documentation reports for all the NEMS modules are also available from EIA (Appendix, "Bibliography").

\section{Purpose of NEMS}

NEMS is used by EIA to project the energy, economic, environmental, and security impacts on the United States of alternative energy policies and of different assumptions about energy markets. Projections are made for each year from the present through 2020. This time period is one in which technology, demographics, and economic conditions are sufficiently understood in order to represent energy markets with a reasonable degree of confidence. NEMS provides a consistent framework for representing the complex interactions of the U.S. energy system and its response to a wide variety of alternative assumptions and policies or policy initiatives.

Baseline forecasts are developed with NEMS and published annually in the Annual Energy Outlook. In accordance with the requirement that EIA remain policy-neutral, the Annual Energy Outlook projections assume that all existing legislation, regulations, and policies remain unchanged. Analyses are also prepared in response to requests for special studies by the U.S. Congress, the DOE Office of Policy and International Affairs, other offices in DOE, and other government agencies. The first version of NEMS, completed in
December 1993, was used to develop the forecasts presented in the Annual Energy Outlook 1994. ${ }^{1}$ This report describes the version of NEMS used for the Annual Energy Outlook $1998,{ }^{2}$ which is the first Annual Energy Outlook to extend the projections through 2020.

The forecasts produced by NEMS are not considered to be absolute predictions of the future. They are contingent on the key assumptions made about U.S. energy systems. Contingencies include, for example, the estimated size of the economically recoverable resource base of fossil fuels, changes in world energy supply and demand, the rate at which new energy technologies are developed and the rate and extent of their penetration into commercial markets, and existing or prospective government actions or policies.

NEMS can be used to analyze the effects of existing and proposed government laws and regulations related to energy production and use; the potential impacts of new and advanced energy production, conversion, and consumption technologies; the impacts of increased use of renewable energy sources; the potential savings from increased efficiency of energy use; and the changes in emission levels that are likely to result from such policies as the Clean Air Act Amendments of 1990 and regulations on the use of alternative or reformulated fuels and climate change policy. Other examples of energy topics that can be, or have been, addressed by NEMS include the following:

- Impacts of energy tax policies on the U.S. economy and energy system

- Responses of the energy and economic systems to changes in world oil market conditions as a result of changing levels of foreign production and demand in the developing countries

- Impacts of new technologies on consumption and production patterns and emissions

- Effects of specific policies, such as mandatory appliance efficiency and building shell standards, on energy consumption

- Impacts of fuel-use restrictions (for example, required use of oxygenated and reformulated gasoline or mandated use of alternative-fueled vehicles) on emissions, energy supply and prices, and economic growth

\footnotetext{
${ }^{1}$ Energy Information Administration, Annual Energy Outlook 1994, DOE/EIA-0383(94) (Washington, DC, January 1994).

2 Energy Information Administration, Annual Energy Outlook 1998, DOE/EIA-0383(98) (Washington, DC, December 1997).
} 
- Impacts on the production and price of crude oil and natural gas resulting from improvements in exploration and production technologies

- Impacts on the price of coal resulting from improvements in productivity

- Impacts on energy prices, energy consumption, and electricity generation in response to carbon mitigation policies such as carbon fees or permit trading systems.

In addition to producing the analyses in the Annual Energy Outlook, NEMS has been used for a variety of DOE studies. Recent studies conducted for the Office of Policy and International Affairs and the Office of Energy Efficiency and Renewable Energy include analyses of the impacts of lower electricity prices due to industry restructuring, more rapid efficiency improvements of consumption technologies due to research and development, lower capital costs of renewable generation technologies, and an analysis of carbon mitigation policies. ${ }^{3}$ Other studies include an analysis of the costs and economic impacts of oil imports for the General Accounting Office ${ }^{4}$ and an analysis of carbon mitigation policies for the U.S. Environmental Protection Agency. ${ }^{5}$ Two analyses were conducted for Senator Jeffords (RVT) on open access regulatory changes and their impacts on the electricity industry ${ }^{6}$ and on Senate bill 687 which proposed renewable portfolio standards and limits on carbon, sulfur dioxide, and nitrogen oxide emissions by electric generators. NEMS has also been used for EIA's own analysis of electricity industry restructuring and competitive prices. ${ }^{\text {? }}$

\section{Representations of Energy Market Interactions}

NEMS was designed to represent the important interactions of supply and demand in U.S. energy markets. In the United States, energy markets are driven primarily by the fundamental economic interactions of supply and demand. Government regulations and policies can exert considerable influence, but the majority of decisions affecting fuel prices and consumption patterns, resource allocation, and energy technologies are made by private individuals or companies attempting to optimize their own economic interests. NEMS represents the market behavior of the producers and consumers of energy at a level of detail that is useful for analyzing the implications of technological improvements and policy initiatives.

\section{Energy Supply/Conversion/Demand Interactions}

NEMS is designed as a modular system. Four end-use demand modules represent fuel consumption in the residential, commercial, transportation, and industrial sectors, subject to delivered fuel prices, macroeconomic influences, and technology characteristics. The primary fuel supply and conversion modules compute the levels of domestic production, imports, transportation costs, and fuel prices that are needed to meet domestic and export demands for energy, subject to resource base characteristics, industry infrastructure and technology, and world market conditions. The modules interact to solve for the economic supply and demand balance for each fuel. Because of the modular design, each sector can be represented with the methodology and the level of detail, including regional detail, that is appropriate for that sector. The modularity also facilitates the analysis, maintenance, and testing of the NEMS component modules in the multi-user environment.

\section{Domestic Energy System/Economy Interactions}

The general level of economic activity, represented by gross domestic product, has traditionally been used as a key explanatory variable or driver for projections of energy consumption at the sectoral and regional levels. In turn, energy prices and other energy system activities influence economic growth and activity. NEIMS captures this feedback between the domestic economy and the energy system. Thus, changes in energy prices affect the key macroeconomic variables-such as gross domestic product, disposable personal income, industrial output, housing starts, employment, and interest rates-that drive energy consumption and capacity expansion decisions.

\footnotetext{
${ }^{3}$ Energy Information Administration, Analysis of Carbon Stabilization Cases, SR-OIAF-97-01 (Washington, DC, October 1997).

${ }^{4}$ Energy Information Administration, The Impacts on U.S. Energy Markets and the Economy of Reducing Oil Imports, SR-OIAF-9604 (Washington, DC, September 1996).

${ }_{5}^{5}$ Energy Information Administration, An Analysis of Carbon Mitigation Cases, SR-OIAF-96-01 (Washington, DC, June 1996).

${ }^{6}$ Energy Information Administration, An Analysis of FERC's Final Environmental Impact Statement for Electricity Open Access and Recovery of Stranded Costs, SR-OIAF-96-03 (Washington, DC, September 1996).

${ }^{7}$ Energy Information Administration, Electricity Prices in a Competitive Environment: Marginal Cost Pricing of Generation Services and Financial Status of Electric Utilities, DOE/EIA-0614 (Washington, DC, August 1997).
} 


\section{Domestic/World Energy Market Interactions}

World oil prices play a key role in domestic energy supply and demand decisionmaking, and oil price assumptions are the typical starting point for energy system projections. The level of oil production and consumption in the U.S. energy system also has a significant influence on world oil markets and prices. In NEMS, an international energy module represents world oil production and demand, as well as the interactions between the domestic and world oil markets, and this module calculates the average world crude oil price and the supply of specific crude oils and petroleum products. As a result, domestic and world oil market projections are internally consistent. Imports and exports of natural gas, electricity, and coal-which are less influenced by volatile world conditions-are represented in the individual fuel supply modules.

\section{Economic Decisionmaking Over Time}

The production and consumption of energy products today are influenced by past investment decisions to develop energy resources and acquire energy-using capital stock. Similarly, the production and consumption of energy in a future time period will be influenced by decisions made today and in the past.

Current investment decisions depend on expectations about future markets. For example, expectations of rising energy prices in the future increase the likelihood of current decisions to invest in developing alternative energy sources. A variety of assumptions about planning horizons, the formation of expectations about the future, and the role of those expectations in economic decisionmaking are applied within the individual NEMS modules.

\section{Technology Representation}

A key feature of NEMS is the representation of technology and technology improvement over time. Five of the sectors-residential, commercial, transportation, electricity generation, and refining-include explicit treatment of individual technologies and their characteristics, such as initial cost, operating cost, date of availability, efficiency, and other characteristics specific to the sector. In addition, for new generating technologies, the electricity sector accounts for technological optimism in the capital costs of first-of-a-kind plants and for a decline in the costs as experience with the technologies is gained both domestically and internationally. In each of these sectors, equipment choices are made for individual technologies as new equipment is needed to meet growing demand for energy services or to replace retired equipment.

In the other sectors-industrial, oil and gas supply, and coal-the treatment of technologies is more limited due to limitations on the availability of data on individual technologies. In the industrial sector, technology in the energy-intensive industries is represented by technology bundles, with technology possibility curves representing efficiency improvement over time. In the oil and gas supply sector, technology progress is represented by trend-based improvement in finding rates, success rates, costs, and the size of the resource base. Productivity improvements over time represent technological progress in coal production.

\section{External Availability}

In accordance with EIA requirements, NEMS is fully documented and archived. EIA runs NEMS on three EIA RS/6000 workstations under the AIX Version 4.2 operating system. The archive file provides the source language, input files, and output files to replicate the Annual Energy Outlook runs on an identically equipped computer; however, it does not include proprietary mathematical libraries from an external vendor. NEMS, or portions of it, is installed at the National Renewable Energy Laboratory, other national laboratories, the Electric Power Research Institute, and several private consulting firms. 

NEMS represents domestic energy markets by explicitly representing the economic decisionmaking involved in the production, conversion, and consumption of energy products. For example, the penetration of a new or advanced technology for electricity generation is projected only if the technology is deemed to be economic when considering the cost-minimizing mix of fuels over the life of the equipment.
Since energy costs and availability and energy-consuming characteristics can vary widely across regions, considerable regional detail is included. Other details of production and consumption categories are represented to facilitate policy analysis and ensure the validity of the results. A summary of the detail provided in NEMS is shown below.

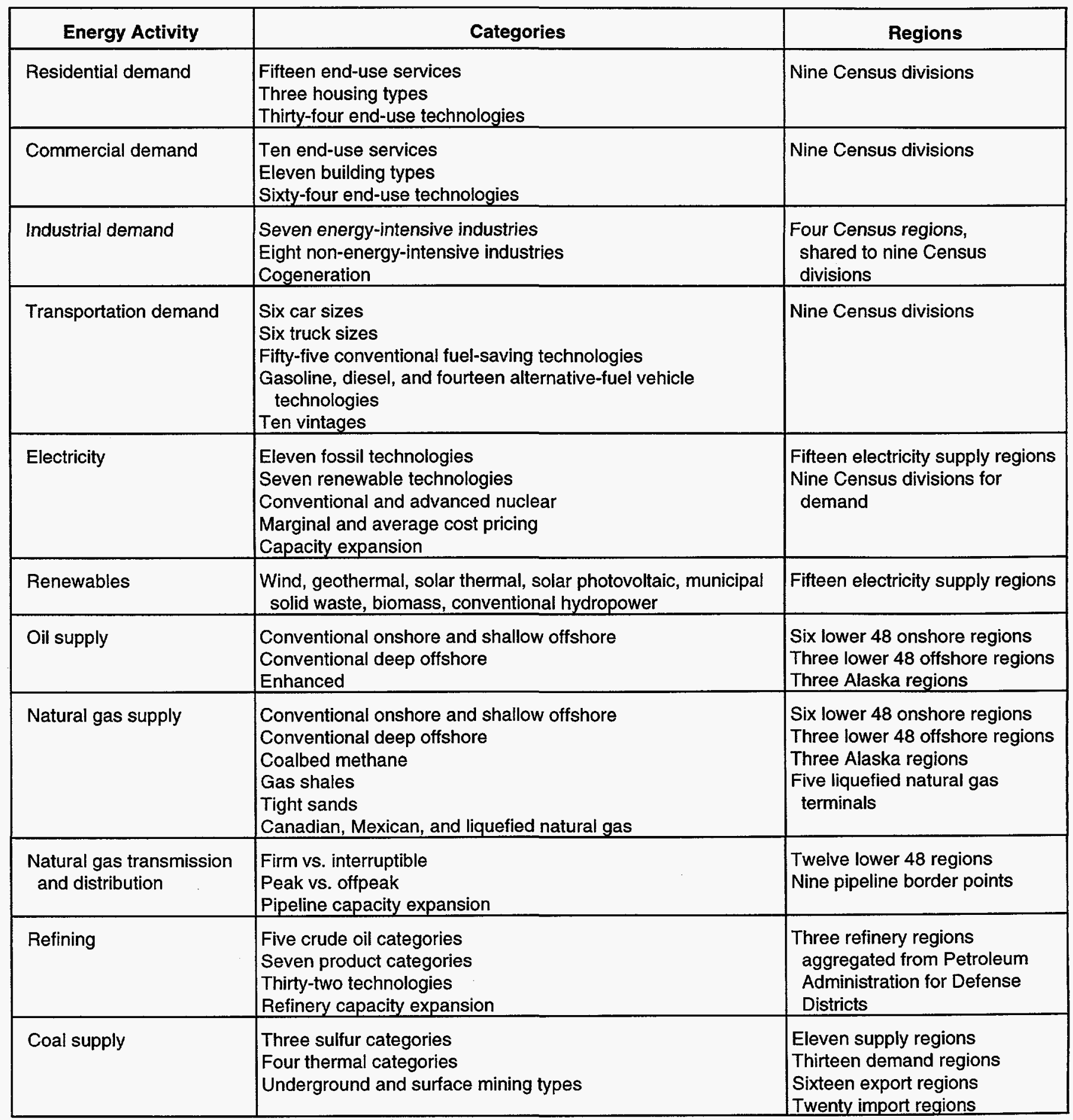




\section{Major Assumptions}

Each module of NEMS embodies many assumptions and data to characterize the future production, conversion, or consumption of energy in the United States. Two major assumptions concern economic growth in the United States and world oil prices, as determined by world oil supply and demand.

The five comprehensive, integrated cases in the Annual Energy Outlook 1998 (AEO98) are defined by setting assumptions that lead to a high, mid, or low economic growth rate for the domestic economy and to a high, mid, or low world oil price path. The reference case uses the mid-range assumptions for both the economic growth rate and the world oil price. Higher and lower economic growth and higher and lower world oil prices define the other four cases. The primary determinants for different economic growth rates are the growth rates of the labor force and productivity, while different assumptions on oil production capacity - in the Organization of Petroleum Exporting Countries (OPEC) and non-OPEC production lead to different levels of world oil prices.

In addition to the five baseline cases, the $A E O 98$ includes 29 other cases that explore the impacts of varying key assumptions in the individual components of NEMS. Many of these cases involve changes in the assumptions that impact the penetration of new or improved technologies, which is a major uncertainty in formulating projections of future energy markets. Other cases include potential legislative and regulatory changes, such as electricity industry restructuring and renewable portfolio standards, changes in nuclear retirement assumptions, a sensitivity on electricity demand growth, changes to oil and gas resource assumptions, and changes to coal supply productivity and miner wages. Some of these cases exploit the modular structure of NEMS by running only a portion of the entire modeling system in order to focus on the first-order impacts of the changes in the assumptions.

\section{NEMS Modular Structure}

Overall, NEMS represents a modeling system that simulates the behavior of energy markets and their interactions with the U.S. economy. The model achieves a supply/demand balance in the end-use demand regions, defined as the nine Census divisions (Figure 1), by solving for the prices of each energy product that will balance the quantities producers are willing to supply with the quantities consumers wish to consume. The system reflects market economics, industry structure, and energy policies and regulations that influence market behavior.

NEMS consists of four supply modules (oil and gas, natural gas transmission and distribution, coal, and renewable fuels); two conversion modules (electricity and petroleum refineries); four end-use demand modules (residential, commercial, transportation, and industrial); one module to simulate energy/economy interactions (macroeconomic activity); one module to simulate world oil markets (international energy activity); and one module that provides the mechanism to achieve a general market equilibrium among all the other modules (integrating module). Figure 2 depicts the high-level structure of NEMS.

Because energy markets are heterogeneous, a single methodology does not adequately represent all supply, conversion, and end-use demand sectors. The modularity of the NEMS design provides the flexibility for each component of the U.S. energy system to use the methodology and coverage that is most appropriate. Furthermore, modularity provides the capability to execute the modules individually or in collections of modules, which facilitates the development and analysis of the separate component modules. The interactions among these modules are controlled by the integrating module.

The NEIMS Global Data Structure is used to coordinate and communicate the flow of information among the modules. These data are passed through common interfaces via the integrating module. The Global Data Structure includes energy market prices and consumption; macroeconomic variables; energy production, transportation, and conversion information; and centralized model control variables, parameters, and assumptions. The Global Data Structure excludes variables that are defined locally within the modules and are not communicated to other modules.

A key subset of the variables in the Global Data Structure are the end-use prices and quantities of fuels which are used to equilibrate the NEMS energy balance in the convergence algorithm. These delivered prices of energy and the quantities demanded are defined by product, region, and sector. The delivered prices of fuel encompass all the activities necessary to produce, import, and transport fuels to the end user. The regions for the price and quantity variables in the Global Data Structure are the nine Census divisions. The four Census regions (shown in Figure 1 by breaks between State groups) and nine Census divisions are a common, mainstream level of regionality widely used by EIA and other organizations for data collection and analysis. 
Figure 1. Census Divisions

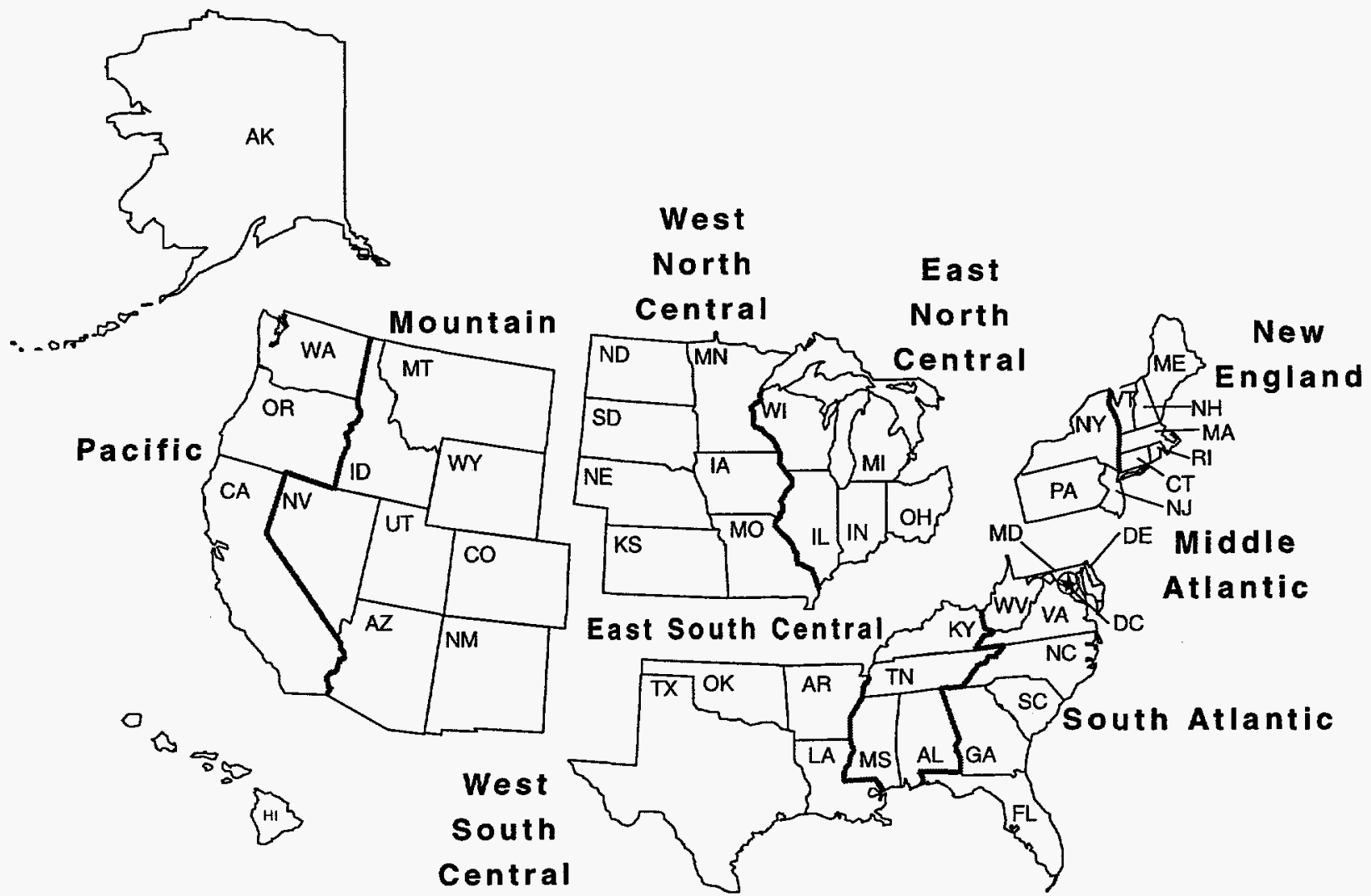

\begin{tabular}{|c|c|c|c|c|}
\hline $\begin{array}{l}\text { Division } 1 \\
\text { New England }\end{array}$ & $\frac{\text { Division } 3}{\text { East North Central }}$ & $\begin{array}{l}\text { Division } 5 \\
\text { South Atlantic }\end{array}$ & $\frac{\text { Division } 7}{\text { West South Central }}$ & $\begin{array}{l}\text { Division.9 } \\
\text { Pacific }\end{array}$ \\
\hline $\begin{array}{l}\text { Connecticut } \\
\text { Maine } \\
\text { Massachusetts } \\
\text { New Hampshire } \\
\text { Rhode Island } \\
\text { Vermont } \\
\text { Division } 2 \\
\text { Middle Atlantic } \\
\text { New Jersey } \\
\text { New York } \\
\text { Pennsylvania }\end{array}$ & $\begin{array}{l}\text { Illinois } \\
\text { Indiana } \\
\text { Michigan } \\
\text { Ohio } \\
\text { Wisconsin } \\
\text { Division } 4 \\
\text { West North Central } \\
\text { lowa } \\
\text { Kansas } \\
\text { Minnesota } \\
\text { Missouri } \\
\text { Nebraska } \\
\text { North Dakota } \\
\text { South Dakota }\end{array}$ & $\begin{array}{l}\text { Delaware } \\
\text { District of Columbia } \\
\text { Florida } \\
\text { Georgia } \\
\text { Maryland } \\
\text { North Carolina } \\
\text { South Carolina } \\
\text { Virginia } \\
\text { West Virginia } \\
\text { Division } 6 \\
\text { East South Central } \\
\\
\text { Alabama } \\
\text { Kentucky } \\
\text { Mississippi } \\
\text { Tennessee }\end{array}$ & $\begin{array}{l}\text { Arkansas } \\
\text { Louisiana } \\
\text { Oklahoma } \\
\text { Texas } \\
\text { Division } 8 \\
\text { Mountain } \\
\text { Arizona } \\
\text { Colorado } \\
\text { Idaho } \\
\text { Montana } \\
\text { Nevada } \\
\text { New Mexico } \\
\text { Utah } \\
\text { Wyoming }\end{array}$ & $\begin{array}{l}\text { Alaska } \\
\text { California } \\
\text { Hawaii } \\
\text { Oregon } \\
\text { Washington }\end{array}$ \\
\hline
\end{tabular}


Figure 2. National Energy Modeling System

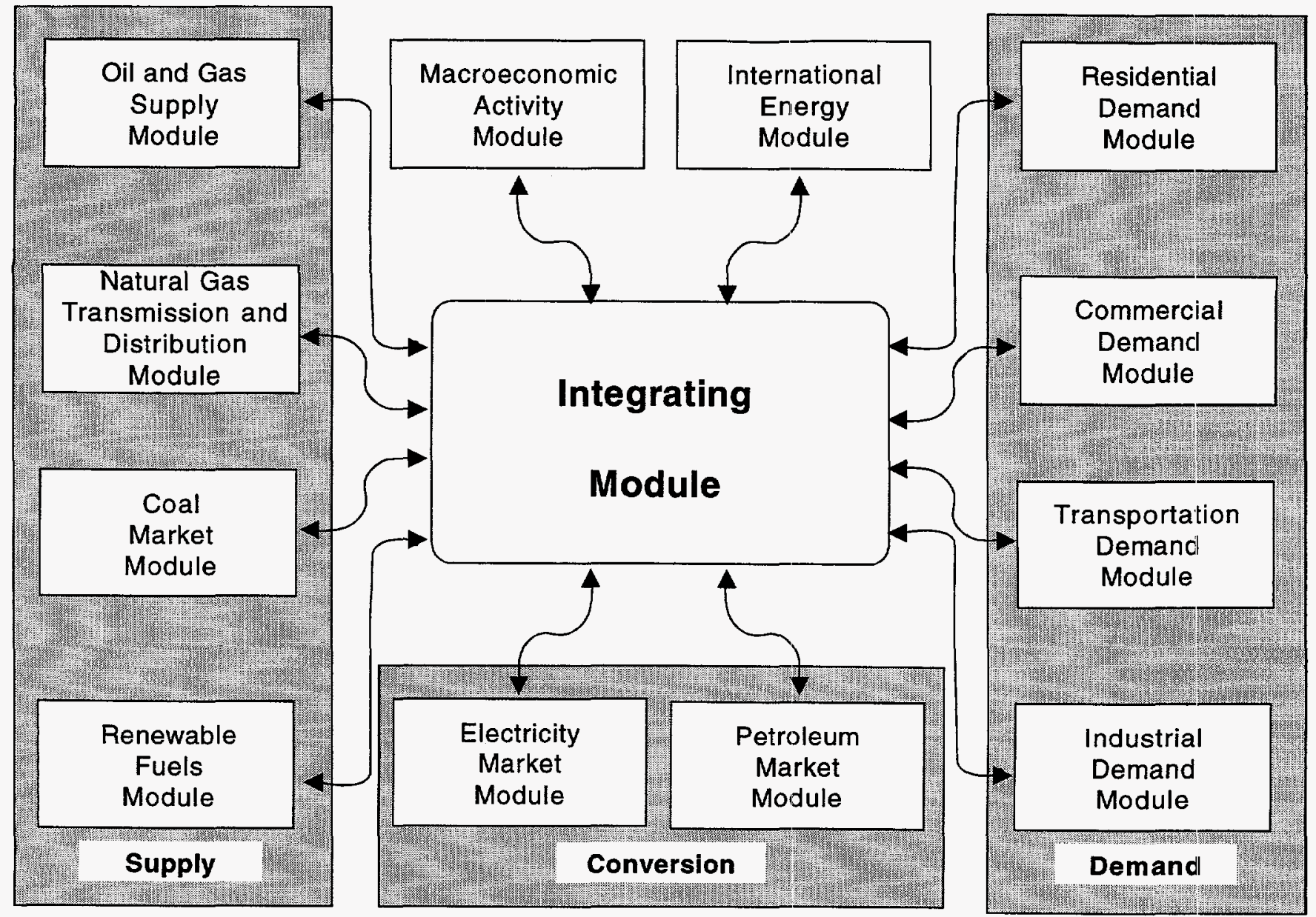

\section{Integrating Module}

The NEMS integrating module controls the entire NEMS solution process as it iterates to determine a general market equilibrium across all the NEMS modules. It has the following functions:

- Manages the NEMS Global Data Structure

- Executes all or any of the user-selected modules in an iterative convergence algorithm

- Checks for convergence, while reporting variables that remain out of convergence

- Implements price relaxation between iterations to accelerate convergence

- Updates expected values of the key NEMS variables.
The integrating module executes the demand, conversion, and supply modules iteratively until it achieves an economic equilibrium of supply and demand in all the consuming and producing sectors. Each module is called in sequence and solved, assuming that all other variables in the energy markets are fixed. The modules are called iteratively until the end-use prices and quantities remain constant within a specified tolerance-a condition defined as convergence. Equilibration is achieved annually throughout the midterm period, currently 2020, for each of the nine Census divisions.

In addition, the macroeconomic and international modules are executed iteratively to incorporate the feedback on the economy and international markets from changes in the domestic energy markets. The convergence tests check the stability of a set of key macroeconomic and international trade variables in response to interaction with the domestic energy system. 
The NEMS algorithm executes the system of modules until convergence is reached. The solution procedure for one iteration involves the execution of all the component modules, as well as the updating of expectation variables (related to foresight assumptions) for use in the next iteration. The system is executed sequentially for each year in the forecast period. During each iteration within a year, each of the analytical modules is executed in turn, with intervening convergence checks that isolate specific modules that are not converging. A convergence check is made for each price and quantity variable to see whether the percentage change in the variable is within the assumed tolerance. To avoid unnecessary iterations for changes in insignificant values, the quantity convergence check is omitted for quantities less than a user-specified minimum level. The order of execution of the modules may affect the rate of convergence but will generally not prevent convergence to an equilibrium solution or significantly alter the results. An optional relaxation routine can be executed to dampen swings in solution values between iterations. With this option, the current iteration values are reset partway between solution values from the current and previous iterations.

Because of the modular structure of NEMS and the iterative solution algorithm, any single module or subset of modules can be executed independently. Modules not executed are bypassed in the calling sequence, and the values they would calculate and provide to the other modules are held fixed at the values in the Global Data Structure, which would be the solution values from a previous run of NEMS. This flexibility is an aid to independent development, debugging, and analysis. 

A part of the integrating module, the carbon emissions submodule (CEM) computes the carbon emissions due to the combustion of energy. The coefficients for carbon emissions are derived from Energy Information Administration, Emissions of Greenhouse Gases in the United States 1996, published in October 1997. The calculations account for the fact that some fossil fuels are used for nonfuel purposes, such as feedstocks, and thus the carbon in the fuel is sequestered in the end product.

CEM also allows for several carbon policy evaluation options to be imposed within NEMS. Although none of the policy options are assumed in the Annual Energy Outlook 1998, the options can be used in special analyses to simulate potential market-based approaches to meet national carbon emission objectives. The policy options implemented in CEM are as follows:

- Carbon Tax. A tax on carbon emissions from fossil fuels is added to raise delivered fossil fuel prices. The resulting higher prices then induce changes in fossil fuel use and carbon emissions, as well as changes in some long-term decisionmaking, such as generating capacity decisions in the electricity market module. For electricity capacity planning, the future carbon taxes are included in the price of fossil fuels.

- Auction of Permits. This option simulates an auction on carbon emissions permits to meet an overall cap on emissions. A carbon permit price is determined that clears the auction market. The permit fee is treated as a carbon tax and used as an adjustment to the fossil fuel prices. A new auction price is set each NEMS iteration until the emissions reach the goal. The revenue generated from the auction is calculated assuming there is no initial allocation of emission permits.

- Market For Permits (Cap and Trade). A market for tradable carbon emissions permits is simulated assuming that an initial distribution of marketable permits to emission sources takes place. The permits are transferable but are not banked between years. As with the carbon tax and auction options, the full market price of the permits is added to the energy prices. The system of marketable permits is implemented in the same way as the permit auction, with the exception of the calculation of revenues from permit sales. Similar treatment is warranted because the marginal cost of a "free" permit is equivalent to one purchased at auction, given the opportunity cost of holding the distributed permit.

In an open, competitive permit market, the permit will tend to be priced at the marginal cost of reducing carbon emissions, regardless of the initial distribution of permits. If permits are purchased by suppliers and passed through to the fuel price, the marginal cost of the carbon emission by a particular sector in a region will be reflected in the individual end-use fuel cost for that sector.

- Market for Permits with Emission Offsets. The offset option allows for the goal on tradeable emissions permits to increase through a user-specified supply of offsets. Offsets could be available from activities like reforestation or coal-bed-methane capture to give relief on emissions limits for activities to increase sequestration of carbon. Another possible use of this option would be to simulate the availability of international carbon emission allowances at particular prices.

The use of any of these emission policy options in NEMS requires a macroeconomic analysis to assess the fiscal and monetary issues, as well as possible international trade effects. The analysis depends on such factors as how revenues generated from the policy would be used, how monetary authorities would react to the fiscal policy changes, and how international agreements to reduce carbon would be implemented. 

Macroeconomic assessment at EIA involves several modes of analysis. The first type of analysis, used in forecasting the Annual Energy Outlook where energy prices change, uses a response surface version of larger macroeconomic and industrial models. This mode of analysis requires a given economic baseline and then calculates the economic impacts of changing energy prices, calculated from the chosen growth path. The economic growth cases are derived from the larger core models and can reflect either high, low, or reference case growth assumptions. Analyzing economic impacts from energy price changes uses the macroeconomic activity module (MAM) within NEMS and provides a subset of the macroeconomic variables available in the larger core models. The composition of the subset is determined by the other energy modules in NEMS, as they use various macroeconomic concepts as assumptions to their particular energy model.

The other type of macroeconomic analysis requires the use of the underlying core macroeconomic models separately. There are four core models, estimated by DRIMcGraw-Hill, that serve as the basis for EIA's macroeconomic assessment. These include: the U.S. Quarterly Model of the Economy, Personal Computer Model of Industrial Output, an Employment Model by Industry, and a Regional Model. All of these models are linked in some fashion, by needing crucial assumptions that are provided by one of the other three models. Using the core models in a standalone fashion requires that the energy market concepts contained in the core models show NEMS-like behavior. To accomplish the goal of duplicating NEMS-like behavior, all energy market concepts in the core models show the same percentage change from base of the corresponding NEMS energy market concepts.

The decision of which type of coverage to use depends upon the particular energy market scenario. For those situations where only energy prices change, then MAM is used, providing relatively accurate estimates of economic impacts from the core models. MAM is compact, fast, linked to the other NEMS energy modules, and able to be released publicly. For energy market scenarios which involve changing energy prices because of taxes, or permit systems, or standards, then the use of MAM is not appropriate. Each of these energy policies imply other important concepts that may impact macroeconomic conditions, such as tax or permit revenue and how the revenue is distributed or certain energy prices rising for reasons other than rising resource costs. For these scenarios, the core macroeconomic models are used in determining economic impacts.

\section{Macroeconomic Activity Module}

The macroeconomic activity module (MAM) provides forecasts of economic variables to the energy modules within NEMS and forecasts the impacts on the aggregate economy of changes in energy market conditions. The MAM consists of three submodules (the national, interindustry, and employment submodules) and a subroutine (the regional subroutine), which are run in sequence. The national submodule provides forecasts of a wide range of economic variables at the national level. In particular, it provides variables that drive other parts of NEMS, including interest rates, final demands for goods and services, and disposable income. The interindustry submodule calculates the industrial output needed to satisfy the final demands from the national submodule. The levels of industrial output are used by the industrial and transportation demand modules in NEMS to calculate energy consumption in those sectors. The employment submodule calculates the levels of employment necessary to produce the output by industry. Finally, the regional subroutine of the MAM takes national variable values from the national and interindustry submodules and transforms them into appropriate regional values. The overall interrelationships are shown in Figure 3.

The sequence of interactions in the MAM begins with the energy supply and demand modules of NEMS, which determine the reaction of energy prices. These energy price effects are passed to the national submodule, and

\begin{tabular}{|c|c|c|}
\hline $\begin{array}{l}\text { Gross domestic product } \\
\text { Other economic activity measures, including } \\
\text { housing starts, commercial floorspace growth, } \\
\text { vehicle sales, population } \\
\text { Price indices and deflators } \\
\text { Production rates for manufacturing } \\
\text { Production rates for nonmanufacturing } \\
\text { Interest rates }\end{array}$ & $\begin{array}{l}\text { Petroleum, natural gas, coal, and electricity } \\
\text { prices } \\
\text { Oil, natural gas, and coal production } \\
\text { Electric and gas industry output } \\
\text { Refinery output }\end{array}$ & $\begin{array}{l}\text { Macroeconomic variables defining } \\
\text { alternative economic growth cases }\end{array}$ \\
\hline
\end{tabular}




\section{MACROECONOMIC ACTIVITY MODULE}

Figure 3. Macroeconomic Activity Module Structure

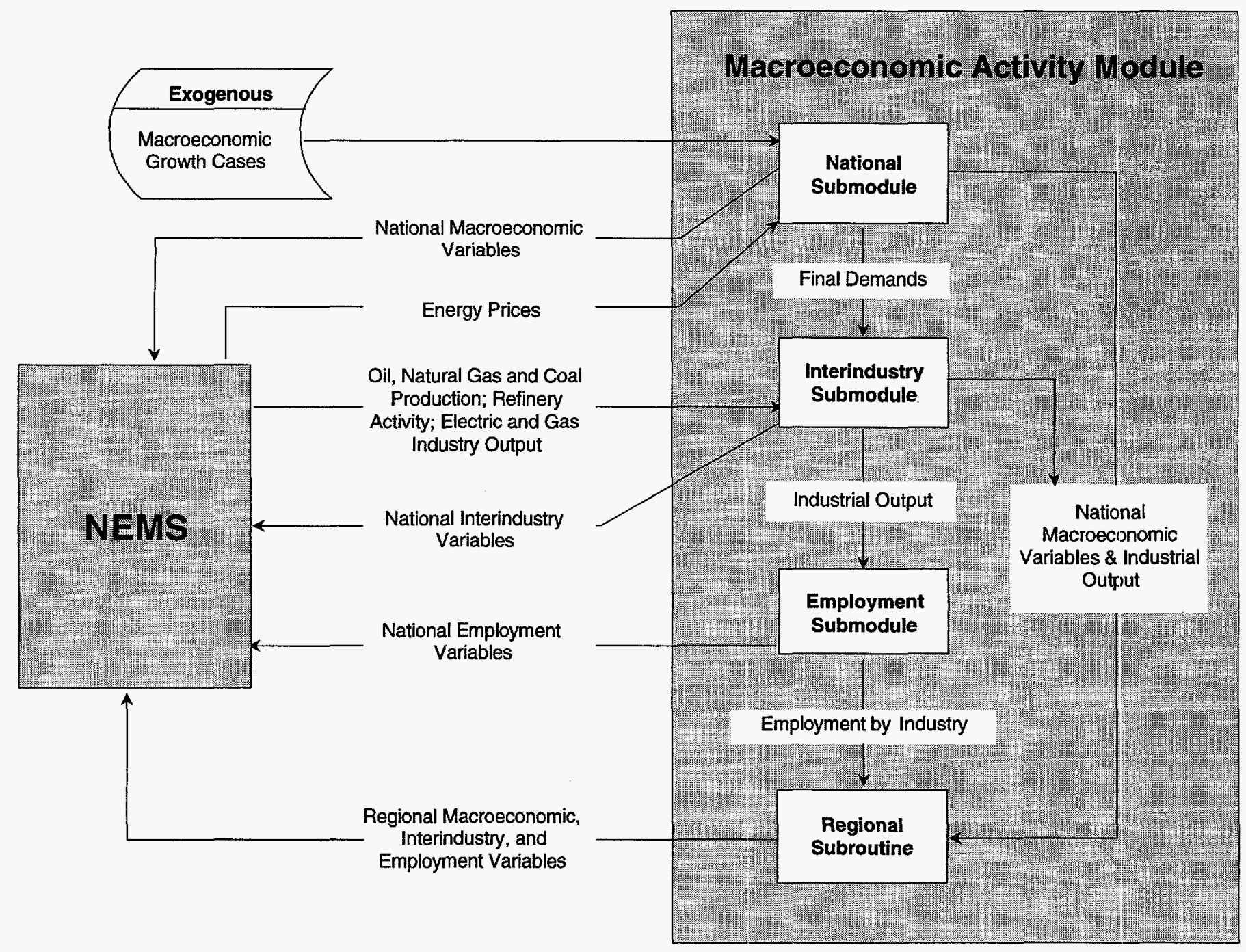

the economy is projected to react to the altered energy price paths. The altered macroeconomic final demands are in turn passed to the interindustry submodule, which calculates their effect on interindustry activity. The altered interindustry projections are then used to determine employment levels.

Macroeconomic concepts, industry gross output and employment levels are passed back to the other NEMS modules, and the system iterates until convergence is achieved.

MAM outputs include measures of macroeconomic performance and manufacturing and nonmanufacturing sector production activities. Depending on the concept, these measures are provided nationally or at the geographic level of the nine Census divisions (see Figure 1).

\section{National Submodule}

The national submodule of MAM is a response surface representation of the Data Resources, Inc. (DRI) U.S. Quarterly Model. (A response surface representation is a set of equations embodying important inputs and outputs of a larger, detailed model. The coefficients of the equations are estimated via statistical/econometric methods, based on "pseudo data" derived from repeated runs of the larger model being represented.) The response surface representation simulates the reaction to changing energy prices of the larger version of the DRI U.S. Quarterly Model. The growth potential of the economy is essentially grounded in the growth of the factors of production-labor, capital, and energy-and the aggregate productivity of these factors. The user can select three different macroeconomic growth cases 
before executing the MAM, and MAM will estimate how the economy changes in response to changing energy prices. These growth cases are initially derived from simulations of the DRI U.S. Quarterly Model and are used as the starting point to examine energy/ economic impacts. Approximately 100 economic variables from the DRI simulations are used by NEMS to define an economic growth case.

\section{Interindustry Submodule}

The interindustry submodule provides industrial output projections to the regional MAM subroutine and the energy modules. It also calculates interindustry impacts associated with changes in national economic activity resulting from energy price changes. A response surface version of the DRI Input-Output Model for the Personal Computer (PCIO) constitutes the core interindustry segment of this submodule, which is fully linked to other NEMS components.

The interindustry submodule calculates deviations from a given baseline interindustry projection whenever macroeconomic final demands change. Because of the top-down structure of input-output modeling, the interindustry and national submodules do not iterate directly with each other. However, through their joint effect on the projections of the energy supply and demand modules, which in turn alter the macroeconomic outlook, changes in interindustry projections affect the results of the national submodule.

\section{Employment Submodule}

The employment submodule provides employment projections to the regional MAM subroutine and the energy modules. It also calculates employment impacts associated with changes in national industrial output resulting from energy price changes. A response surface version of the DRI Employment Model by Industry constitutes the core employment segment of the submodule, which is fully linked to other NEMS components.

\section{Regional Subroutine}

The initial implementation of the regional subroutine is a set of equations that share national economic and industrial output data to specific regions. The sharing equations are derived from the Regional Macroeconomic Model developed by DRI. The regional subroutine disaggregates national economic variables such as disposable income, industrial production, and consumer prices into appropriate regional values.

\section{Use of the Underlying Core Models}

MAM estimates macroeconomic impacts of energy price changes. In order to estimate these energy price impacts, an underlying baseline has to be provided. As the NEMS energy prices change, MAM estimates the resulting changes to the macroeconomic variables provided in the baseline. The underlying core models are used in two ways: to provide economic baselines upon which percentage change impacts are calculated and to provide response surface coefficients by running each underlying model many times to simulate its behavior when energy prices change. The core models are provided by DRI/McGraw-Hill and include their U.S. Quarterly Model of the Economy, PCIO Industrial Output Model, an Employment Model by Industry, and a Regional Economic Model. All four of these models are used in order to provide the macroeconomic growth cases (the high economic growth, reference case and low economic growth). The response surface coefficients are used to estimate the economic impacts of the high and low world oil price cases.

MAM provides a good estimate of economic impacts when only energy prices change. If energy markets change as a result of government policy, such as energy taxes, permits, or standards, then using MAM to estimate macroeconomic impacts is not warranted because increases in end use energy prices are not due solely to increases in energy resource costs. There are also other nuances in the analysis, such as treatment of energy tax or permit revenue, that have significant impact on estimating macroeconomic impacts but are not involved when only resource costs change. ${ }^{8}$ When EIA is asked to provide analysis of these policies, the core DRI models are used, using the energy prices and quantities from the NEMS model. Roughly 25 energy concepts from the NEMS model are used in the DRI core models. These concepts range from prices (from the residential, transportation, and industrial demand sectors) to energy quantities supplied and demanded (such as oil and gas production and total energy demand). The energy sector variables included in the set of DRI core models show the same percentage change from base that the corresponding energy concepts in NEMS show for any particular detailed energy scenario that includes changing energy prices for reasons other than changing resource prices.

\footnotetext{
${ }^{8}$ Response surface coefficients are calculated using simulations where only resource costs change, leading to resulting changes in other prices and macroeconomic variables.
} 

The international energy module (IEM) consists of four submodules (Figure 4) that perform the following functions:

- world oil market submodule-calculates the average annual world oil price (imported refiner acquisition cost) that is consistent with worldwide petroleum demand and supply availability

- crude oil supply submodule-provides imported crude oil supply curves for five crude oil quality classes

- petroleum products supply submodule-provides imported refined product supply curves for ten types of refined products

- oxygenates supply submodule-provides imported oxygenates supply curves for methyl tertiary butyl ether (MTBE) and methanol.

The world oil price that is generated by the world oil market submodule is used by all the modules of NEMS as well as the other submodules of the IEM. The import supply curves for crude oils, refined products, and oxygenates are used by the petroleum market module.

\section{World Oil Market Submodule}

In NEMS, the U.S. oil market is modeled in considerable detail, while foreign markets retain a less-detailed formulation. The EIA's modeling of the near- to midterm world oil market depends on two key assumptions: (1) oil is the marginal fuel and (2) the Organization of Petroleum Exporting Countries (OPEC) is the marginal supplier of oil. The first assumption implies that competition between oil and other fuels is not significant enough to impact the world oil price. In addition, prices remain sufficiently low such that the market penetration of new technologies that would reduce the demand for oil is inhibited. In the second assumption,
OPEC producers are assumed to expand oil production capacity in order to meet the growth in worldwide oil demand.

The various price cases examined by the EIA differ in the magnitude to which OPEC producers expand their production capacity. Lower prices imply considerable capacity expansion activity with a probable assist from foreign investment interests. Higher prices imply an unwillingness on the part of OPEC producers to invite foreign investment participation. The world oil market submodule forecasts the world oil price and produces a regional world oil market supply/demand balance that is consistent with the forecasted price. The world oil price forecast is based upon a regression analysis of the price in the previous time period and the percent utilization of OPEC production capacity. The IEM has either the capability to forecast world oil prices given OPEC production capacity estimates or the capability to forecast OPEC production given an exogenous world oil price path.

\section{Crude Oil Supply Submodule}

The crude oil supply submodule consists of a set of import supply curves to all five Petroleum Administration for Defense Districts (PADDs) for each of five quality classes of crude oils and for each simulation year. The petroleum market module uses the supply curves to determine the quantities and prices of the crude oils to be imported. Because the petroleum market module is a linear programming formulation, the imported crude oil supply curves are formulated as 3 -step, piecewise-linear functions. The five classes of imported crude oils categorized by sulfur content and American Petroleum Institute (API) gravity include: low-sulfur light, medium-sulfur heavy, high-sulfur light, high-sulfur heavy, high-sulfur very heavy.

The imported crude oil supply curves are developed exogenous to NEMS using a large-scale linear programming

\begin{tabular}{|l|l|l|}
\hline \multicolumn{1}{|c|}{ IEM Outputs } & \multicolumn{1}{|c|}{ Inputs from NEMS } & \multicolumn{1}{c|}{ Exogenous Inputs } \\
\hline World oil price & Domestic crude oil production \\
Crude oil import supply curves & Domestic natural gas liquids production \\
Refined product import supply curves & Domestic other liquids production & $\begin{array}{l}\text { OPEC production path } \\
\text { Reference non-U.S. oil supply } \\
\text { and demand } \\
\text { Non-U.S. economic parameters } \\
\text { Base import supply curves for crude } \\
\text { oils, refined products, and oxygenates }\end{array}$ \\
& Domestic refinery gain. & \\
& Domestic product supplied & GDP price deflators \\
& Domestic crude oil imports & \\
& Domestic refined product imports & \\
& Domestic oxygenate imports & \\
\hline
\end{tabular}


Figure 4. International Energy Module Structure

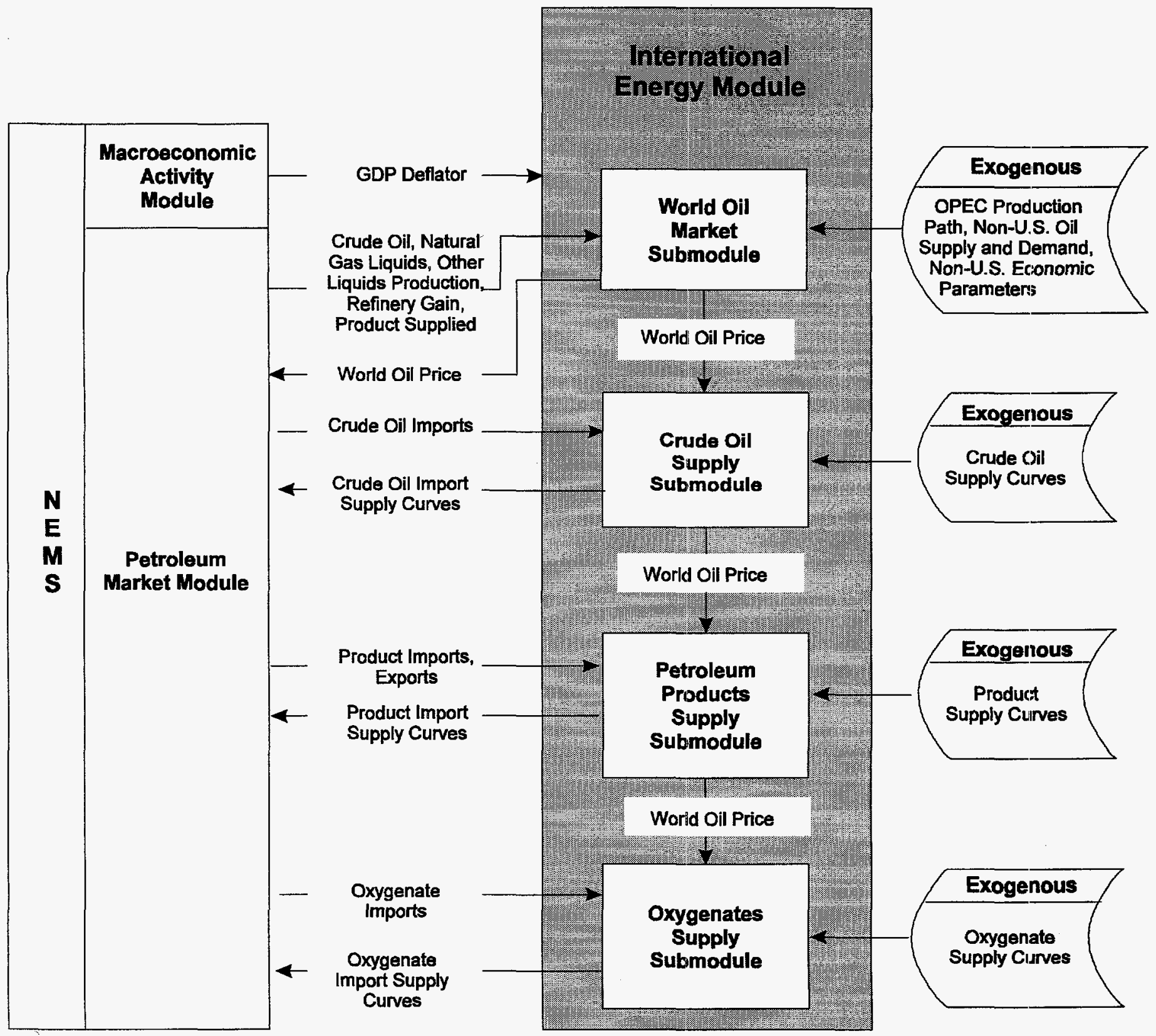

programming formulation of international refining and transportation. This formulation, known as the World Oil Refining, Logistics, and Demand (WORLD) model, is run repetitively, parameterizing on the import levels of the five crude oil classes into each PADD. From these runs, base price/quantity relationships for imported crude oils are established. Within NEMS, these base relationships are shifted as a function of the world oil price and presented to the petroleum market module as a flexible set of crude oil import alternatives. By observing which import supply curves are selected by the petroleum market module, it becomes possible to map these selections back into the WORLD model in order to provide estimates of future sources of crude oil imports into the United States.

\section{Petroleum Products Supply Submodule}

The petroleum products supply submodule consists of a set of import supply curves to all five PADDs for each of ten refined product types and for each simulation year. The petroleum market module uses the supply curves to 
determine the quantities and prices of refined products to be imported. Because the petroleum market module is a linear programming formulation, the imported refined product supply curves are formulated as 3-step, piecewise-linear functions. The ten types of imported refined products include: traditional gasoline (including aviation), reformulated gasoline, No. 2 heating oil, lowsulfur distillate fuel, high- and low-sulfur residual fuel, jet fuel (including naphtha jet), liquefied petroleum gas, petrochemical feedstocks, and other petroleum products.

Similar to the imported crude oil supply curves, the imported refined product supply curves are also developed exogenous to NEMS using the WORLD model. By observing which import supply curves are selected by the petroleum market module, it becomes possible to map these selections back into the WORLD model in order to provide estimates of future sources of refined product imports into the United States.

\section{Oxygenates Supply Submodule}

The oxygenates supply submodule consists of a set of import supply curves to all five PADDs for the oxygenates MTBE and methanol and for each simulation year. The petroleum market module uses the supply curves to determine the quantities and prices of oxygenates to be imported. Because the petroleum market module is a linear programming formulation, the imported oxygenate supply curves are formulated as 3 -step, piecewise-linear functions. Similar to the imported crude oil supply curves, the imported oxygenate supply curves are developed exogenous to NEMS using the WORLD model. By observing which import supply curves are selected by the petroleum market module, it becomes possible to map these selections back into the WORLD model in order to provide estimates of future sources of oxygenate imports into the United States.

Because of the potential expansion of the U.S. ethanol industry and the lack of commercial markets for other oxygenates, it is assumed that ethanol, ethyl tertiary butyl ether (ETBE), tertiary amyl methyl ether (TAME), and tertiary butyl alcohol (TBA) are all supplied from domestic sources. Therefore, the IEM does not provide import supply curves for these oxygenates.

By presenting NEMS with a flexible array of import choices, valuable insights can be gained on such issues as the future crude oil/refined product import composition, potential U.S. refinery expansion (both distillation capacity and downstream capacity), and future sources of petroleum imports (including Persian Gulf import dependence). 

The residential demand module (RDM) forecasts energy consumption by Census division for seven marketed energy sources plus solar thermal and geothermal energy. The RDM is a structural model and its forecasts are built up from projections of the residential housing stock and of the energy-consuming equipment contained therein. The components of the RDM and its interactions with the NEMS system are shown in Figure 5. NEMS provides forecasts of residential energy prices, population, and housing starts, which are used by the RDM to develop forecasts of energy consumption by fuel and Census division.

The RDM incorporates the effects of four broadlydefined determinants of energy consumption: economic and demographic effects, structural effects, technology turnover and advancement effects, and energy market effects. Economic and demographic effects include the number, dwelling type (single-family, multi-family or mobile homes), occupants per household, and location of housing units. Structural effects include increasing average dwelling size and changes in the mix of desired end-use services provided by energy (new end uses and/or increasing penetration of current end uses, such as the increasing popularity of electronic equipment and computers). Technology effects include changes in the stock of installed equipment caused by normal turnover of old, worn out equipment with newer versions which tend to be more energy efficient, the integrated effects of equipment and building shell (insulation level) in new construction, and in the projected availability of even more energy-efficient equipment in the future. Energy market effects include the short-run effects of energy prices on energy demands, the longer-run effects of energy prices on the efficiency of purchased equipment and the efficiency of building shells, and limitations on minimum levels of efficiency imposed by legislated efficiency standards.

\section{Housing Stock Submodule}

The base housing stock by Census division and dwelling type is derived from EIA's 1993 Residential Energy Consumption Survey (RECS). Each element of the base stock is retired on the basis of a constant rate of decay for each dwelling type. The RDM receives as an input from the macroeconomic activity module forecasts of housing additions by type and Census division. The RDM supplements the surviving stocks from the previous year with the forecast additions by dwelling type and Census division. The average square footage of new construction is based on recent upward trends developed from the 1993 RECS.

\section{Appliance Stock Submodule}

The installed base of appliances is also taken from the 1993 RECS. The efficiency of the base stock is derived from historical shipments by efficiency level over a many-year interval for the following equipment: heat pumps, gas furnaces, central air conditioners, room air conditioners, water heaters, refrigerators, freezers, dishwashers, clothes washers and clothes dryers. A linear retirement function with both minimum and maximum equipment lives is used to retire equipment in surviving housing units. For equipment where shipment data are available, the efficiency of the retiring equipment varies over the projection. In early years, the retiring efficiency tends to be lower as the older, less efficient equipment in the stock turns over first. Also, as housing units retire, the associated appliances are removed from the base appliance stock as well. Additions to the base stock are tracked separately for housing units existing in 1993 and for cumulative new construction. As appliances are removed from the stock, they are replaced by new appliances with generally higher efficiencies due to technology improvements, equipment standards and market forces. Appliances added into new construction are accumulated and retired parallel to appliances in the existing stock. Appliance stocks are maintained by fuel, end use, and technology as shown in the table.

\section{Technology Choice Submodule}

Fuel-specific equipment choices are made for both new construction and replacement purchases. For new construction, initial heating system shares (provided by

\begin{tabular}{|l|l|l|}
\hline \multicolumn{1}{|c|}{ RDM Outputs } & \multicolumn{1}{|c|}{ Inputs from NEMS } & \multicolumn{1}{c|}{ Exogenous Inputs } \\
\hline $\begin{array}{l}\text { Energy product demand } \\
\text { Changes in housing and appliance } \\
\text { stocks }\end{array}$ & $\begin{array}{l}\text { Energy product prices } \\
\text { Housing starts } \\
\text { Appliance stock efficiency }\end{array}$ & $\begin{array}{l}\text { Current housing stocks, retirement rates } \\
\text { Population }\end{array}$ \\
& & $\begin{array}{l}\text { New appliance types, efficiencies, costs } \\
\text { Housing shell retrofit indices } \\
\text { Unit energy consumption } \\
\text { Square footage }\end{array}$ \\
\hline
\end{tabular}


Figure 5. Residential Demand Module Structure

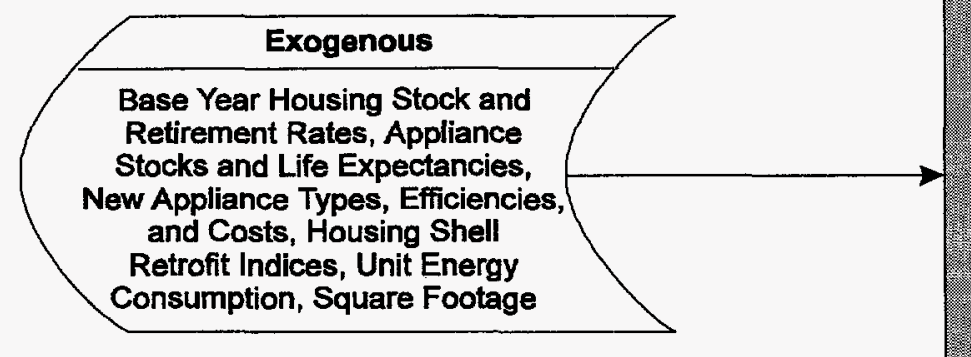

\section{Restedental Demant Mouke}

Tocks and Life Expectancies, and Costs, Housing Shell

Retrofit Indices, Unit Energy

Consumption, Square Footage

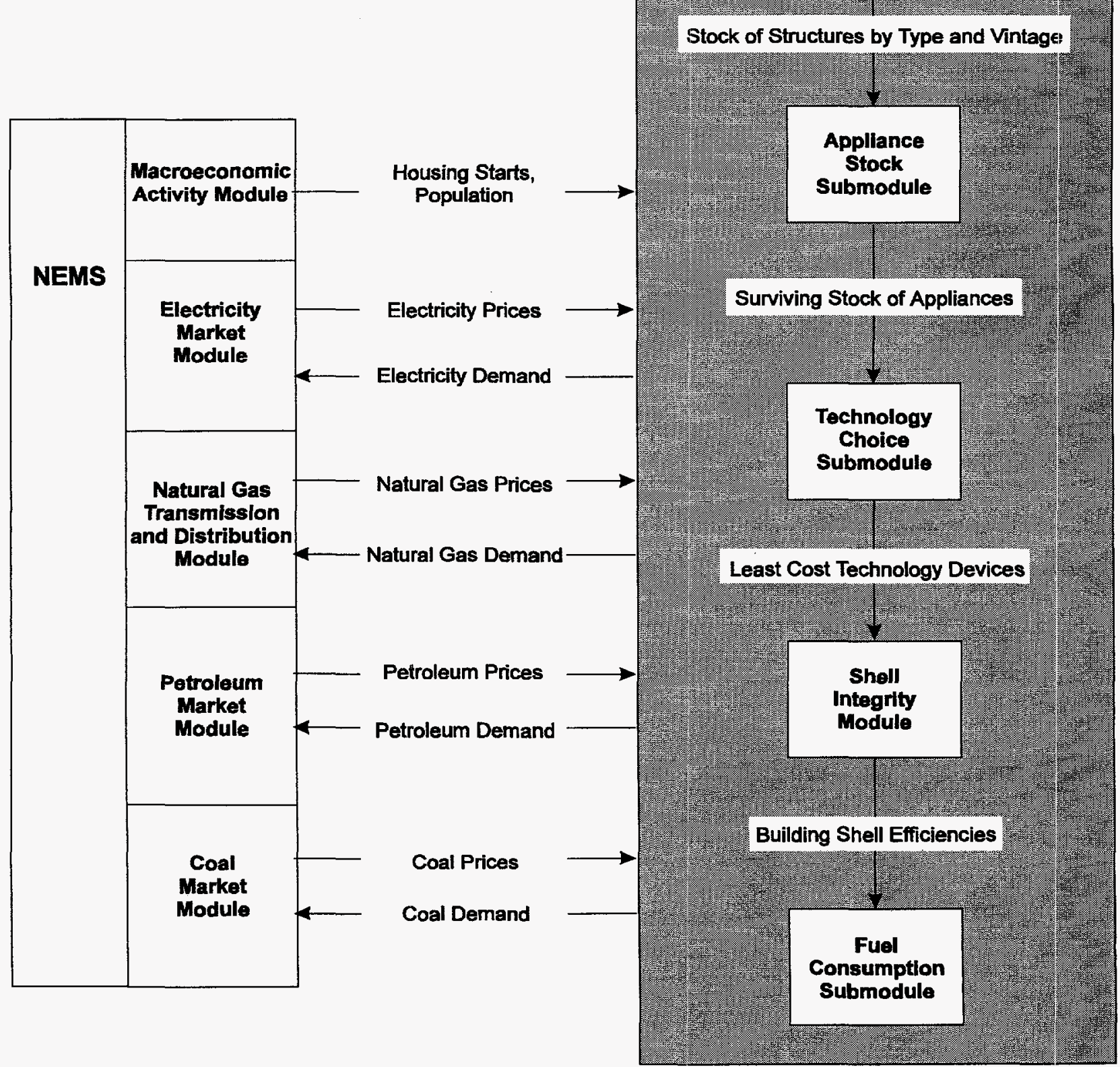


Space Heating Equipment: electric furnace, electric airsource heat pump, natural gas furnace, natural gas hydronic, kerosene furnace, liquefied petroleum gas, distillate furnace, distillate hydronic, wood stove, groundsource heat pump, natural gas heat pump.

Space Cooling Equipment: room air conditioner, central air conditioner, electric air-source heat pump, ground-source heat pump, natural gas heat pump.

Water Heaters: solar, natural gas, electric, oil, liquefied petroleum gas.

Refrigerators: 18 cubic foot top-mounted freezer, 25 cubic foot side-by-side with through-the-door features.

Freezers: chest - manual defrost, upright - manual defrost.

Lighting: incandescent, compact fluorescent, mercury vapor.

Clothes Dryers: natural gas, electric.

Cooking: natural gas, electric, liquefied petroleum gas.

Dishwashers

Clothes Washers

the most recently available Census Bureau survey data covering new construction, currently 1995) are adjusted based on relative life cycle costs for all competing technology and fuel combinations. Once new home heating system shares are established, the fuel choices for other services, such as water heating and cooking, are determined based on the fuel chosen for space heating. For replacement purchases fuel switching is allowed for an assumed percentage of all replacements, but is dependent on the estimated costs of fuel-switching (switching from electricity to gas heating is assumed to involve the costs of running a new gas line).

For both replacement equipment and new construction, a "second-stage" of the equipment choice decision requires selecting from several projected available efficiency levels. The projected efficiency range of available equipment represents a "menu" of efficiency levels and installed cost combinations projected to be available at the time the choice is being made. Costs and efficiencies for selected appliances are shown in the following table, derived from the report Assumptions to the Annual Energy Outlook 1998. ${ }^{9}$ At the low end of the efficiency range are the minimum levels required by legislated standards. In any given year, higher efficiency levels are associated with higher installed costs. Thus, purchasing higher than the minimum efficiency involves a trade-off between higher installation costs and future savings in energy expenditures. In the RDM, these trade-offs are calibrated to recent shipment, cost, and efficiency data. Changes in projected purchases by efficiency level are based on changes in either the installed capital costs or changes in the first-year operating costs across the available efficiency levels. As energy prices increase, the incentive of greater energy expenditures savings will promote increased purchases of higher-efficiency equipment. In some cases, due to government programs or general projections of technology improvements, projected increases in efficiency or decreases in the installed costs of higher-efficiency equipment will also promote purchases of higher-efficiency equipment.

\section{Shell Integrity Submodule}

Shell integrity is also tracked separately for the existing housing stock and the stock of cumulative new construction. Shell integrity for existing construction is assumed to respond to increases in real energy prices by becoming more efficient. There is no change in existing shell integrity when real energy prices decline. New shell efficiencies are projected to increase, based on recent trends in shell efficiency measures and building codes. All shell efficiencies are subject to a maximum shell efficiency based on studies of currently available residential construction methods.

\section{Fuel Consumption Submodule}

The fuel consumption submodule modifies base year energy consumption intensities in each forecast year. Base year energy consumption for each end use is derived from energy intensity estimates from the 1993 RECS. The base year energy intensities are modified for five effects: (1) increases in efficiency, based on a comparison of the projected appliance stock serving this end use relative to the base year stock, (2) changes in shell integrity for space heating and cooling end uses, (3) changes in real fuel prices-short-run price elasticity effects, (4) changes in square footage, (5) changes in the number of occupants per household, (6) changes in weather relative to the base year, and (7) adjustments in utilization rates caused by efficiency increases (efficiency "rebound" effects). Once these modifications are made, total energy use is computed across end uses and housing types and then summed by fuel for each Census division.

\footnotetext{
${ }^{9}$ Energy Information Administration, Assumptions to the Annual Energy Outlook 1998, ftp://ftp.eia.doe.gov/pub/ forecasting/aeo98/aeo98asu.pdf (Washington, DC, December 1997).
} 
RESIDENTIAL DEMAND MODULE

Characteristics of Selected Equipment

\begin{tabular}{|c|c|c|c|c|c|}
\hline Equipment Type & $\begin{array}{l}1995 \text { Capital Cost } \\
\text { (1996 Dollars) }\end{array}$ & Efficiency & $\begin{array}{l}2005 \text { Capital Cost } \\
\text { (1996 Dollars) }\end{array}$ & Efficiency & Discount Rate \\
\hline $\begin{array}{l}\text { Electric Heat Pump } \\
\text { Minimum } \\
\text { Best }\end{array}$ & $\begin{array}{l}3,280 \\
5,621\end{array}$ & $\begin{array}{l}10.0 \\
14.5\end{array}$ & $\begin{array}{l}3,280 \\
5,621\end{array}$ & $\begin{array}{l}10.0 \\
16.9\end{array}$ & 20 \\
\hline $\begin{array}{l}\text { Natural Gas Furnace } \\
\text { Minimum } \\
\text { Best }\end{array}$ & $\begin{array}{l}1,523 \\
3,514\end{array}$ & $\begin{array}{l}0.78 \\
0.95\end{array}$ & $\begin{array}{l}1,523 \\
2,928\end{array}$ & $\begin{array}{l}0.78 \\
0.96\end{array}$ & 15 \\
\hline $\begin{array}{l}\text { Room Air Conditioner } \\
\text { Minimum } \\
\text { Best }\end{array}$ & $\begin{array}{l}702 \\
996\end{array}$ & $\begin{array}{c}8.7 \\
12.0\end{array}$ & $\begin{array}{l}702 \\
996\end{array}$ & $\begin{array}{c}9.7 \\
12.5\end{array}$ & 100 \\
\hline $\begin{array}{l}\text { Central Air Conditioner } \\
\text { Minimum } \\
\text { Best }\end{array}$ & $\begin{array}{l}2,460 \\
3,514\end{array}$ & $\begin{array}{l}10.0 \\
14.5\end{array}$ & $\begin{array}{l}2,460 \\
3,572\end{array}$ & $\begin{array}{l}10.0 \\
16.9\end{array}$ & 50 \\
\hline $\begin{array}{l}\text { Refrigerator (18 cubic feet) } \\
\text { Minimum } \\
\text { Best }\end{array}$ & $\begin{array}{l}585 \\
761\end{array}$ & $\begin{array}{l}690 \\
550\end{array}$ & $\begin{array}{l}585 \\
820\end{array}$ & $\begin{array}{l}483 \\
400\end{array}$ & 19 \\
\hline $\begin{array}{l}\text { Electric Water Heater } \\
\text { Minimum } \\
\text { Best }\end{array}$ & $\begin{array}{c}410 \\
1,790\end{array}$ & $\begin{array}{l}0.88 \\
2.60\end{array}$ & $\begin{array}{c}410 \\
1,240\end{array}$ & $\begin{array}{l}0.88 \\
2.80\end{array}$ & 111 \\
\hline
\end{tabular}


The commercial demand module (CDM) forecasts energy consumption by Census division for eight marketed energy sources plus solar thermal energy. For the three major commercial sector fuels, electricity, natural gas and distillate oil, the CDM is a "structural" model and its forecasts are built up from projections of the commercial floorspace stock and of the energy-consuming equipment contained therein. For the remaining five marketed "minor fuels," simple econometric projections are made.

The commercial sector encompasses business establishments that are not engaged in industrial or transportation activities. Commercial sector energy is consumed mainly in buildings, except for a relatively small amount for services such as street lights and water supply. The CDM incorporates the effects of four broadly-defined determinants of energy consumption: economic and demographic effects, structural effects, technology turnover and change effects, and energy market effects. Demographic effects include total floorspace, building type and location. Structural effects include changes in the mix of desired end-use services provided by energy (such as the penetration of telecommunications equipment, personal computers and other office equipment). Technology effects include changes in the stock of installed equipment caused by normal turnover of old, worn out equipment to newer versions which tend to be more energy efficient, the integrated effects of equipment and building shell (insulation level) in new construction, and the projected availability of equipment with even greater energyefficiency. Energy market effects include the short-run effects of energy prices on energy demands, the longerrun effects of energy prices on the efficiency of purchased equipment, and limitations on minimum levels of efficiency imposed by legislated efficiency standards.

The model structure carries out a sequence of four basic steps, as shown in Figure 6. The first step is to forecast commercial sector floorspace. The second step is to forecast the energy services (space heating, lighting, etc.) required by the projected floorspace. The third step is to select specific technologies (natural gas furnaces, fluorescent lights, etc.) to meet the demand for energy services. The last step is to determine how much energy will be consumed by the equipment chosen to meet the demand for energy services.

\section{Floorspace Submodule}

The base stock of commercial floorspace by Census division and building type is derived from EIA's 1992 Commercial Buildings Energy Consumption Survey (CBECS). The CDM receives forecasts of total floorspace by building type and Census division from the macroeconomic activity module (MAM) based on DRIDodge definitions of the commercial sector. These forecasts embody both economic and demographic effects on commercial floorspace. Since the definition of commercial floorspace from DRI-Dodge is not calibrated to CBECS, the CDM estimates the surviving floorspace from the previous year and then calibrates its new construction so that growth in total floorspace matches that from the MAM by building type and Census division. The CDM models commercial floorspace for the following 11 building types:

- Assembly

- Education

- Food sales

- Food service

- Health care

- Lodging

- Office-large

- Office-small

- Mercantile and service

- Warehouse

- Other

\section{Energy Service Demand Submodule}

Energy consumption is derived from the demand for energy services. So the next step is to forecast energy service demands for the projected floorspace. The CDM models service demands for the following ten end-use services:

- Heating

- Cooling

- Ventilation

- Water heating

- Lighting

\begin{tabular}{|l|l|l|}
\hline \multicolumn{1}{|c|}{ CDM Outputs } & \multicolumn{1}{|c|}{ Inputs from NEMS } & \multicolumn{1}{c|}{ Exogenous Inputs } \\
\hline $\begin{array}{l}\text { Energy product demands } \\
\text { Changes in floorspace and appliance stocks }\end{array}$ & $\begin{array}{l}\text { Energy product prices } \\
\text { Interest rates } \\
\text { Floorspace growth }\end{array}$ & $\begin{array}{l}\text { Existing commercial floorspace } \\
\text { Floorspace survival rates } \\
\text { Appliance stocks and survival rates } \\
\text { New appliance types, efficiencies, costs } \\
\text { Energy use intensities }\end{array}$ \\
\hline
\end{tabular}


Figure 6. Commercial Demand Module Structure

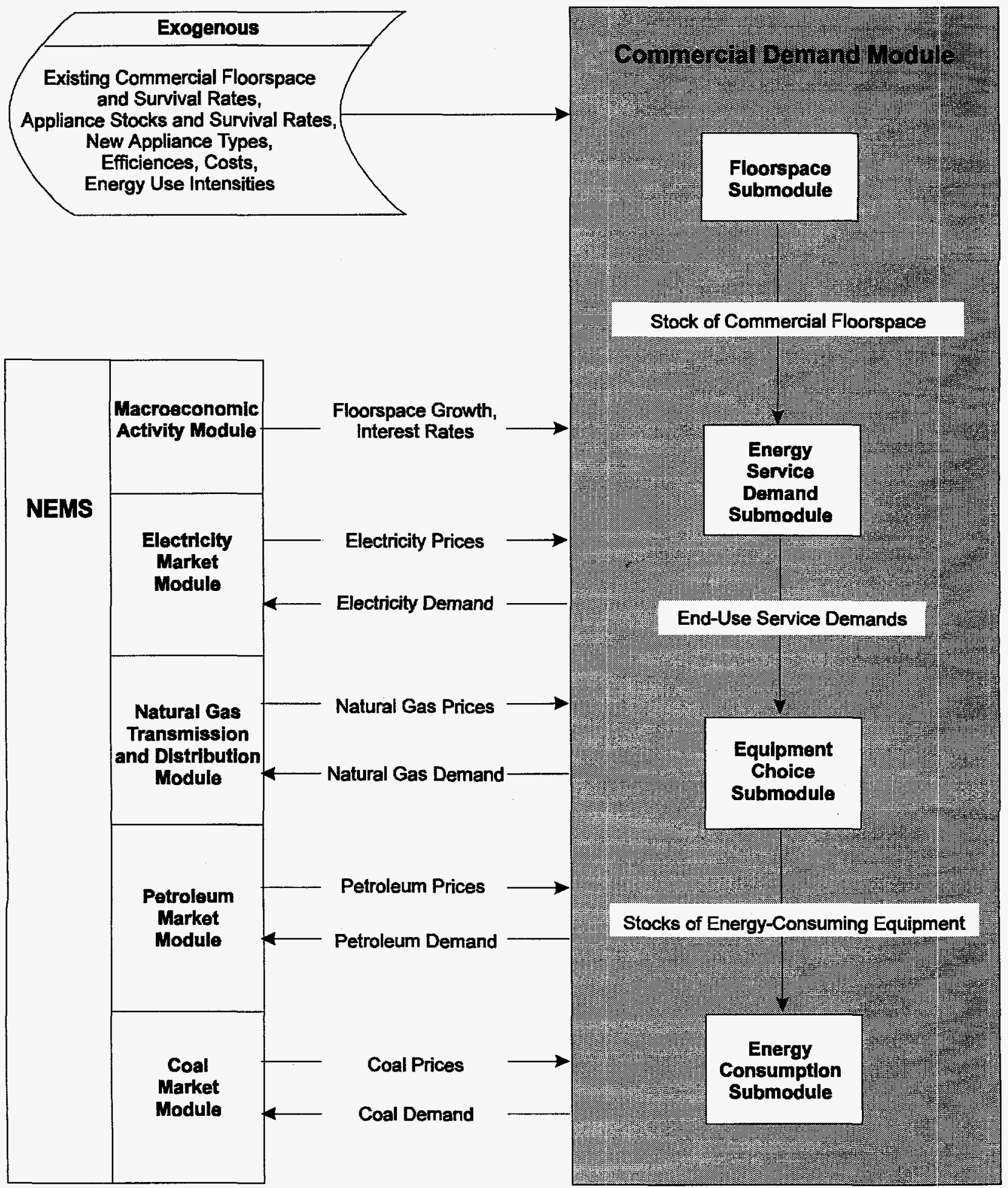


- Cooking

- Refrigeration

- Office equipment personal computer (PC)

- Office equipment other

- Other end uses.

Different building types require unique combinations of energy services. A hospital must have more light than a warehouse. An office building in the Northeast requires more heating than one in the South. Total service demand for any service depends on the floorspace, type, and location of buildings. Base service demand by end use by building type and Census division is derived from estimates developed from CBECS energy consumption. Projected service demands are adjusted for trends in new construction based on CBECS data concerning recent construction.

\section{Equipment Choice Submodule}

Once service demands are projected, the next step is to project the type and efficiency of equipment that will be used to satisfy the demands. The bulk of equipment required to meet service demand will carry over from the equipment stock of the previous model year. However, equipment must always be purchased to satisfy service demand for new construction. It must also be purchased for equipment which has either worn out (replacement equipment) or reached the end of its economically useful life (retrofit equipment). For required equipment replacements, the CDM uses a constant decay rate based on equipment life. A technology will be "retrofitted" only if the combined annual operating and maintenance costs plus annualized capital costs of a potential technology are lower than the annual operating and maintenance costs of an existing technology.

Equipment choices are made based on a comparison of annualized capital and operating and maintenance costs across all allowable equipment for a particular end-use service. In order to add "inertia" to the equipment choices, only subsets of the total menu of potentially available equipment may be allowed for defined market segments. For example, for replacement space heating equipment in large office buildings, 8 percent of floorspace is free to consider all available equipment using any fuel or technology. A second segment of 33 percent must select from technologies using the same fuel as already installed. A third segment, the remaining 59 percent of floorspace, is constrained to consider only different efficiency levels of the same fuel and technology already installed. For lighting, all choices are limited to the same technology, where technologies are broadly defined to encompass principal competing technologies (outdoor lighting types do not compete for indoor lighting service demand).

When computing annualized costs for determining equipment choices, commercial floorspace is segmented by what are referred to as "implicit discount rates" (to distinguish them from the generally lower and more common notion of financial discount rates). Six segments are used to simulate consumer behavior when purchasing commercial equipment. The segments range from rates as low as 20 percent, to rates high enough to guarantee that only equipment with the lowest capital cost (and least efficiency) is chosen. As real energy prices increase (decrease) there is an incentive for all but the highest implicit discount rate segments to purchase increased (decreased) levels of efficiency.

The equipment choice submodule is designed to choose among a discrete set of technologies that are characterized by a "menu" which defines availability, capital costs, maintenance costs, efficiencies, and equipment life. Technology characteristics for selected space heating equipment are shown in the following table, derived from the report Assumptions to the Annual Energy Outlook $1998 .^{10}$ This menu of projected equipment models projects technological innovation, market developments, and policy interventions. For Annual Energy Outlook 1998, the technology types that are included for seven of the ten service demand categories are listed in the last table.

The remaining three end use services (PC-related office equipment, other office equipment, and other end uses) are considered "minor services" and are forecast using exogenous equipment efficiency and market penetration trends.

\section{Energy Consumption Submodule}

Once the required equipment choices have been made, the total stock and efficiency of equipment for a particular end use are determined. Energy consumption by fuel can be calculated from the amount of service demand satisfied by each technology and the corresponding efficiency of the technology. At this stage, adjustments to energy consumption are also made.

\footnotetext{
${ }^{10}$ Energy Information Administration, Assumptions to the Annual Energy Outlook 1998, ftp://ftp.eia.doe.gov/pub/forecasting/ aeo98/aeo98asu.pdf (Washington, DC, December 1997).
} 


\section{Characteristics of Selected Space Heating Equipment}

\begin{tabular}{|c|c|c|c|c|c|}
\hline Equipment Type & Vintage & Efficiency & $\begin{array}{l}\text { Capital Cost } \\
\text { (1996 Dollars } \\
\text { per Thousand } \\
\text { Btu per Hour) }\end{array}$ & $\begin{array}{l}\text { Maintenance } \\
\text { Cost } \\
\text { (1996 Dollars } \\
\text { per Thousand } \\
\text { Btu per Hour) }\end{array}$ & $\begin{array}{c}\text { Service } \\
\text { Life } \\
\text { (Years) }\end{array}$ \\
\hline \multirow[t]{3}{*}{ Electric Heat Pump } & 1995 & 10.2 & 190 & 5 & 12 \\
\hline & 2010-low efficiency & 8.5 & 122 & 5 & 12 \\
\hline & 2010-high efficiency & 12.0 & 198 & 5 & 12 \\
\hline \multirow[t]{3}{*}{ Ground-Source Heat Pump } & 1995 & 13.0 & 208 & 4 & 13 \\
\hline & 2010-low efficiency & 13.0 & 167 & 4 & 13 \\
\hline & 2010-high efficiency & 14.3 & 267 & 4 & 13 \\
\hline \multirow[t]{3}{*}{ Natural Gas Boiler } & 1995 & 0.80 & 20 & 0.20 & 20 \\
\hline & 2010-low efficiency & 0.78 & 15 & 0.15 & 20 \\
\hline & 2010-high efficiency & 0.80 & 20 & 0.20 & 20 \\
\hline \multirow[t]{4}{*}{ Natural Gas Heat Pump } & 2005-engine driven & 1.02 & 192 & 6 & 13 \\
\hline & 2005-absorption & 1.45 & 183 & 5 & 15 \\
\hline & 2010-engine driven & 1.02 & 192 & 6 & 13 \\
\hline & 2010-absorption & 1.45 & 183 & 5 & 15 \\
\hline
\end{tabular}

These include adjustments for changes in real energy prices (short-run price elasticity effects), adjustments in utilization rates caused by efficiency increases (efficiency "rebound" effects), and changes for weather relative to the CBECS survey year. Once these modifications are made, total energy use is computed across end uses and building types for the three major fuels, for each Census division. Combining these projections with the econometric/trend projections for the five minor fuels yields total projected commercial energy consumption. 


\begin{tabular}{|c|c|}
\hline End-Use Service by Fuel & Technology Types \\
\hline Electric Space Heating: & air-source heat pump, ground-source heat pump, boiler, packaged space heating \\
\hline Natural Gas Space Heating: & boiler, furnace, engine-driven heat pump, absorption heat pump \\
\hline Fuel Oil Space Heating: & boiler, furnace \\
\hline Electric Space Cooling: & $\begin{array}{l}\text { air-source heat pump, ground-source heat pump, reciprocating chiller, centrifugal } \\
\text { chiller, rooftop air conditioner, residential style central air conditioner, window unit }\end{array}$ \\
\hline Natural Gas Space Cooling: & $\begin{array}{l}\text { absorption chiller, engine-driven chiller, rooftop air conditioner, engine-driven heat } \\
\text { pump, absorption heat pump }\end{array}$ \\
\hline Electric Water Heating: & electric resistance, heat pump water heater, tankless water heater \\
\hline Natural Gas Water Heating: & natural gas water heater, tankless water heater \\
\hline Fuel Oil Water Heating: & fuel oil water heater \\
\hline Ventilation: & $\begin{array}{l}\text { small Constant Air Volume (CAV) system, large CAV system, small Variable Air } \\
\text { Volume (VAV) system, large VAV system, fan coil unit, multi-zone CAV system }\end{array}$ \\
\hline Electric Cooking: & range, convection oven, deck oven, fryer, griddle, other electric \\
\hline Natural Gas Cooking: & $\begin{array}{l}\text { range, range w/power burner, deck oven, fryer, infrared fryer, griddle, infrared } \\
\text { griddle, other }\end{array}$ \\
\hline Incandescent Style Lighting: & $\begin{array}{l}\text { incandescent, compact fluorescent, halogen, halogen-infrared, coated filament, } \\
\text { hafnium carbide }\end{array}$ \\
\hline Four-foot Fluorescent Lighting: & $\begin{array}{l}\text { magnetic ballast, electronic ballast, electronic w/controls, electronic w/reflectors, } \\
\text { scotopic, electrodeless }\end{array}$ \\
\hline Eight-foot Fluorescent Lighting: & $\begin{array}{l}\text { magnetic ballast, electronic ballast, magnetic-high output, electronic-high output, } \\
\text { scotopic, electrodeless }\end{array}$ \\
\hline High Intensity Discharge Lighting: & metal halide, mercury vapor, high pressure sodium, sulfur \\
\hline Medium Temperature Refrigeration: & $\begin{array}{l}\text { strip curtain, open case, glass door, mechanical sub-cooling, non-CFC 2-stage R- } \\
22 \text { system }\end{array}$ \\
\hline Low Temperature Refrigeration: & $\begin{array}{l}\text { open case, glass door, time control, high efficiency motor, non-CFC 2-stage R-22 } \\
\text { system }\end{array}$ \\
\hline Very Low Temperature Refrigeration: & $\begin{array}{l}\text { open case, glass door, hot glass defrost, high efficiency motor, non-CFC 2-stage R- } \\
22 \text { system }\end{array}$ \\
\hline
\end{tabular}




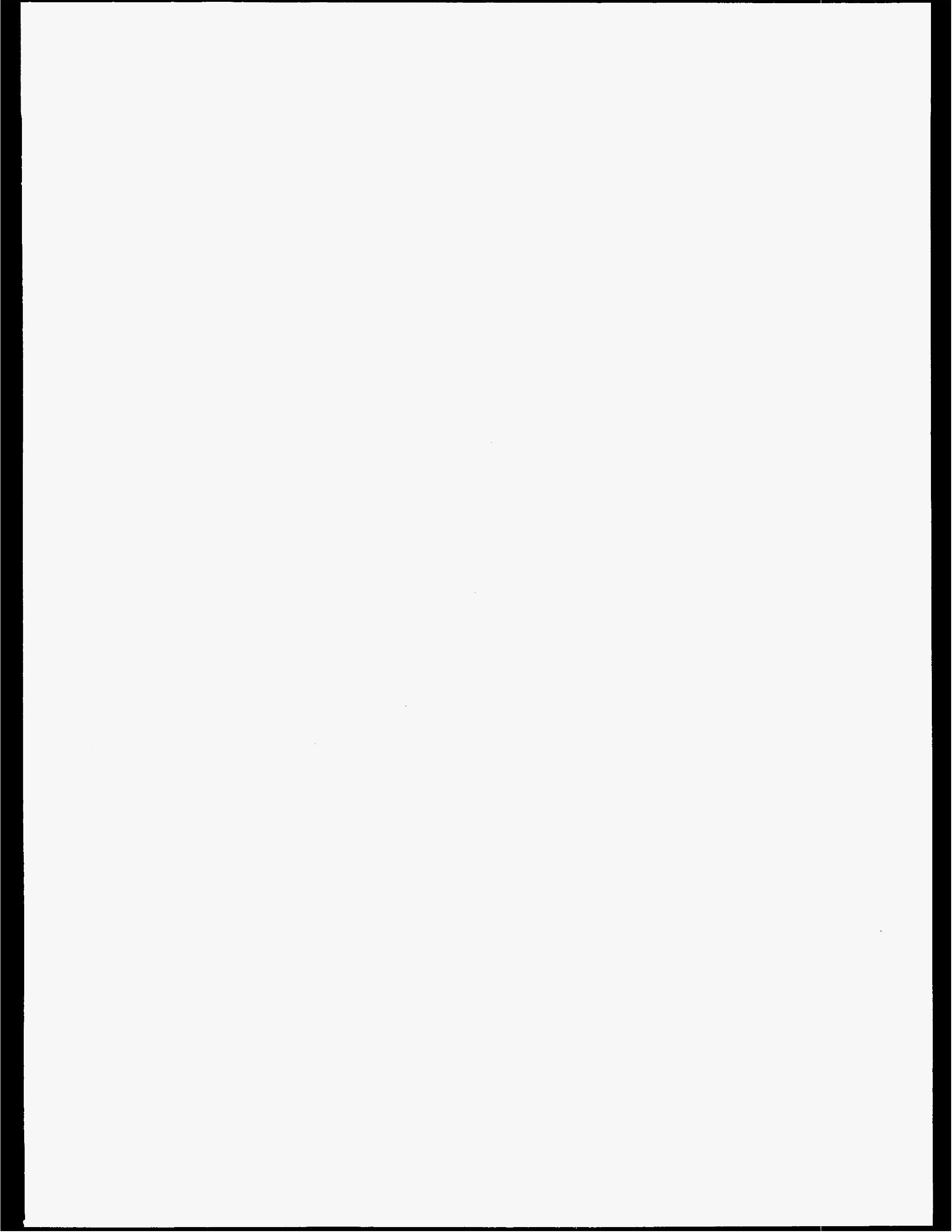


The industrial demand module (IDM) forecasts energy consumption for fuels and feedstocks for 9 manufacturing industries and 6 nonmanufacturing industries, subject to delivered prices of energy and macroeconomic variables representing the value of output for each industry. The module includes industrial cogeneration of electricity that is either used in the industrial sector or sold to electric utilities. The IDM structure is shown in Figure 7.

Industrial energy demand is projected as a combination of "bottom up" characterizations of the energy-using technology and "top down" econometric estimates of behavior. The influence of energy prices on industrial energy consumption is modeled in terms of the efficiency of use of existing capital, the efficiency of new capital acquisitions, and the mix of fuels utilized, given existing capital stocks. Energy conservation from technological change is represented over time by trend-based "technology possibility curves." These curves represent the aggregate efficiency of all new technologies that are likely to penetrate the future markets as well as the aggregate improvement in efficiency of 1991 technology.

The IDM incorporates three major industry categories: energy-intensive manufacturing industries, non-energyintensive manufacturing industries, and nonmanufacturing industries. The level and type of modeling and the attention to detail is different for each. Manufacturing disaggregation is at the 2-digit Standard Industrial Classification (SIC) level, with some further disaggregation of more energy-intensive or large energyconsuming industries. Industries treated in more detail include food, paper, chemicals, glass, cement, steel, and aluminum. Energy product demands are calculated independently for each industry.

Each industry is modeled (where appropriate) as three interrelated components: buildings (BLD), boilers/ steam/cogeneration (BSC), and process/ assembly (PA) activities. Buildings are estimated to account for 3 percent of energy consumption in manufacturing industries (in nonmanufacturing industries, building energy consumption is assumed to be negligible).
Consequently, the IDM uses a simple modeling approach for the BLD component. Energy consumption in industrial buildings is assumed to grow at the same rate as employment in that industry. The BSC component consumes energy to meet the steam demands from the other two components and to provide internally generated electricity to the BLD and PA components. The boiler component consumes fossil fuels to produce steam, which is passed to the PA component. Parameter estimates for the cogeneration component are based on regression from a panel of pooled time-series and crosssectional data. The IDM models cogeneration based on

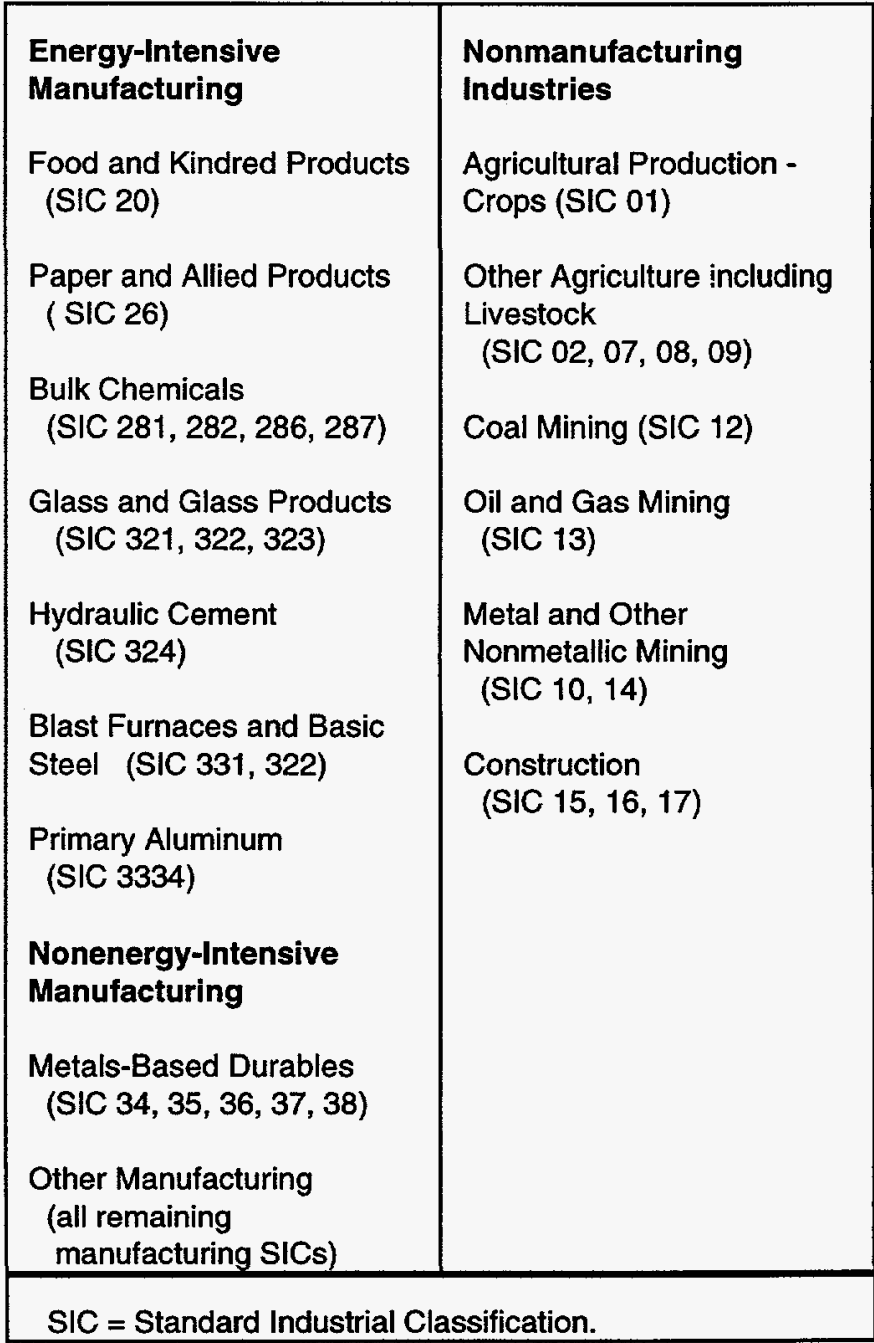

\begin{tabular}{|l|l|l|}
\hline \multicolumn{1}{|c|}{ IDM Outputs } & \multicolumn{1}{|c|}{ Inputs from NEMS } & \multicolumn{1}{c|}{ Exogenous Inputs } \\
\hline $\begin{array}{l}\text { Energy product demand } \\
\text { Electricity sales to grid } \\
\text { Cogeneration output and fuel consumption }\end{array}$ & $\begin{array}{l}\text { Energy product prices } \\
\text { Economic output by industry } \\
\text { Refinery fuel consumption } \\
\text { Lease and plant fuel consumption } \\
\text { Cogeneration from refineries and oil } \\
\text { and gas production }\end{array}$ & $\begin{array}{l}\text { Production stages } \\
\text { in energy-intensive industries } \\
\text { Technology possibility curves } \\
\text { Unit energy consumption } \\
\text { Stock retirement rates }\end{array}$ \\
\hline
\end{tabular}


Figure 7. Industrial Demand Module Structure

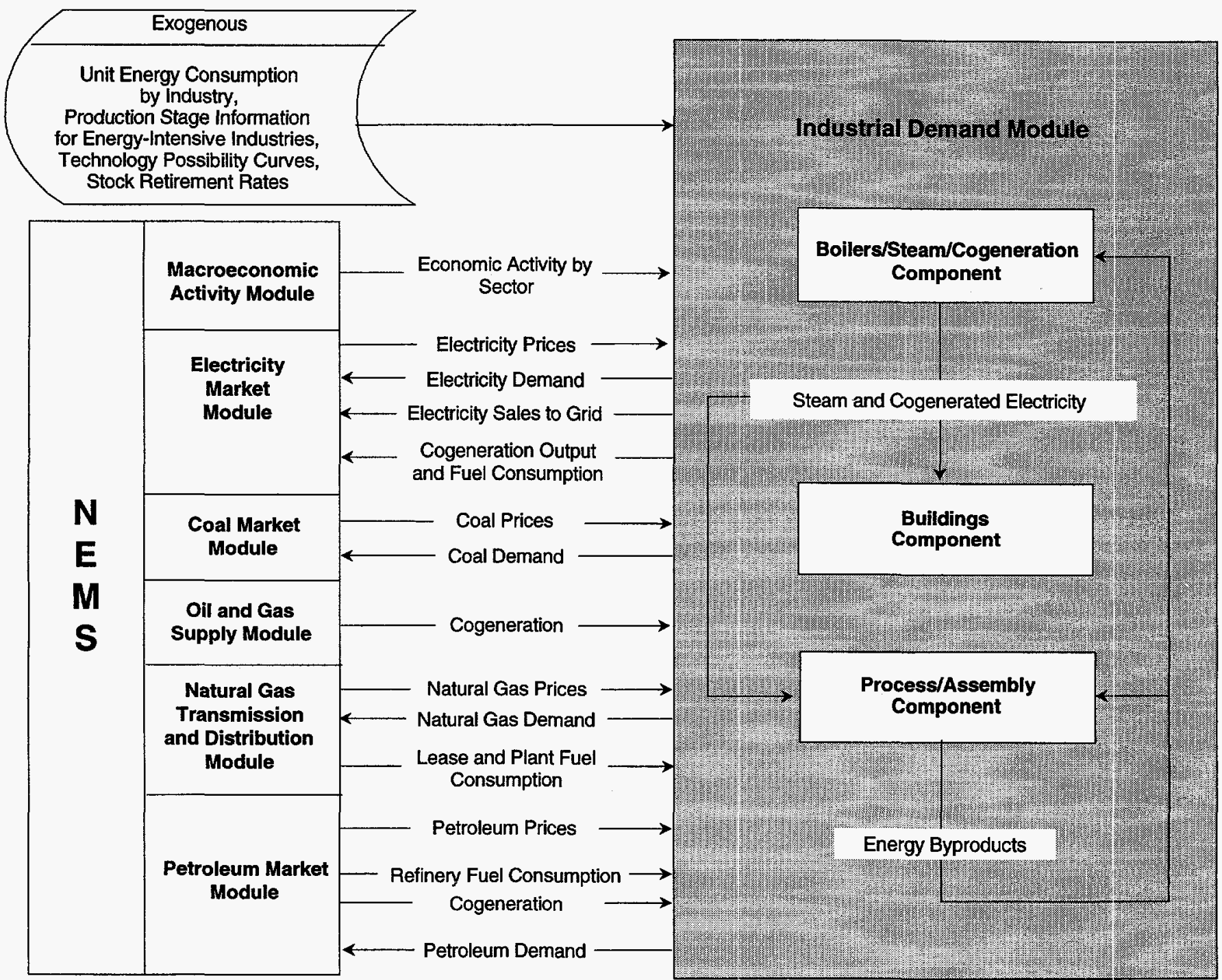

steam demand from the BLD and the PA components and represents planned "traditional" cogeneration units based on data from the Form EIA-867, "Annual Nonutility Power Producer Report." The "nontraditional" cogeneration units are represented in the electricity market module since these units are mainly grid-serving, electricity-price-driven entities.

The PA component accounts for the largest share of direct energy consumption for heat and power, 53 percent. For the seven most energy-intensive industries, process steps or end uses are modeled using engineering concepts. The production process is decomposed into the major steps, and the energy relationships among the steps are specified.
The energy intensities of the process steps or end uses vary over time, both for existing technology and for technologies expected to be adopted in the future. In the IDM, this variation is based on engineering judgment and is reflected in the parameters of technology possibility curves, which show the declining energy intensity of existing and new capital relative to the 1991 stock.

The IDMI uses "technology bundles" to characterize technological change in the energy-intensive industries. These bundles are defined for each production process step for five of the industries and for end use in two of the industries. The process step industries are pulp and paper, glass, cement, steel, and aluminum. The end-use industries are food and bulk chemicals. 


\section{End Use Characterization}

Food: direct fuel, hot water/steam, refrigeration, and other electric.

Bulk Chemicals: direct fuel, hot water/steam, electrolytic, and other electric.

\section{Process Step Characterization}

Pulp and Paper: wood preparation, waste pulping, mechanical pulping, semi-chemical pulping, Kraft pulping, bleaching, and papermaking.

Glass: batch preparation, melting/refining, and forming.

Cement: dry process clinker, wet process clinker, and finish grinding.

Steel: coke oven, open hearth steel making, basic oxygen furnace steel making, electric arc furnace steel making, ingot casting, continuous casting, hot rolling, and cold rolling.

Aluminum: only primary aluminum smelting is explicitly included.

The unit energy consumption is defined as the energy use per ton of throughput at a process step or as energy use per dollar of output for the end use industries. The "Existing UEC" is the current average installed intensity as of 1991. The "New 1991 UEC" is the intensity expected to prevail for a new installation in 1991. Similarly, the "New 2015 UEC" is the intensity expected to prevail for a new installation in 2015. For intervening years, the intensity is interpolated. The same implied rate of change is also applied through 2020 .

The rate at which the average intensity declines is determined by the rate and timing of new additions to capacity. In the current IDM, the rate and timing of new additions are functions of retirement rates and industry growth rates.

The IDM uses a vintaged capital stock accounting framework that models energy use in new additions to the stock and in the existing stock. This capital stock is represented as the aggregate vintage of all plants built within an industry and does not imply the inclusion of specific technologies or capital equipment.
The capital stock is grouped into three vintages: old, middle, and new. The old vintage consists of capital in production prior to 1991, which is assumed to retire at a fixed rate each year. Middle-vintage capital is that added after 1990, excluding the year of the forecast. New production capacity is built in the forecast years when the capacity of the existing stock of capital in the IDM cannot produce the output forecasted by the NEMS regional subcomponent of the macroeconomic activity module. Capital additions during the forecast horizon are retired in subsequent years at the same rate as the pre-1990 capital stock.

The energy-intensive and/or large energy-consuming industries are modeled with a structure that explicitly describes the major process flows or "stages of production" in the industry (some industries have major consuming uses).

Technology penetration at the level of major processes in each industry is based on a technology penetration curve relationship. A second relationship can provide additional energy conservation resulting from increases in relative energy prices. Major process choices (where applicable) are determined by industry production, specific process flows, and exogenous assumptions.

The IDM achieves fuel switching by application of a logit function methodology for estimating fuel shares in the boilers/steam/cogeneration component. Additional fuel switching capability takes place within the nonenergy-intensive manufacturing sector through the application of the translog function methodology for estimating fuel shares.

Recycling, waste products, and byproduct consumption are modelled using parameters based on off-line analysis and assumptions about the manufacturing processes or technologies applied within industry. These analyses and assumptions are mainly based upon environmental regulations such as government requirements about the share of recycled paper used in offices. The IDM also accounts for trends within industry toward the production of more specialized products such as specialized steel which can be produced using scrap material versus raw iron ore. 

The transportation demand module (TRAN) forecasts the consumption of transportation sector fuels by transportation mode, including the use of renewables and alternative fuels, subject to delivered prices of energy fuels and macroeconomic variables, including disposable personal income, gross domestic product, level of imports and exports, industrial output, new car and light truck sales, and population. The structure of the module is shown in Figure 8.

NEMS projections of future fuel prices influence the fuel efficiency, vehicle-miles traveled, and alternative-fuel vehicle (AFV) market penetration for the current fleet of vehicles. Alternative-fuel shares are projected on the basis of a multinomial logit vehicle attribute model, subject to State and Federal government mandates.

\section{Fuel Economy Submodule}

This submodule projects new light-duty vehicle fuel efficiency by 12 U.S. Environmental Protection Agency (EPA) vehicle size classes and 16 engine technologies (gasoline, diesel, and $14 \mathrm{AFV}$ technologies) as a function of energy prices and income-related variables. There are 56 fuel-saving technologies which vary in cost and marginal fuel savings by size class. Characteristics of a sample of these technologies are shown on page 38 , derived from Assumptions to the Annual Energy Outlook 1998. ${ }^{11}$ Technologies penetrate the market based on a cost-effectiveness algorithm which compares the technology cost to the discounted stream of fuel savings and the value of performance to the consumer. In general, higher fuel prices lead to higher fuel efficiency estimates within each size class, a shift to a more fuelefficient size class mix, and an increase in the rate at which alternative-fuel vehicles enter the marketplace.

\section{Regional Sales Submodule}

Vehicle sales from the macroeconomic activity module are divided into car and light truck sales based on demographic analysis. The remainder of the submodule is a simple accounting mechanism that uses endogenous estimates of new car and light truck sales and the historical regional vehicle sales adjusted for regional population trends to produce estimates of regional sales, which are subsequently passed to the alternative-fuel vehicle and the light-duty vehicle stock submodules.

\section{Alternative-Fuel Vehicle Submodule}

This submodule projects the sales shares of alternativefuel technologies as a function of time, technology attributes, costs, and fuel prices. Vehicle attributes are shown on page 38, derived from Assumptions to the Annual Energy Outlook 1998. Both conventional and new technology vehicles are considered. The alternativefuel vehicle submodule receives regional new car and light truck sales by size class from the regional sales submodule.

The forecast of vehicle sales by technology requires a three-stage nested decision process. The first stage consists of endogenously calculating the sales shares between conventional and total alternative-fuel vehicles on a regional level, based on the following factors: regional fuel operating costs per mile (fuel price divided by fuel efficiency), vehicle price, range, regional fuel availability, commercial availability, and regional regulatory constraints.

Once the level of total alternative-fuel vehicles per region has been calculated, the second stage estimates shares among the alternative-fuel vehicle technologies within each region, based on the same regional factors and methodology used in the prior step to calculate the shares of conventional and total alternative-fuel vehicle sales. The third stage subdivides electric vehicle sales into individual electric vehicle technologies. TRAN includes the following alternative-fuel technologies:

\begin{tabular}{|c|c|c|}
\hline TRAN Outputs & Inputs from NEMS & Exogenous Inputs \\
\hline $\begin{array}{l}\text { Fuel demand by mode } \\
\text { Sales, stocks and characteristics of } \\
\text { vehicle types by size class } \\
\text { Vehicle-miles traveled } \\
\text { Fuel efficiencies by technology type } \\
\text { Alternative-fuel vehicle sales by } \\
\text { technology type } \\
\text { Light-duty commercial fleet vehicle } \\
\text { characteristics }\end{array}$ & $\begin{array}{l}\text { Energy product prices } \\
\text { Gross domestic product } \\
\text { Disposable personal income } \\
\text { Industrial output } \\
\text { Vehicle sales } \\
\text { International trade } \\
\text { Natural gas pipeline consumption }\end{array}$ & $\begin{array}{l}\text { Current and projected demographics } \\
\text { Existing vehicle stocks by vintage and } \\
\text { fuel efficiency } \\
\text { Vehicle survival rates } \\
\text { New vehicle technologies } \\
\text { Fuel availability } \\
\text { Commercial availability } \\
\text { Vehicle safety and emissions regulations } \\
\text { Vehicle miles-per-gallon degradation rates }\end{array}$ \\
\hline
\end{tabular}

\footnotetext{
${ }^{11}$ Energy Information Administration, Assumptions to the Annual Energy Outlook 1998, ftp://ftp.eia.doe.gov/pub/forecasting/ aeo98/aeo98asu.pdf (Washington, DC, December 1997).
} 


\section{TRANSPORTATION DEMAND MODULE}

Figure 8. Transportation Demand Module Structure
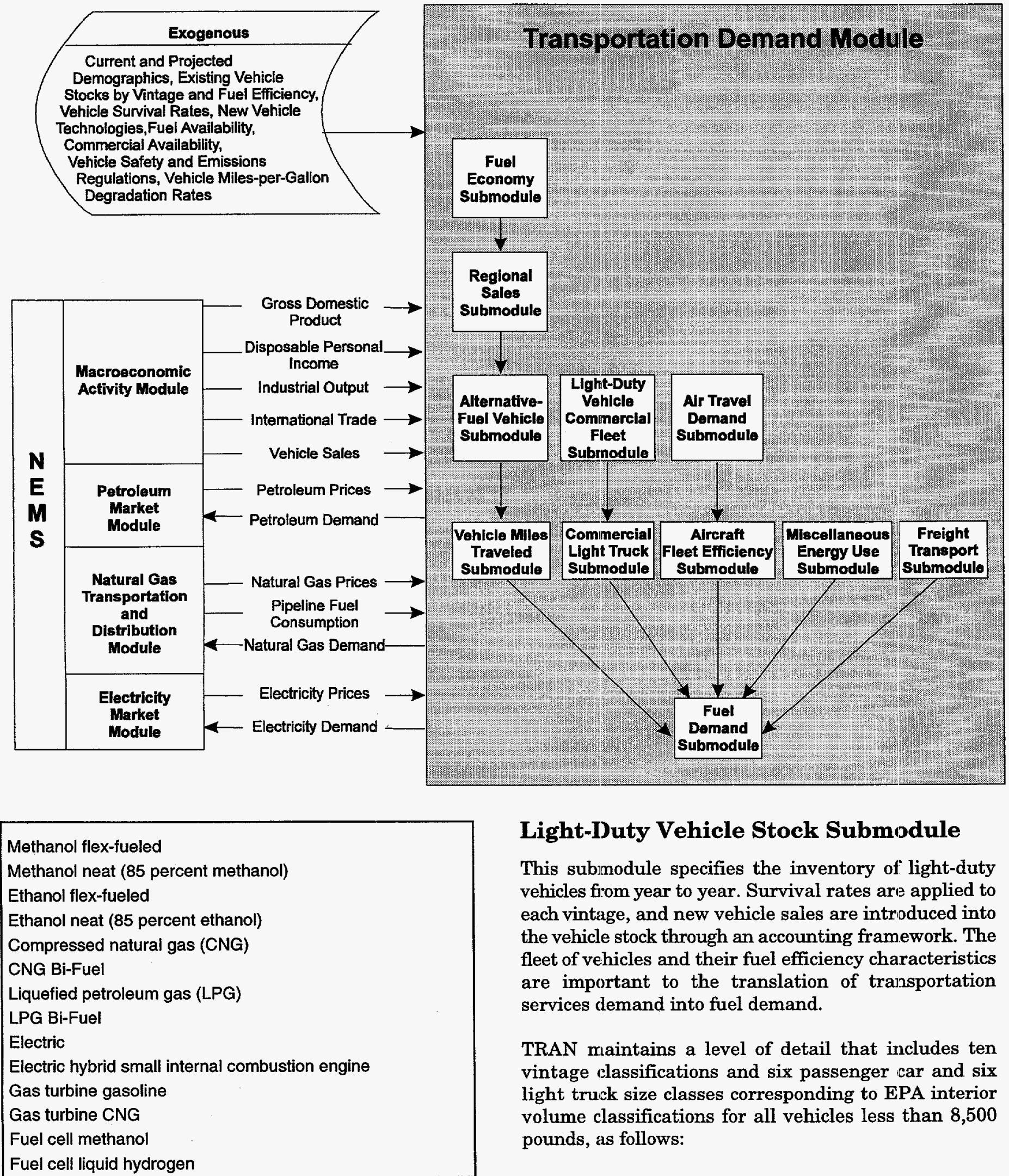

\section{Light-Duty Vehicle Stock Submodule}

This submodule specifies the inventory of light-duty vehicles from year to year. Survival rates are applied to each vintage, and new vehicle sales are introduced into the vehicle stock through an accounting framework. The fleet of vehicles and their fuel efficiency characteristics are important to the translation of transportation services demand into fuel demand.

TRAN maintains a level of detail that includes ten vintage classifications and six passenger car and six light truck size classes corresponding to EPA interior volume classifications for all vehicles less than 8,500 pounds, as follows: 


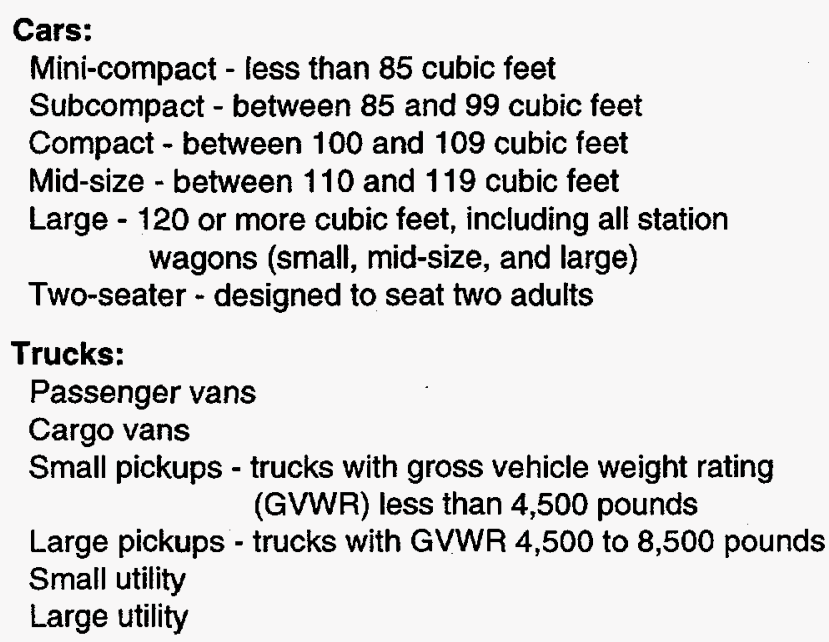

\section{Vehicle-Miles Traveled (VMT) Submodule}

This submodule projects travel demand for automobiles and light trucks. VMT per capita estimates are based on the fuel cost of driving per mile, per capita disposable personal income, an index that reflects the aging of the population, and an adjustment for female-to-male driving ratios. Total VMT is calculated by multiplying VMT per capita by the driving age population.

\section{Light-Duty Vehicle Commercial Fleet Submodule}

This submodule generates estimates of the stock of cars and trucks used in business, government, and utility fleets. It also estimates travel demand, fuel efficiency, and energy consumption for the fleet vehicles prior to their transition to the private sector at predetermined vintages.

\section{Commercial Light Truck Submodule}

The commercial light truck submodule estimates sales, stocks, fuel efficiencies, travel, and fuel demand for all trucks greater than 8,500 pounds and less than 10,000 pounds.

\section{Air Travel Demand Submodule}

This submodule estimates the demand for both passenger and freight air travel. Passenger travel is forecasted by domestic travel, which is disaggregated between business and personal travel, and international travel. Dedicated air freight travel is disaggregated between the total air freight demand and air freight carried in the lower hull of commercial passenger aircraft. In each of the market segments, the demand for air travel is estimated as a function of the cost of air travel (including fuel costs) and economic growth (GDP, disposable income, and merchandise exports).

\section{Aircraft Fleet Efficiency Submodule}

This submodule forecasts the total stock and the average fleet efficiency of narrow body and wide body aircraft required to meet the projected travel demand. The stock estimation is based on the growth of travel demand and a logistic function that calculates the survival of the older planes. The overall fleet efficiency is determined by the weighted average of the surviving aircraft efficiency (including retrofits) and the efficiencies of the newly acquired aircraft. The efficiency improvements of the new aircraft are determined by technology choice (ultra-high bypass, propfan, hybrid laminar flow, advanced aerodynamics, weight-reducing materials, or thermodynamics) which depends on the trigger fuel price and the time in which the technology has been commercially viable.

\section{Freight Transport Submodule}

This submodule translates NEMS estimates of industrial production into ton-miles traveled requirements for rail and ship travel, and into vehicle-miles traveled for trucks, then into fuel demand by mode of freight travel. The freight truck stock submodule is subdivided into medium and heavy-duty trucks. VMT freight estimates by truck size class and technology are based on matching freight needs, as measured by the growth in industrial output by Standard Industrial Classification (SIC) code, to VMT levels associated with truck stocks and new vehicles.

Rail and shipping ton-miles traveled are also estimated as a function of growth in industrial output. Freight truck fuel efficiency growth rates relative to fuel prices are tied to historical growth rates by size class and are also dependent on the maximum penetration, introduction year, fuel trigger price (based on cost-effectiveness) and fuel economy improvement of the technologies including alternative-fuel technologies. In the rail and shipping modes, energy efficiency estimates are structured to evaluate the potential of both technology trends and efficiency improvements related to energy prices.

\section{Miscellaneous Energy Use Submodule}

This submodule projects the use of energy in military operations, mass transit vehicles, recreational boats, and automotive lubricants, based on endogenous variables within NEMS (e.g., vehicle fuel efficiencies) and exogenous variables (e.g., the military budget). 
Selected Technology Characteristics for Automobiles

\begin{tabular}{|l|c|c|c|}
\hline & $\begin{array}{c}\text { Fractional Fuel } \\
\text { Efficiency Change }\end{array}$ & First Year Introduced & $\begin{array}{c}\text { Fractional Horsepower } \\
\text { Change }\end{array}$ \\
\hline Front Wheel Drive & 0.060 & 1980 & 0 \\
\hline 4-Speed Automatic & 0.045 & 1980 & 0.05 \\
\hline 5-Speed Automatic & 0.065 & 1995 & 0.07 \\
\hline 6-Speed Manual & 0.020 & 1991 & 0.05 \\
\hline Electronic Transmission I & 0.005 & 1988 & 0 \\
\hline Electronic Transmission II & 0.015 & 1998 & 0 \\
\hline Emissions Tier I & -0.010 & 1994 & 0 \\
\hline Emissions Tier II & -0.010 & 2003 & 0 \\
\hline Side Impact & -0.005 & 1996 & 0 \\
\hline
\end{tabular}

Examples of Domestic Midsize Attributes

\begin{tabular}{|l|c|c|c|c|c|c|c|}
\hline & Year & Gasoline & $\begin{array}{c}\text { Ethanol } \\
\text { Flex }\end{array}$ & $\begin{array}{c}\text { Methanol } \\
\text { Flex }\end{array}$ & LPG & $\begin{array}{c}\text { Electric } \\
\text { Vehicle } \\
\text { Hybrid }\end{array}$ & $\begin{array}{c}\text { Fuel Cell } \\
\text { Mlethanol }\end{array}$ \\
\hline $\begin{array}{l}\text { Vehicle Price (thousand 1996 } \\
\text { dollars) }\end{array}$ & 1995 & 17.5 & 18.2 & 18.2 & 20.9 & 48.2 & 130.2 \\
\cline { 2 - 8 } & 2015 & 20.4 & 20.9 & 20.9 & 23.4 & 30.6 & 40.7 \\
\hline Vehicle Miles per Gallon & 1995 & 27.62 & 28.25 & 28.52 & 29.00 & 40.84 & 48.59 \\
\cline { 2 - 8 } & 2015 & 29.77 & 30.30 & 30.57 & 30.74 & 40.18 & 47.61 \\
\hline \multirow{2}{*}{ Vehicle Range (100 miles) } & 1995 & 4.51 & 3.29 & 2.57 & 3.84 & 4.51 & 4.51 \\
\cline { 2 - 8 } & 2015 & 5.00 & 3.65 & 2.85 & 4.25 & 5.00 & 5.00 \\
\hline \multirow{2}{*}{$\begin{array}{l}\text { Fuel Availability Relative to } \\
\text { Gasoline }\end{array}$} & 1995 & 1.00 & 1.00 & 1.00 & 0.01 & 1.00 & 0.01 \\
\cline { 2 - 8 } & 2015 & 1.00 & 1.00 & 1.00 & 0.10 & 1.00 & 0.10 \\
\hline \multirow{2}{*}{$\begin{array}{l}\text { Commercial Availability Relative } \\
\text { to Gasoline }\end{array}$} & 1995 & 1.00 & 0.076 & 0.076 & 0.007 & 0.076 & 0.001 \\
\cline { 2 - 8 } & 2015 & 1.00 & 0.999 & 0.999 & 0.993 & 0.999 & 0.001 \\
\hline
\end{tabular}


The electricity market module (EMM) represents the generation, transmission, and pricing of electricity, subject to: delivered prices for coal, petroleum products, and natural gas; the cost of centralized generation from renewable fuels; macroeconomic variables for costs of capital and domestic investment; and electricity load shapes and demand. The submodules consist of capacity planning, fuel dispatching, finance and pricing, and load and demand-side management (Figure 9). In addition, nonutility supply and electricity trade are represented in the fuel dispatching and capacity planning submodules. Nonutility generation from cogenerators and other facilities whose primary business is not electricity generation is represented in the demand and fuel supply modules. All other nonutility generation is represented in the EMM. The generation of electricity is accounted for in 15 supply regions (Figure 10), and fuel consumption is allocated to the 9 Census divisions.

Operating (dispatch) decisions are provided by the costminimizing mix of fuel and variable operating and maintenance (O\&M) costs, subject to environmental costs. Capacity expansion is determined by the leastcost mix of all costs, including capital, O\&M, and fuel. Construction of generating plants with long leadtimes is selected with planning horizons up to six periods into the future; the planning horizon can change with respect to the generating technology being considered. Electricity demand is represented by load curves, which vary by region, season, and time of day.

The solution to the submodules of the EMM is simultaneous in that, directly or indirectly, the solution for each submodule depends on the solution to every other submodule. A solution sequence through the submodules can be viewed as follows:

- The load and demand-side management submodule processes electricity demand to construct load curves.

- The electricity capacity planning submodule projects the construction of new utility and nonutility plants, the level of firm power trades, and the addition of scrubbers for environmental compliance.

- The electricity fuel dispatch submodule dispatches the available generating units, both utility and nonutility, allowing surplus capacity in select regions to be dispatched for another region's needs (economy trade).

- The electricity finance and pricing submodule calculates total revenue requirements for each utility operation and computes average and marginal-cost based electricity prices.

\section{Electricity Capacity Planning Submodule}

The electricity capacity planning (ECP) submodule determines how best to meet expected growth in electricity demand, given available resources, expected load shapes, expected demands and fuel prices, environmental constraints, and costs for utility and nonutility technologies. When new capacity is required to meet electricity demand, then the timing of the demand increase, the expected utilization of the new capacity, the operating efficiencies and the construction and operating costs of available technologies determine what technology is chosen.

The expected utilization of the capacity is important in the decisionmaking process. A technology with relatively high capital costs but comparatively low operating costs (primarily fuel costs) may be the appropriate choice if the capacity is expected to operate continuously (base load). However, a plant type with high operating costs but low capital costs may be the most economical selection to serve the peak load (i.e., the highest demands on the system), which occurs infrequently. Intermediate or cycling load occupies a middle ground between base and peak load and is best served by plants that are cheaper to build than baseload plants and cheaper to operate than peak load plants.

\begin{tabular}{|l|l|l|}
\hline \multicolumn{1}{|c|}{ EMM Outputs } & \multicolumn{1}{|c|}{ Inputs from NEMS } & \multicolumn{1}{|c|}{ Exogenous Inputs } \\
\hline Electricity prices and price components & Electricity sales & Financial data \\
Fuel demands & Fuel prices & Tax assumptions \\
Capacity additions & Cogeneration supply and fuel consumption & Capital costs \\
Capital requirements & Electricity sales to the grid & Operation and maintenance costs \\
Emissions & Renewable technology characteristics, & Operating parameters \\
Renewable capacity & allowable capacity, and costs & Emissions rates \\
Avoided costs & Renewable capacity factors & New technologies \\
& Gross domestic product & Existing facilities \\
& Interest rates & Transmission constraints \\
\hline
\end{tabular}




\section{Figure 9. Electricity Market Module Structure}

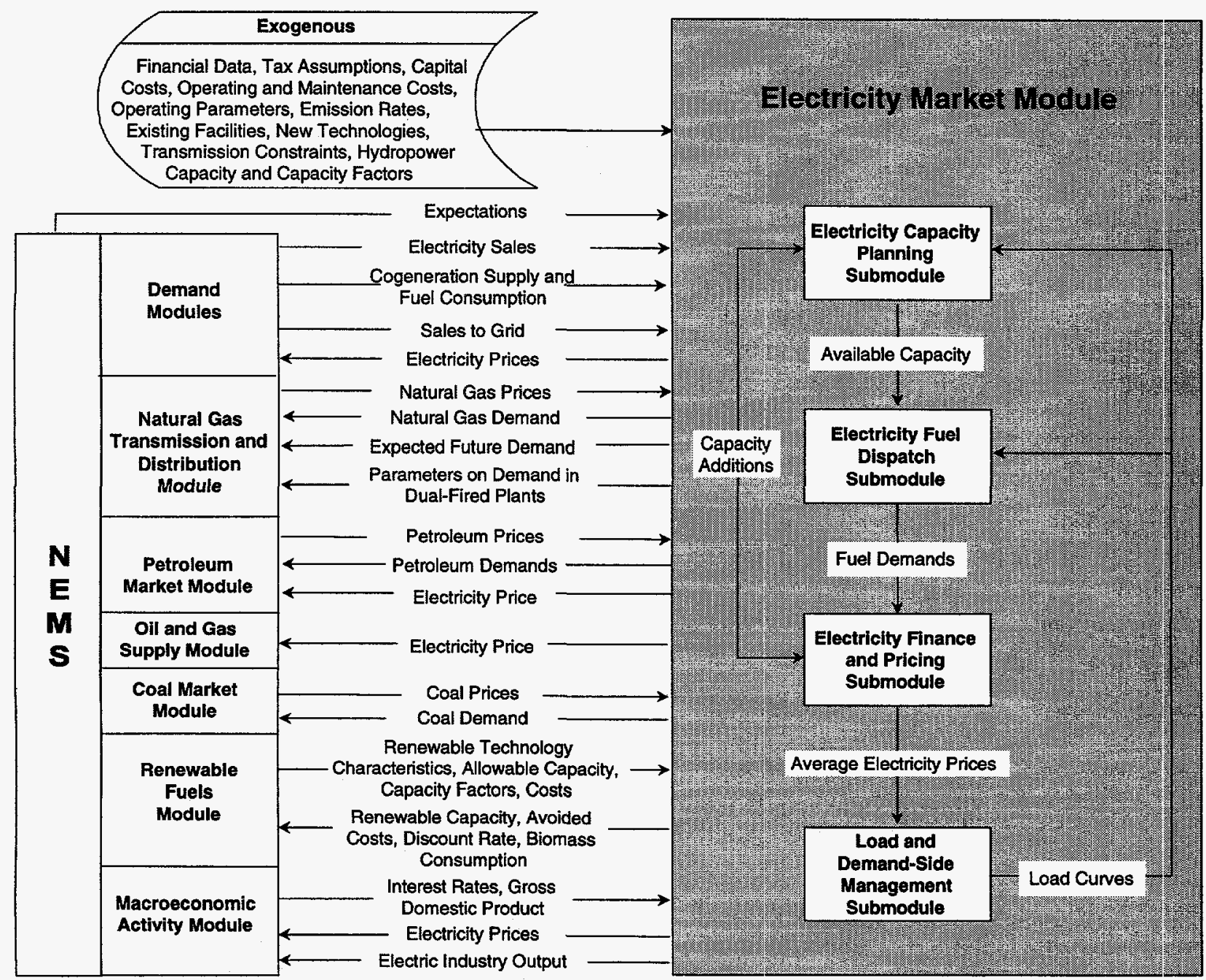

Technologies are compared on the basis of total capital and operating costs incurred over a 20 -year period. As new technologies become available, they are competed against conventional plant types. Fossil-fuel, nuclear, and renewable generating technologies are represented.

The timing of the demand increase is important, because the construction leadtimes of technologies differ. The ECP submodule looks up to six periods into the future when identifying new capacity needs. A multiperiod optimization is performed, whereby capacity choices in each year are made by looking at several years in the future rather than a single year.

Construction lead times also contribute to uncertainty about investment decisions. Technologies with long leadtimes are subject to greater financial risk. Compared to plants with shorter leadtimes, they are more sensitive to market changes in interest and inflation rates and are more vulnerable to uncertain demand projections that determine the need for new capacity. To capture these factors, the discount rate for each technology is adjusted using risk premiums based on the construction leadtime. The risk-adjusted discount rate results in the perception that a technology with a long leadtime is less economically attractive than another technology with similar costs, but a shorter leadtime.

Uncertainty about investment costs for new technologies is captured in the ECP using technological optimism and learning factors. The technological optimism factor reflects the inherent tendency to underestimate costs for new technologies. The degree of technological optimism depends on the complexity of the engineering design and the stage of development. As development proceeds 


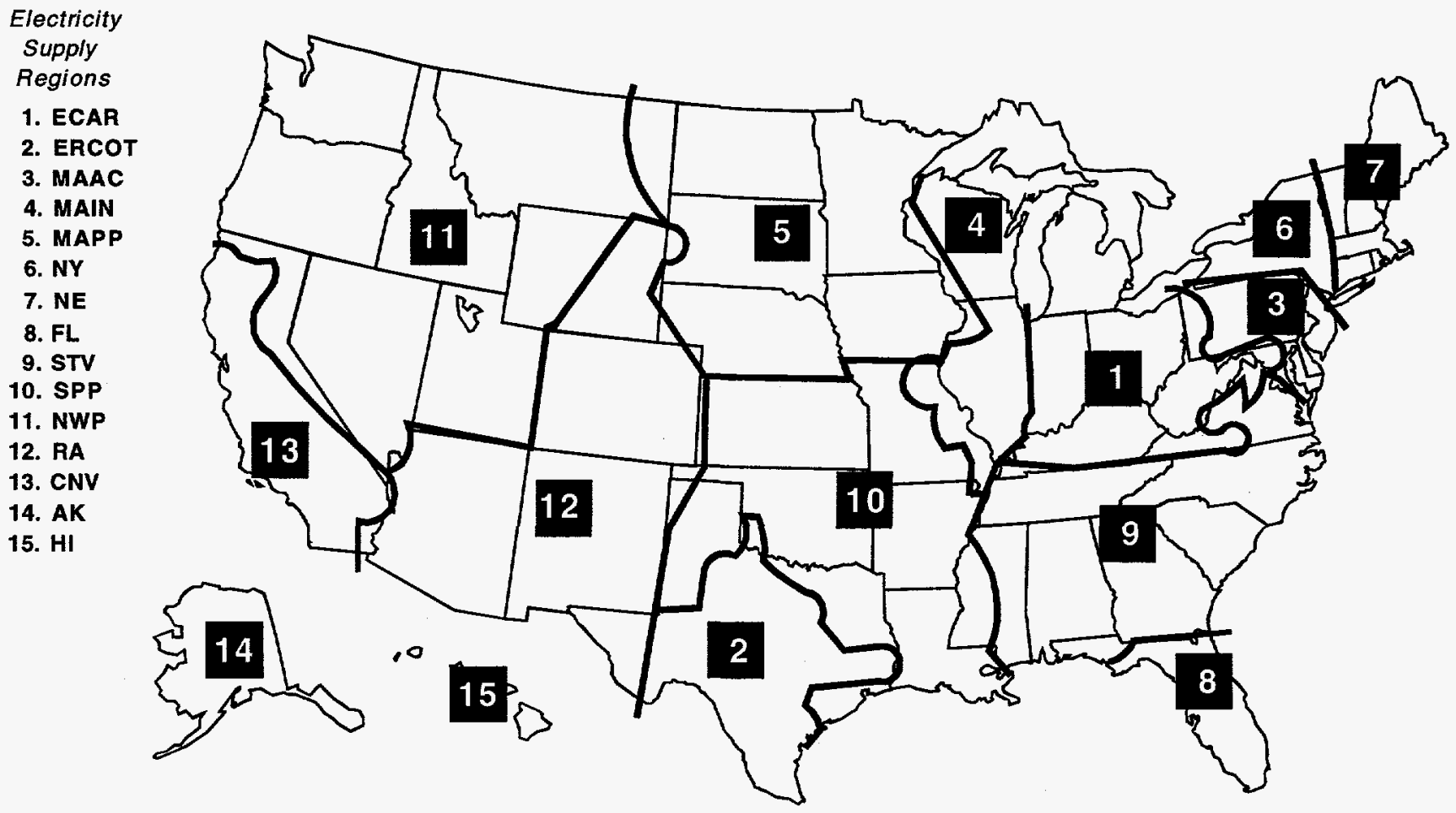

and more data become available, cost estimates become more accurate and the technological optimism factor declines. Learning factors represent reductions in capital costs due to "learning-by-doing." For new technologies, cost reductions due to learning also account for international experience in building generating capacity.

Overnight costs for advanced generating technologies decrease by 10 percent for each doubling of capacity for the first through the fifth unit, decrease by 5 percent for each doubling of capacity for the sixth through the fortieth unit, and decrease by 2.5 percent for each doubling of capacity past the forty-first unit. In the case of conventional generating technologies, base overnight costs are assumed to be the cost per kilowatt for the first forty units constructed. Costs then decrease by 2.5 percent for each doubling of capacity past forty units.

Capital costs for all new electricity generating technologies (fossil, nuclear, and renewable) decrease in response to foreign and domestic experience. Foreign units of new technologies are assumed to contribute to reductions in capital costs for units that are installed in the United States to the extent that (1) the technology characteristics are similar to those used in U.S. markets, (2) the design and construction firms and key personnel compete in the U.S. market, (3) the owning and operating firm competes actively in the United States, and (4) there exists relatively complete information about the status of the associated facility. If the new foreign units do not satisfy one or more of these requirements, they are given a reduced weight or not included in the learning effects calculation. Capital costs from the Annual Energy Outlook 1998 reference case are shown on page 43. (For renewable technologies, the capital costs are for California, which is representative of the United States.)

Initially, investment decisions are determined in the ECP using cost and performance characteristics that are represented as single point estimates corresponding to the average (expected) cost. However, these parameters are also subject to uncertainty and are better represented by distributions. If the distributions of two or more options overlap, the option with the lowest average cost is not likely to capture the entire market. Therefore, the ECP uses a market-sharing algorithm to adjust the initial solution and reallocate some of the capacity expansion decisions to technologies that are "competitive" but do not have the lowest average cost.

Both fossil-fired steam plant retirements and life extensions are calculated exogenously to the model. Life 
extension costs, such as capital additions, are included in the regulated price of electricity.

The operating life of nuclear plants is determined differently from all other generating units. The licensing status as of year end 1996 defines unit operating life of nuclear plants. This information includes the recoupment of construction time for those plants whose licenses have been redefined by the Nuclear Regulatory Commission. The majority of nuclear units are assumed to operate until the expiration of their license; however, recent experience has indicated that utilities will retire units before their license expiration date for a variety of reasons, including either operating costs or costs to refurbish the unit that are excessively high. The units chosen to retire early are specified exogenously to the model.

The ECP submodule also determines whether to contract for unplanned firm power imports from Canada and from neighboring electricity supply regions. Imports from Canada are competed using supply curves developed from cost estimates for potential hydroelectric projects in Canada. Imports from neighboring electricity supply regions are competed in the ECP based on the cost of the unit in the exporting region plus the additional cost of transmitting the power. Transmission costs are computed as a fraction of revenue.

After building new capacity, the submodule passes total available capacity to the electricity fuel dispatch submodule and new capacity expenses to the electricity finance and pricing submodule. The following technologies are considered:

\begin{tabular}{|l|}
\multicolumn{1}{|c|}{ Fossil Fuel Fired } \\
\hline Coal without FGD pre-1965 \\
Coal without FGD post-1965 \\
Coal with FGD \\
New pulverized coal with FGD \\
Advanced clean coal technology \\
Gas/oil steam \\
Conventional gas/oil combined cycle \\
Advanced combined cycle \\
Conventional combustion turbine \\
Advanced combustion turbine \\
Fuel cells \\
(FGD = flue gas desulfurization)
\end{tabular}

\begin{tabular}{|l|}
\hline \multicolumn{1}{|c|}{ Nuclear } \\
\hline $\begin{array}{l}\text { Conventional nuclear } \\
\text { Advanced nuclear }\end{array}$ \\
\hline \\
\hline Conventional hydropower \\
Geothermal \\
Solar-thermal \\
Solar-photovoltaic \\
Wind \\
Wood \\
Municipal solid waste \\
\hline
\end{tabular}

\section{Electricity Fuel Dispatch Submodule}

Given available capacity, firm purchased-power agreements, fuel prices, and load curves, the electricity fuel dispatch (EFD) submodule minimizes variable costs as it solves for generation facility utilization and economy power exchanges to satisfy demand in each time period and region. The submodule uses merit order dispatching; that is, utility, independent power producer, and small power producer plants are dispatched until demand is met in a sequence based on their operating costs, with least-cost plants being operated first. Limits on emissions of sulfur dioxide from generating units and the engineering characteristics of units serve as constraints. During off-peak periods, the submodule institutes load following, which is the practice of running plants near their minimum operating levels rather than shutting them down and incurring shutoff and startup costs. In addition, to account for scheduled and unscheduled maintenance, the capacity of each plant is derated (lowered) to the expected availability level. Finally, the operation of utility and nonutility plants for each region is simulated over six seasons to reflect the seasonal variation in electricity demand.

Interregional economy trade is also represented in the EFD submodule by redetermining the dispatch decision and allowing surplus generation in one region to satisfy electricity demand in an importing region, resulting in a cost savings. Economy trade with Canada is determined in a similar manner as interregional economy trade. Surplus Canadian energy is allowed to displace energy in an importing region if it results in a cost savings. After dispatching, fuel use is reported back to the fuel supply modules and operating expenses and revenues from trade are reported to the electricity finance and pricing submodule. 


\section{Electricity Finance and Pricing Submodule}

The costs of building capacity, buying power, and generating electricity are tallied in the electricity finance and pricing (EFP) submodule, which simulates the cost-ofservice method often used by State regulators to determine the price of electricity. Using historical costs for existing plants (derived from various sources such as Federal Energy Regulatory Commission (FERC) Form 1, "Annual Report of Major Electric Utilities, Licensees and Others," and Form EIA-412, "Annual Report of Public Electric Utilities"), cost estimates for new plants, fuel prices from the NEMS fuel supply modules, unit operating levels, plant decommissioning costs, plant phase-in costs, and purchased power costs, the EFP submodule calculates total revenue requirements for each area of utility operation-generation, transmission, and distribution. Revenue requirements shared over sales by customer class yield the price of electricity for each class. Electricity prices are returned to the demand modules. In addition, the submodule generates detailed financial statements.

The EFP also determines "competitive" prices for electricity generation. Unlike cost-of-service prices, which are based on average costs, competitive prices are based on marginal costs. Marginal costs are primarily the operating costs of the most expensive plant required to meet demand. The competitive price also includes a "reliability price adjustment," which represents the value consumers place on reliability of service when demands are high and available capacity is limited. Prices for transmission and distribution are assumed to remain regulated, so the delivered electricity price under competition is the sum of the marginal price of generation and the average price of transmission and distribution.

\section{Load and Demand-Side Management Submodule}

The load and demand-side management (LDSM) submodule generates load curves representing the demand for electricity. The demand for electricity varies over the course of a day. Many different technologies and end uses, each requiring a different level of capacity for different lengths of time, are powered by electricity. For operational and planning analysis, an annual load duration curve, which represents the aggregated hourly demands, is constructed. Because demand varies by geographic area and time of year, the LDSM submodule generates load curves for each region and season.

\section{Emissions}

The EMM tracks emission levels for sulfur dioxide $\left(\mathrm{SO}_{2}\right)$ and nitrogen oxides $\left(\mathrm{NO}_{\mathrm{x}}\right)$. Facility development, retrofitting, and dispatch are constrained to comply with the pollution constraints of the Clean Air Act Amendments of 1990 (CAAA90) and other pollution constraints. An innovative feature of this legislation is a system of trading emissions allowances. The trading system allows a utility with a relatively low cost of compliance to sell its excess compliance (i.e., the degree to which its emissions per unit of power generated are below maximum allowable levels) to utilities with a relatively high cost of compliance. The trading of emissions allowances does not change the national aggregate emissions level set by CAAA90, but it does tend to minimize the overall cost of compliance.

Capital Costs by Technology for the Reference Case (1996 Dollars per Kilowatt of Capacity)

\begin{tabular}{|l|c|c|c|c|}
\hline \multicolumn{1}{|c|}{ Technology Type } & 1996 & 2000 & 2010 & 2020 \\
\hline Advanced Combustion Turbine & 459 & 300 & 256 & 251 \\
\hline Conventional Combustion Turbine & 325 & 299 & 296 & 295 \\
\hline Advanced Gas/Oil Combined Cycle & 572 & 442 & 324 & 315 \\
\hline Conventional Gas/Oil Combined Cycle & 440 & 437 & 431 & 431 \\
\hline Gas/Oil Steam Turbine & 992 & 984 & 982 & 982 \\
\hline Scrubbed Coal New & 1,080 & 1,080 & 1,053 & 1,029 \\
\hline Integrated Gas Combined Cycle & 1,796 & 1,644 & 1,644 & 1,644 \\
\hline Fuel Cells & 2,185 & 2,185 & 2,185 & 2,185 \\
\hline Advanced Nuclear & 2,357 & 2,357 & 2,357 & 2,357 \\
\hline Biomass & 3,368 & 3,361 & 3,092 & 2,190 \\
\hline Solar Photovoltaic & 4,488 & 4,378 & 2,705 & 2,599 \\
\hline Wind & 1,013 & 795 & 750 & 732 \\
\hline
\end{tabular}



The renewable fuels module (RFM) consists of five submodules that represent the various types of renewable energy technologies used for grid-connected U.S. electricity supply (Figure 11). Since most renewables (wind, solar, and geothermal) are used to generate electricity, the interaction with the electricity market module (EMM) is important for modeling grid-connected renewable-electric applications. In the current version of the RFM, only central station grid-connected applications are modeled endogenously; data on distributed applications are input exogenously. Off-grid applications are not represented. The penetration of grid-connected generation technologies, with the exception of municipal solid waste, is determined by the EMM. Hydropower is included in the EMM directly.

Each submodule of the RFM is solved independently of the rest. Because variable operation and maintenance costs for renewable technologies are lower than for any other major generating technology and they produce almost no air pollution, all available renewable generating capacity is dispatched first by the EMM.

Costs for renewable energy technologies increase if supply expands rapidly-greater than 25 percent a year nationally. Wind or biomass technology capital costs also increase when the degree of technology use necessitates using higher cost resources; costs increase because of natural resource degradation, costs of upgrading the existing transmission or distribution network, or competition for use of the resources.

\section{Wind-Electric Submodule}

The wind-electric submodule projects the availability of wind resources as well as the cost and performance of wind turbine generators. This information is passed to the EMM so that wind turbines can be built and dispatched in competition with other electricity generating technologies. The wind turbine data are expressed in the form of energy supply curves that provide the maximum amount of turbine generating capacity that could be installed, given the available land area, wind speed, and capacity factor.

\section{Geothermal-Electric Submodule}

The geothermal-electric submodule provides the EMM with the amounts of new geothermal capacity that can be built at 51 individual sites, along with related cost and performance data. The information is expressed in the form of a supply curve that represents the aggregate amount of new capacity and associated costs that can be offered in each year. The factors determining the offered amounts of capacity include total reservoir heat, temperature, and the history of previously installed capacities.

Geothermal resource data are based on Sandia National Laboratory's 1991 geothermal resource assessment. Only hydrothermal (hot water and steam) resources are considered. Hot dry rock resources are not included, because they are not expected to be exploited during the NEMS forecast horizon.

Capital and operating costs are estimated separately, and life-cycle costs are calculated according to standardized NEMS assumptions. The costing methodology includes ways to analyze effects of Federal and State energy tax construction and production incentives (if any). Individual reservoirs and their sizes and locations are mapped and matched to the NEMS electricity supply regions (see Figure 10).

\section{Solar-Electric Submodule}

The solar-electric submodule models both solar-photovoltaic and thermal-electric installations. Only central station grid-connected applications constructed by a utility or independent power producer are considered as generators. Grid-connected solar facilities can be utility or nonutility, a distinction that is internal to the EMM. The required input information is identical.

Capacity projections are developed endogenously by competing them against other generating technologies on the basis of capital costs, capacity factors, and fixed and variable operation and maintenance costs. Solar energy is a form of renewable energy that requires a

\begin{tabular}{|c|c|c|}
\hline RFM Outputs & Inputs from NEMS & Exogenous Inputs \\
\hline $\begin{array}{l}\text { Energy production capacities } \\
\text { Capital costs } \\
\text { Operating costs (including wood supply } \\
\text { prices for the wood submodule) } \\
\text { Capacity factors } \\
\text { Available capacity } \\
\text { Biomass fuel costs }\end{array}$ & $\begin{array}{l}\text { Installed energy production capacity } \\
\text { Gross domestic product } \\
\text { Population } \\
\text { Interest rates } \\
\text { Avoided cost of electricity } \\
\text { Discount rate } \\
\text { Capacity additions } \\
\text { Biomass consumption }\end{array}$ & $\begin{array}{l}\text { Site-specific geothermal resource quality data } \\
\text { Site-specific wind resource quality data } \\
\text { Plant utilization (capacity factor) } \\
\text { Technology cost and performance parameters } \\
\text { Landfill gas capacity } \\
\text { Municipal solid waste management trends and } \\
\text { regionality }\end{array}$ \\
\hline
\end{tabular}


Figure 11. Renewable Fuels Module Struture

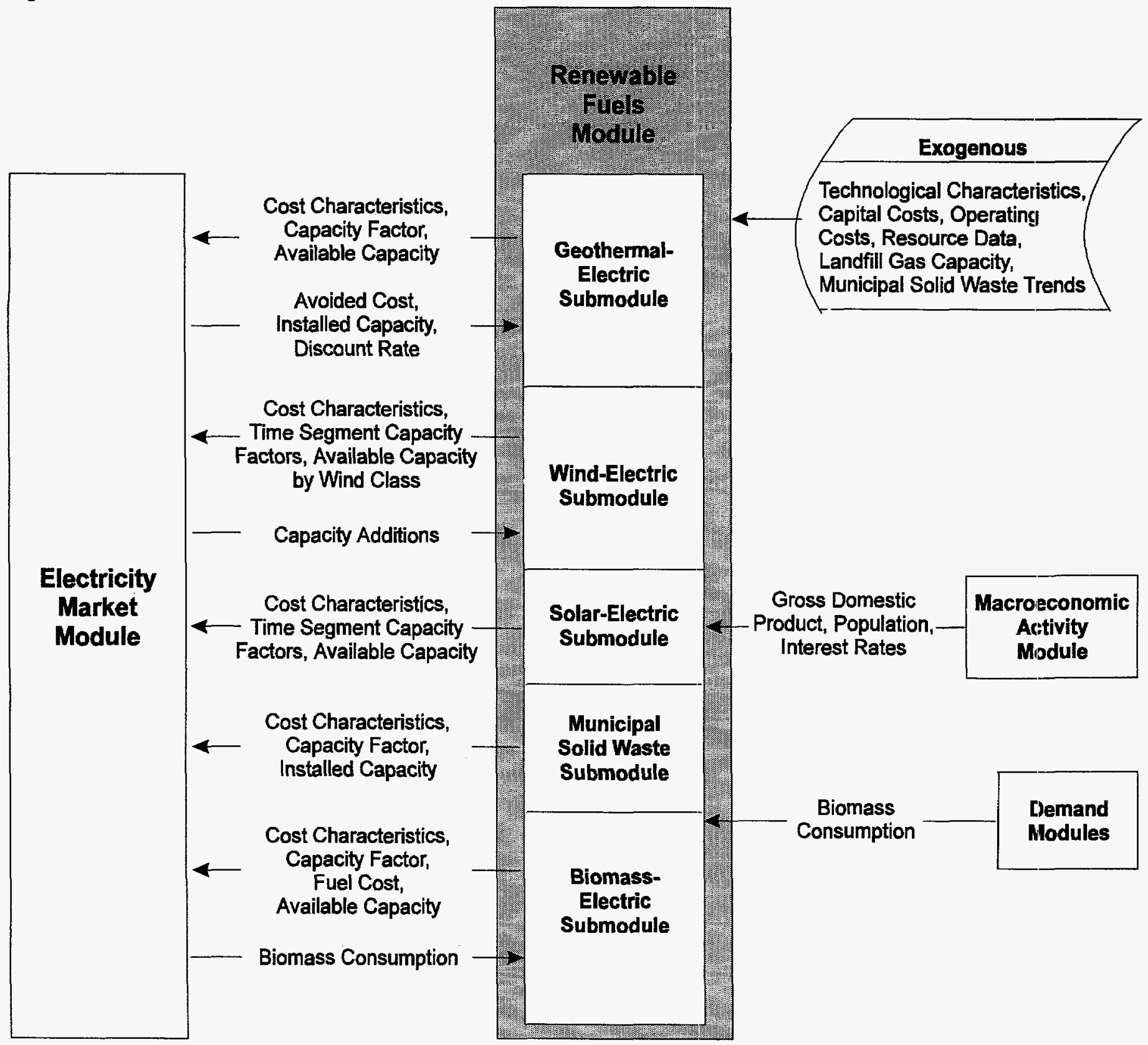

more detailed characterization to represent its regionality and intermittent nature. This is dealt with by the regional load shapes used by the EMM and different seasonal and daily time periods to represent intermittency.

\section{Biomass-Electric Submodule}

The biomass submodule provides biomass-fired plant technology characterizations (capital costs, operating costs, capacity factors, etc.) and fuel information for the
EMM, thereby allowing biomass-fueled power plants to compete with other electricity generating technologies.

Biomass fuel prices are represented by a supply curve constructed according to the accessibility of wood resources to the electricity generation sector. The supply curve employs resource inventory and cost data from the U.S. Forest Service, as well as quantity and cost information for dedicated energy crops starting in 2010 . Fuel distribution and preparation cost data are built 
into these curves. The supply schedule of biomass fuel prices are combined with other variable operating costs associated with burning biomass. The aggregate variable cost is then passed to the EMM.

\section{Municipal Solid Waste Submodule}

The municipal solid waste (MSW) submodule provides annual projections of energy produced from the incineration of MSW. It uses the quantity of MSW produced (derived from an econometric equation that uses gross domestic product and population as the forecast drivers), the heating value of a pound of MSW, and shares of MSW combusted for energy recovery. In addition, the submodule supplies the EMM with capital and operating cost information, which is used only for calculations of electricity prices. MSW energy produc- tion does not compete with other electricity generating technologies, because MSW is viewed as a byproduct of a community's waste disposal activities rather than a competitive alternative to other fuels.

An exogenous projection of landfill gas-fueled generating capacity is added to the total projection of MSW before it is passed to the EMM. This projection uses the same MSW forecast as combustion units. EIA assumes that a constant share of waste is combusted, but that increasing recycling results in a decline in the share of MSW landfilled. Calculations applying a landfill gas production profile to quantities landfilled yields total annual methane emissions. This total is then combined with an assumed increasing percent of emissions captured for energy conversion, and the resulting energy is converted to equivalent generating capacity. 

The oil and gas supply module (OGSM) consists of a series of process submodules that project the availability of:

- Domestic crude oil production and dry natural gas production from onshore, offshore, and Alaskan reservoirs

- Imported pipeline-quality gas from Mexico and Canada

- Imported liquefied natural gas.

The OGSM regions are shown in Figure 12.

The driving assumption of the OGSM is that domestic oil and gas exploration and development are undertaken if the discounted present value of the recovered resources at least covers the present value of taxes and the cost of capital, exploration, development, and production, subject to a budget constraint. In contrast, international gas trade is determined in part by scenario-dependent, noneconomic factors. Crude oil is transported to refineries (which are simulated in the petroleum market module) for conversion and blending into refined petroleum products. The individual submodules of the oil and gas supply module are solved independently, with feedbacks achieved through NEMS solution iterations (Figure 13).

Technological progress is represented in OGSM through annual increases in the finding rates, economically recoverable resources, and success rates, as well as annual decreases in costs. While the OGSM methodology assumes that increases in cumulative drilling lower the finding rate, the methodology permits this decline to be partially, fully, or more than fully offset by improvements in technology. This "technological stretch" effect is represented by an assumed upwards shift in the finding rate function at the end of each forecast year. Moreover, the rate of decline in finding rates during a given year is assumed to be inversely related to the size of the remaining economically recoverable resource base. This rate of decline is slowed in OGSM through an assumed expansion of the economically recoverable resource base over time due to technological progress. Another representation of technology is in the success rates for exploratory wells, which are assumed to increase annually by a given constant percentage due to technological progress. Finally, technology is represented on the cost side by the existence of time-trend proxy coefficients in the cost equations. These coefficients are intended to capture the beneficial (costreducing) effects of technology by putting downward pressure on the drilling, lease equipment, and operating cost projections.

\section{Lower 48 Onshore and Shallow Offshore Supply Submodule}

The lower 48 supply submodule projects oil and gas production by conventional recovery methods in onshore and shallow offshore regions and unconventional gas recovery in onshore regions. Unconventional gas is defined as gas produced from nonconventional geologic formations, as opposed to conventional (sandstones) and carbonate rock formations. The three nonconventional geologic formations considered are low-permeability or tight sandstones, gas shales, and coalbed methane. Enhanced oil recovery from onshore regions is handled separately. The lower 48 submodule actually consists of three separate submodules: onshore lower 48 conventional oil and gas supply, offshore oil and gas supply, and unconventional gas recovery supply.

The lower 48 submodule accounts for drilling, reserves estimates, and production capacity-computed independently (for the most part) for each region (6 onshore and 3 offshore) by well class (exploratory and developmental) and fuel category (conventional oil, conventional shallow gas, conventional deep gas, and unconventional gas):

- First, the prospective costs of a representative drilling project (for a given fuel category and well class within a given region) are computed. Costs are a function of national levels of drilling activity and the effects of technological progress.

\begin{tabular}{|c|c|c|}
\hline OGSM Outputs & Inputs from NEMS & Exogenous Inputs \\
\hline $\begin{array}{l}\text { Crude oil production } \\
\text { Domestic and Canadian natural gas supply } \\
\text { curves } \\
\text { Pipeline gas and liquefied natural gas } \\
\text { imports (excluding Canada) and exports } \\
\text { Cogeneration from oil and gas production } \\
\text { Reserves and reserve additions } \\
\text { Drilling levels } \\
\text { Associated-dissolved gas production }\end{array}$ & $\begin{array}{l}\text { Natural gas production by fuel type } \\
\text { Oil, gas, and electricity prices } \\
\text { Canadian natural gas imports and } \\
\text { production }\end{array}$ & $\begin{array}{l}\text { Resource levels } \\
\text { Initial finding rate parameters and } \\
\text { costs } \\
\text { Production profiles } \\
\text { Tax parameters } \\
\text { Import capacity, costs, and } \\
\text { availability }\end{array}$ \\
\hline
\end{tabular}


Figure 12. Oil and Gas Supply Module Regions
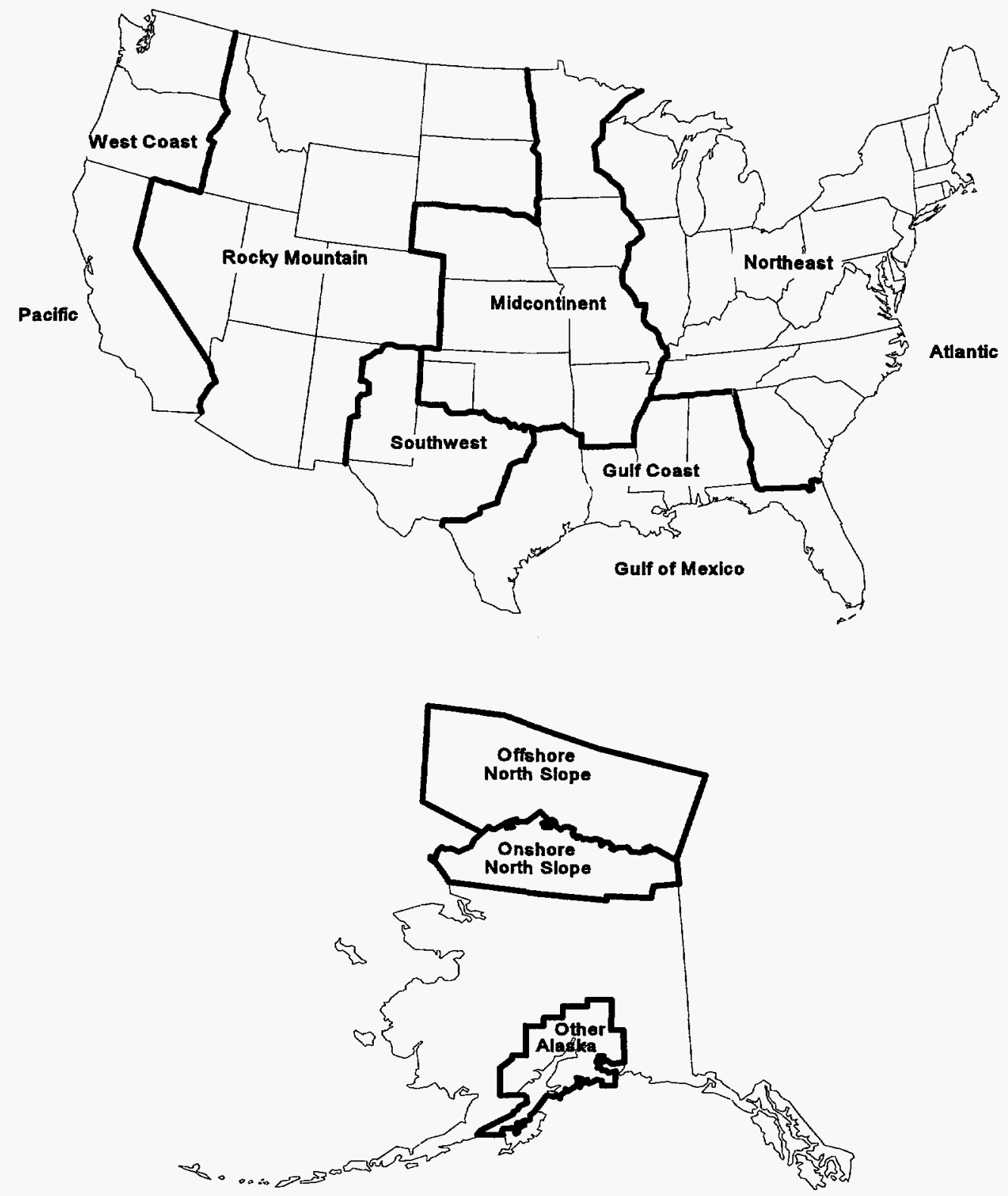

- Second, the present value of the discounted cash flows (DCF) associated with the representative project is computed. These cash flows include both the capital and operating costs of the project (including royalties and taxes) and the revenues derived from a declining well production profile (computed after taking into account the progressive effects of resource depletion and valued at constant real prices as of the year of initial valuation).

- Third, drilling levels are calculated as a function of projected profitability as measured by the projected DCF levels for each project.
- Fourth, regional finding rate equations are used to forecast new field discoveries from new field wildcats, new pools and extensions from other exploratory drilling, and reserve revisions from development drilling.

- Fifth, production is determined on the basis of reserves (including new reserve additions), previous productive capacity, flow from new wells, and, in the case of natural gas, fuel demands. This occurs within the market equilibration of the natural gas transmission and distribution module for natural gas and within OGSM for oil. 
Figure 13. Oil and Gas Supply Module Structure

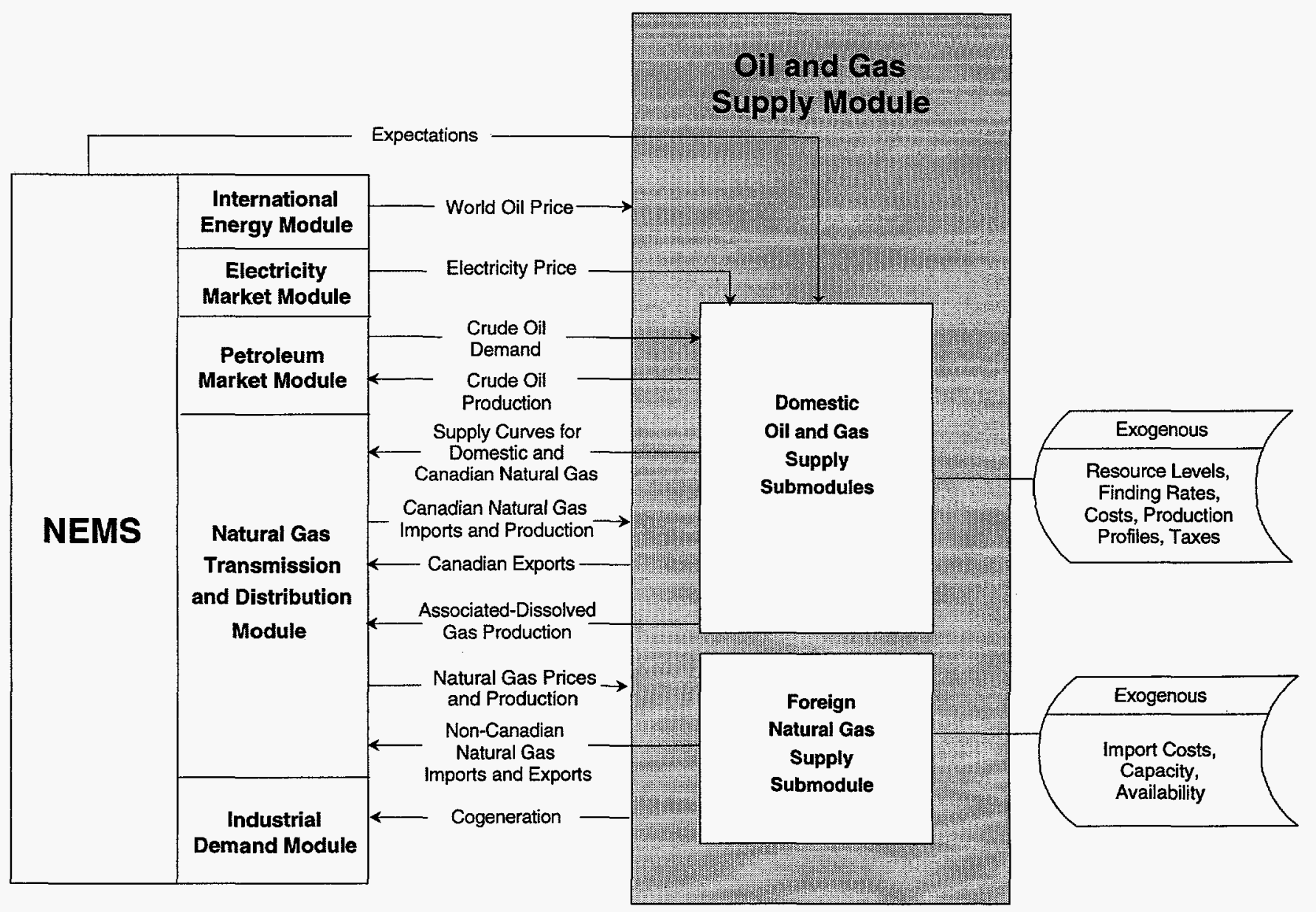

\section{Deep Water Offshore Supply Submodule}

This submodule uses a field-based engineering and economic analysis approach to project reserve additions and production from resources in the deep water offshore Gulf of Mexico Outer Continental Shelf subregion. Two structural components make up the deep water offshore supply submodule, an exogenous price/ supply data generation routine and a endogenous reserves and production timing algorithm.

The price/supply data generation methodology employs a rigorous field-based discounted cash flow (DCF) approach. This offline model utilizes key field properties data, algorithms to determine key technology components, and algorithms to determine the exploration, development and production costs, and computes a minimum acceptable supply price (MASP) at which the discounted net present value of an individual prospect equals zero. The MASP and the recoverable resources for the different fields are aggregated by planning region and by resource type to generate resource-specific price-supply curves. In addition to the overall supply price and reserves, costs components for exploration, development drilling, production platform, and operating expenses, as well as exploration and development well requirements, are also carried over to the endogenous component.

After the exogenous price/supply curves have been developed, they are transmitted to and manipulated by an endogenous program within the OGSM. The endogenous program makes choices for field exploration and development based on relative economics of the project profitability compared with the equilibrium crude oil and natural gas prices determined by the petroleum market module and natural gas transmission and distribution module. Development of economically recoverable resources into proved reserves is constrained by drilling activity. Proved reserves are translated into production based on a production to reserves $(P / R)$ ratio. The drilling activity and the $P / R$ ratio are both determined by extrapolating the historical information. 


\section{Alaska Oil and Gas Submodule}

This submodule projects the crude oil and natural gas produced in Alaska. The Alaska oil and gas submodule is divided into three sections: new field discoveries, development projects, and producing fields. Oil and gas transportation costs to lower 48 facilities are used in conjunction with the relevant market price of oil or gas to calculate the estimated net price received at the wellhead, sometimes called the "netback price." A discounted cash flow method is used to determine the economic viability of each project at the netback price.

Alaskan oil and gas supplies are modeled on the basis of discrete projects, in contrast to the onshore lower 48 conventional oil and gas supplies, which are modeled on an aggregate level. The continuation of the exploration and development of multiyear projects, as well as the discovery of a new field, is dependent on its profitability. Production is determined on the basis of assumed drilling schedules and production profiles for new fields and developmental projects, historical production patterns, and announced plans for currently producing fields.

\section{Enhanced Oil Recovery Submodule}

A field-based engineering submodule with hybrid exogenous (off-line) and endogenous (on-line) components is used to simulate the exploration and development of enhanced oil recovery (EOR) resources-a process that differs significantly from conventional oil and gas exploration and development:

- The exogenous EOR component creates tabular outputs that are subsequently used as inputs by the endogenous EOR component, which runs interactively within the OGSM. Inputs to the exogenous EOR component include assumed future natural gas prices and rates of technological progress, as well as resource levels, reserves, producing wells, production profiles, oil gravity, reservoir depth, carbon dioxide/oil or steam/oil ratios, well drilling and completion unit expenditures, unit operating costs, and fiscal/financial parameters.

- The endogenous EOR component develops reserveaddition and production projections for both thermal EOR and other EOR production (mostly from gasmiscible methods), based on regional oil prices (appropriate to the quality of EOR oil produced) provided interactively by the NEMS system. The endogenous EOR component also projects associated cogeneration capacity and production.
Separate sets of tabular inputs from the exogenous EOR component are used by the endogenous EOR component for the high oil price, low oil price, and technological progress cases. These sets are developed by the exogenous EOR component based on differing assumptions regarding assumed future natural gas prices and rates of technological progress, as appropriate.

\section{Foreign Natural Gas Supply Submodule}

The foreign natural gas supply submodule projects natural gas trade via pipeline as well as liquefied natural gas (LNG) trade. The receiving regions for foreign gas supplies correspond to those of the natural gas integrating framework as established for the natural gas transmission and distribution module. Pipeline natural gas imports flow from two sources: Canada and Mexico. U.S. natural gas trade with Canada is represented by six entry/exit points, and trade with Mexico is represented by three entry/exit points (Figure 14).

Net Canadian natural gas supplies to the United States are deterrnined at the six border crossing locations, over a range of gas prices. The initial step is to provide projections of Canadian drilling activity and supply. Canadian demand is then subtracted from supply to determine gas available for export. Gas supply availability is allocated to regional Canadian/U.S. border crossing points by an allocation algorithm that accounts for the associated pipeline capacities and the price responsiveness of supplies at the border points. The determination of the import volumes themselves occurs in the equilibration process of the natural gas transmission and distribution module.

Mexican gas trade is a highly complex issue. A range of noneconomic factors influences, if not determines, flows of gas between the United States and Mexico. The uncertainty is so great that not only is the magnitude of flow for any future year in doubt, but also the direction of flow. Reasonable scenarios have been developed and defended in which Mexico may be either a net importer or exporter of hundreds of billions of cubic feet of gas by 2020 . The vast uncertainty and the importance of noneconomic factors in future Mexican gas trade with the United States suggest that these flows should be handled on a scenario basis. Such a scenario can be introduced into the Mexican gas submodule as a user-specified path of future Mexican imports and exports. Otherwise, the analysis uses a prespecified default outlook for Mexican trade, drawn from an assessment of current and expected industry and market circumstances, as indicated in industry announcements or articles and reports in relevant publications. The 
Figure 14. Foreign Natural Gas Trade via Pipeline and Liquefied Natural Gas Terminals

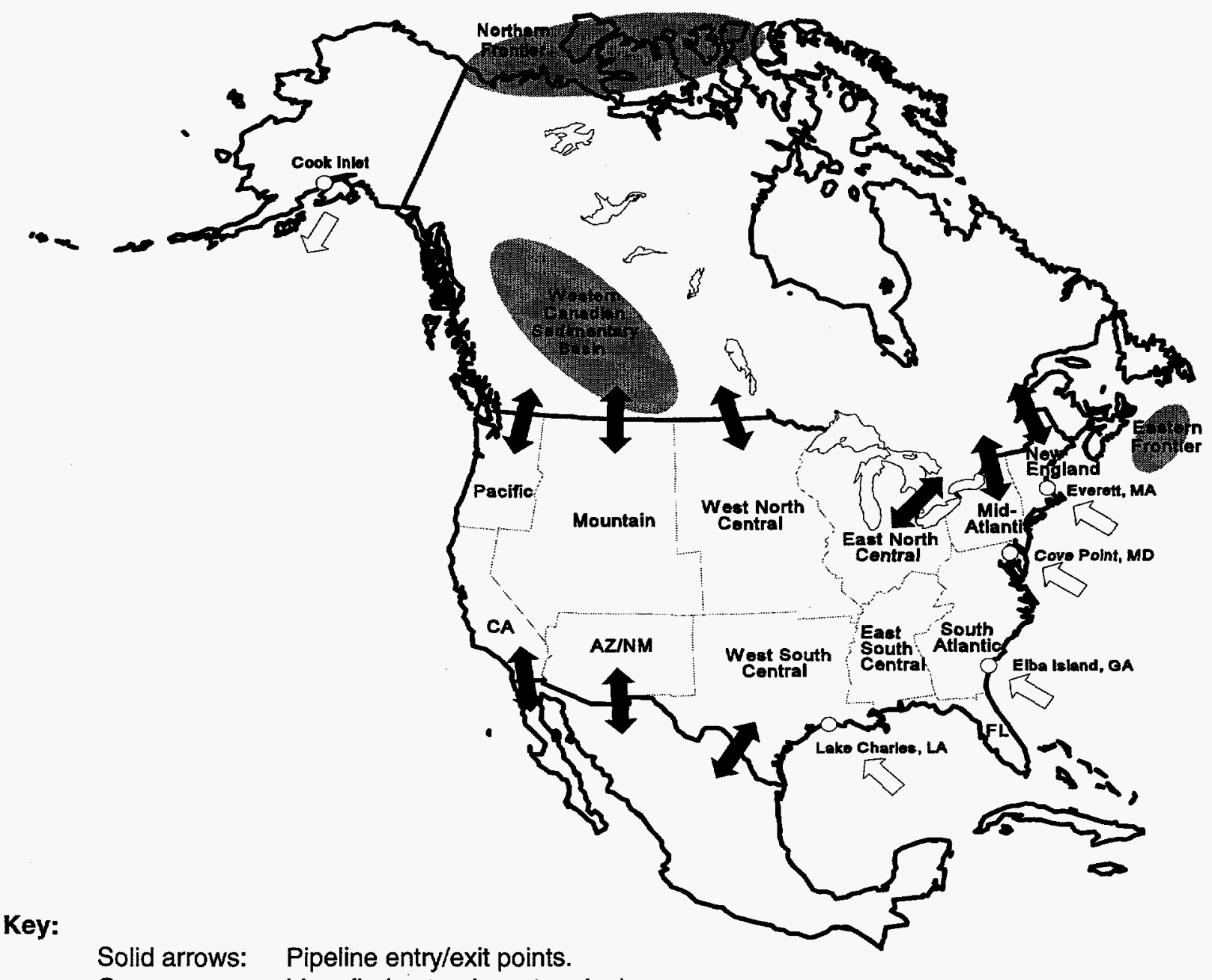

Open arrows: Liquefied natural gas terminals.

outlook, regardless of its source, is fixed and is not responsive to energy price changes.

The volume of LNG imports into the United States is projected at four LNG terminals. Imported LNG costs compete with the purchase price of gas prevailing in the vicinity of the import terminal. This is a significant element in evaluating the competitiveness of LNG supplies, since LNG terminals vary greatly in their proximity to domestic producing areas. Terminals close to major consuming markets and far from competing producing areas may provide a sufficient economic advantage to make LNG a competitive gas supply source in some markets. In addition to costs, extensive operational assumptions are required to determine LNG imports. Dominant general factors affecting the outlook include expected developments with respect to the use of existing capacity, expansion at existing sites, and construction at additional locations. The LNG forecast also requires the specification of a combination of factors: available gasification capacity, schedules for and lags between constructing and opening a facility, tanker availability, expected utilization rates, and worldwide liquefaction capacity. For inactive terminals, it is necessary to determine the length of time required to restart operations (normally, between 12 and 18 months). These considerations are taken into account when the economic viability of LNG supplies is determined. The model accounts for LNG exports to Japan from Alaska using an exogenously specified forecast. 

The natural gas transmission and distribution module (NGTDM) is the component of NEMS that represents the natural gas market. The NGTDM models the natural gas transmission and distribution network in the lower 48 States, which links suppliers (including importers) and consumers of natural gas. The module determines regional market-clearing prices for natural gas supplies (including border prices) and end-use consumption.

The NGTDM has four primary submodules: the annual flow submodule, the capacity expansion submodule, the pipeline tariff submodule, and the distributor tariff submodule. The annual flow submodule-the central component of the NGTDM-is used to derive flows and prices of natural gas in conjunction with an annual natural gas market equilibrium. Conceptually, the annual flow submodule is a simplified representation of the physical natural gas transmission and distribution system, structured as a network of nodes and arcs. The network representation is in terms of 12 internal nodes and 9 border transshipment nodes (Figure 15). The other three submodules provide parameters to the annual flow submodule that define some of the characteristics of the system's nodes and arcs. Other parameters for defining the natural gas market (such as supply and demand curves) are derived from information passed from other NEMS modules. The capacity expansion submodule provides the annual flow submodule with maximum annual flows allowed along each of the arcs in the network. The pipeline and distributor tariff submodules provide price parameters for establishing the tariffs to be charged along each of the interregional, intraregional, and distribution arcs. Data are also passed back to these submodules from the annual flow submodule and between the other submodules.
The primary outputs from the NGTDM, which are used as input in other NEMS modules, result from establishing a natural gas market equilibrium solution: enduse prices, wellhead and border crossing prices, and associated production; and Canadian import levels. In addition, the module provides a forecast of lease and plant fuel consumption and pipeline fuel use, as well as pipeline and distributor tariffs, pipeline and storage capacity expansion, and interregional natural gas flows. The basic NGTDM structure and its relationship with other NEMS modules is shown in Figure 16.

\section{Annual Flow Submodule}

The annual flow submodule is the main integrating component of the NGTDM. One of its major functions is to simulate the natural gas price determination process. The annual flow submodule brings together all major economic and technological factors that influence regional natural gas trade in the United States. The economic considerations include the demand for and the supply of natural gas and the competition from imported natural gas.

The annual flow submodule integrates all components of the NGTDM-the annual flow submodule itself, the capacity expansion submodule, the pipeline tariff submodule, and the distributor tariff submodule. Through this integration process, the annual flow submodule derives average annual natural gas prices (wellhead, city gate, and end-use) that reflect a leastcost market equilibrium among competing gas supplies, end-use sector consumption, and transportation routes. End-use prices are derived for both core and noncore markets. Within NEMS, the classification of customers is predetermined. It is assumed that core customers purchase firm transportation service and noncore customers purchase interruptible service.

\begin{tabular}{|l|l|l|}
\hline \multicolumn{1}{|c|}{ NGTDM Outputs } & \multicolumn{1}{|c|}{ Inputs from NEMS } & \multicolumn{1}{c|}{ Exogenous Inputs } \\
\hline End-use natural gas prices & End-use natural gas demands & Historical consumption patterns \\
Natural gas wellhead prices & Domestic and Canadian natural gas & Historical flow patterns \\
Natural gas border crossing prices & supply curves & Rate design specifications \\
Domestic natural gas production & Mexican and liquefied natural gas imports & Company-level financial data \\
Canadian natural gas imports and production & Natural gas exports & Pipeline and storage capacity \\
Lease and plant fuel consumption & and utilization data \\
Pipeline fuel use & plants & Historical end-use prices \\
Pipeline and distribution tariffs & Macroeconomic variables & State and Federal tax parameters \\
Interregional natural gas flows & Associated-dissolved natural gas & Pipeline and storage expansion cost \\
Storage and pipeline capacity expansion & data \\
Synthetic gas production & production & Synthetic gas production from coal \\
\hline
\end{tabular}




\section{NATURAL GAS TRANSMISSION AND DISTRIBUTION MODULE}

\section{Figure 15. Natural Gas Transmission and Distribution Module Network}

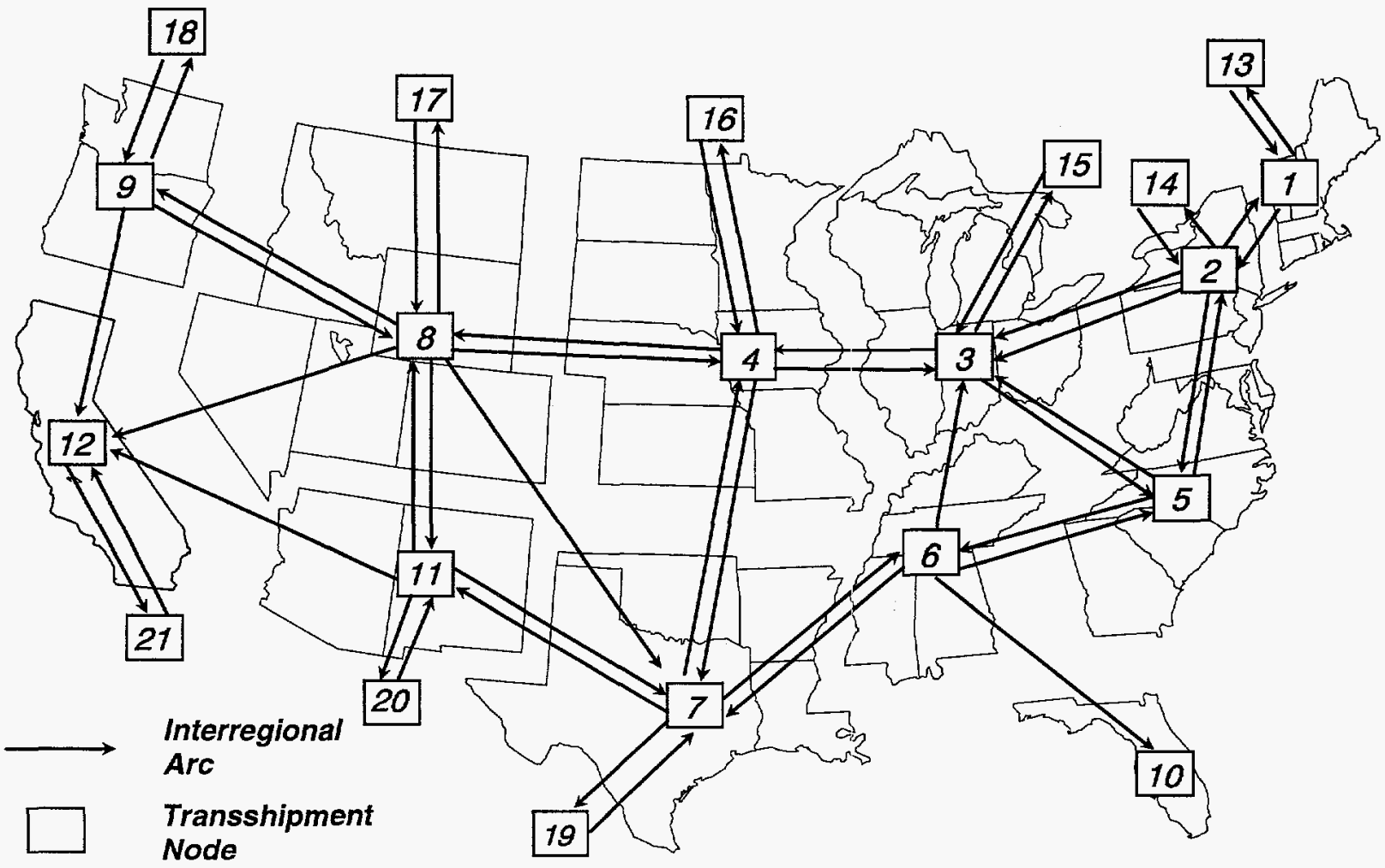

\section{Capacity Expansion Submodule}

The capacity expansion submodule simulates the decisionmaking process for expanding pipeline and/or storage capacity in the U.S. gas market. In simulating gas pipeline capacity expansion, the capacity expansion submodule (1) determines the amount of pipeline and storage capacity to be added between or within regions in the NGTDM and (2) establishes effective (or practical) maximum annual utilization rates for each of the interregional pipeline routes represented in the annual flow submodule. Maximum utilization rates (or load factors) for pipeline routes are established to capture the impact of variations in seasonal demand on the maximum amount of gas that can practically flow between regions within a year. Pipeline capacity additions are used in the annual flow submodule (in combination with the maximum load factors) to set limits on annual interregional flows. These capacity additions are also used in the pipeline tariff submodule for the determination of interregional pipeline tariffs.

\section{Pipeline Tariff Submodule}

The pipeline tariff submodule computes tariffs for transportation and storage services provided by interstate pipeline companies. The tariffs are computed for individual pipeline companies, then aggregated to the major gas pipeline corridors or arcs in the United States specified in the NGTDM network (Figure 15). An accounting system is used to track costs and compute tariffs under various rate design and regulatory scenarios. Tariffs are computed for both firm and interruptible transportation and storage services. Transportation tariffs are computed for the interregional arcs defined by the NGTDM network. These network tariffs represent an aggregation of the tariffs for individual pipeline companies supplying the network arc. The tariffs are used within the annual flow submodule to derive wellhead, border crossing, and end-use prices and within the capacity expansion submodule to derive capacity additions. 


\section{NATURAL GAS TRANSMISSION AND DISTRIBUTION MODULE}

Figure 16. Natural Gas Transmission and Distribution Module Structure

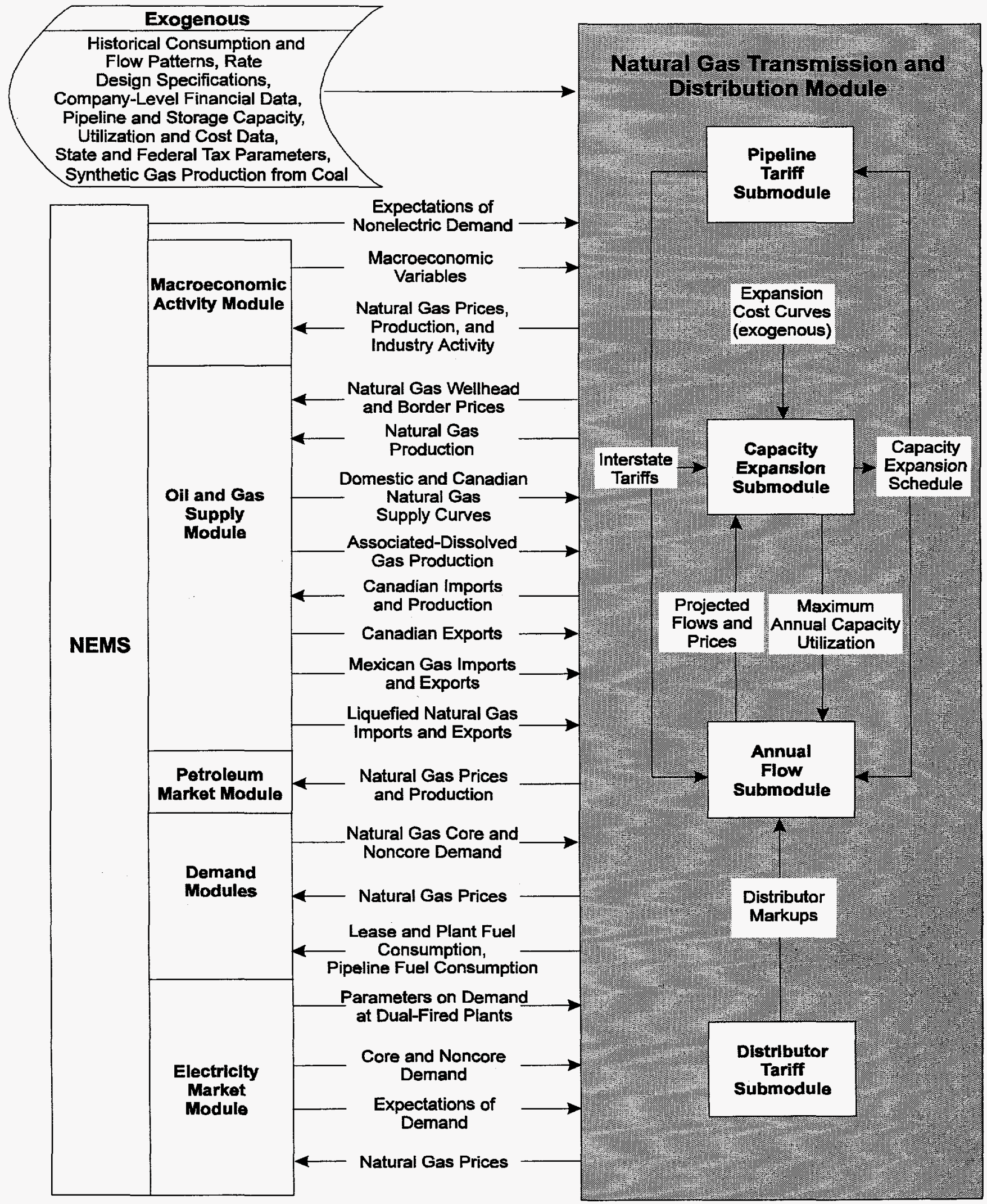




\section{NATURAL GAS TRANSMISSION AND DISTRIBUTION MODULE}

\section{Distributor Tariff Submodule}

Markups for residential, commercial, and core industrial customers include the cost of service provided by intrastate pipelines and local distributors. The intrastate tariffs are accounted for endogenously through historical model benchmarking. The distribution tariffs are initially based on 1996 historical data, but they are adjusted throughout the forecast in response to changes in consumption levels and cost of labor and capital and assumed industry efficiency improvements. It is assumed that independent of changes in costs related to the cost of capital and labor and consumption levels, the cost of providing distribution services will decline 1 percent per year through 2015, as a result of efficiency improvenents, and remain constant thereafter.

Markups for industrial noncore customers and core and noncore electric generator customers are endogenously derived as the difference between estimated historical 1996 end-use prices and the NGTDM regional core or noncore hub prices and are held constant throughout the forecast. 
The petroleum market module (PMM) represents domestic refinery operations and the marketing of petroleum products to consumption regions. The PMM solves for petroleum product prices, crude oil and product import activity (in conjunction with the international energy module), and domestic refinery capacity expansion and fuel consumption. The solution is derived, satisfying the demand for petroleum products and incorporating the prices for raw material inputs and imported petroleum products, the costs of investment, and the domestic production of crude oil and natural gas liquids. The relationship of the PMM to other NEMS modules is illustrated in Figure 17.

The PMM is a regional, linear-programming representation of the U.S. petroleum market. Refining operations are represented by a three-region linear programming formulation of the five Petroleum Administration for Defense Districts (PADDs) (Figure 18). PADDs I and V are each treated as single regions, while PADDs II, III, and IV are aggregated into one region. Each region is considered as a single firm where more than 30 distinct refinery processes are modeled. Refining capacity is allowed to expand in each region, but the model does not distinguish between additions to existing refineries or the building of new facilities. Investment criteria are developed exogenously, although the decision to invest is endogenous.

The PMM assumes that the petroleum refining and marketing industry is competitive. The market will move toward lower-cost refiners who have access to crude oil and markets. The selection of crude oils, refinery process utilization, and logistics (transportation) will adjust to minimize the overall cost of supplying the market with petroleum products.
Although the petroleum market responds to pressure, it rarely strays from the underlying refining costs and economics for long periods of time. If demand is unusually high in one region, the price will increase, driving down demand and providing economic incentives for bringing supplies in from other regions, thus restoring the supply/demand balance.

Existing regulations concerning product types and specifications, the cost of environmental compliance, and Federal and State taxes are also modeled. The PMM incorporates taxes imposed by the 1993 Budget Reconciliation Act as well as costs resulting from the Clean Air Act Amendments of 1990 (CAAA90) and other environmental legislation. The costs of producing new formulations of gasoline and diesel fuel as a result of the CAAA90 are determined within the linear programming representation by incorporating specifications and demands for these fuels.

An important innovation in the NEMS involves the relationship between the domestic and international markets. Whereas earlier models postulated entirely exogenous prices for oil on the international market (the world oil price), NEMS includes an international energy module that estimates supply curves for imported crude oils and products based on, among other factors, U.S. participation in international trade.

\section{Regions}

The PMM models U.S. crude oil refining capabilities based on the five PADDs which were established during World War II and are still used by EIA for data collection and analysis. The use of PADD data permits the PMM to take full advantage of EIA's historical database and allows analysis and forecasting within the same framework as the petroleum industry uses.

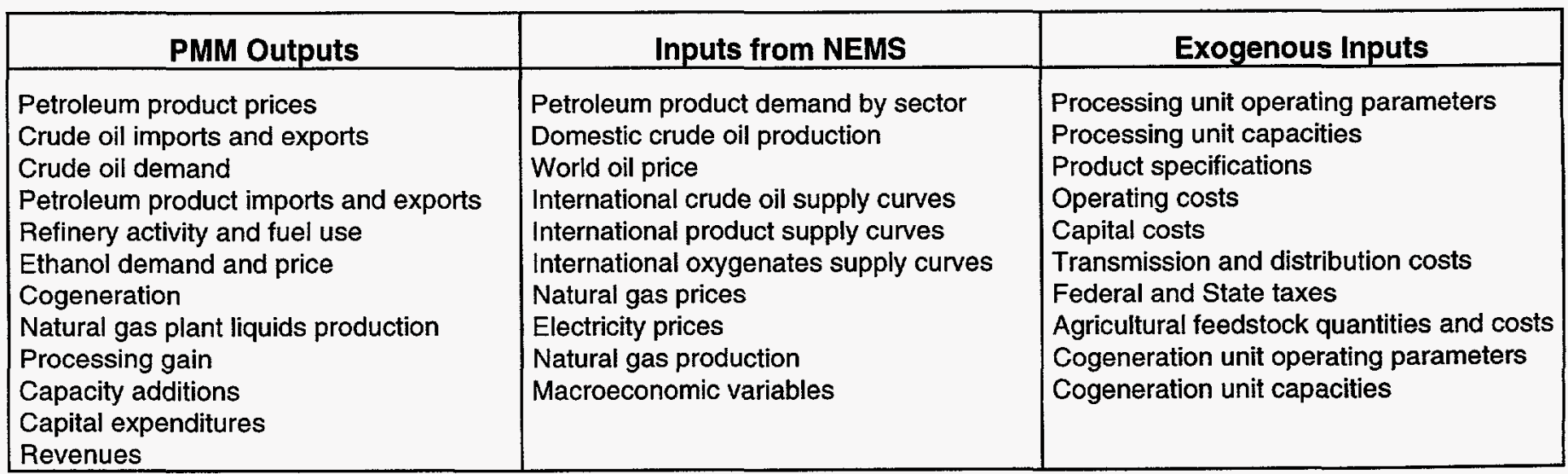


Figure 17. Petroleum Market Module Structure

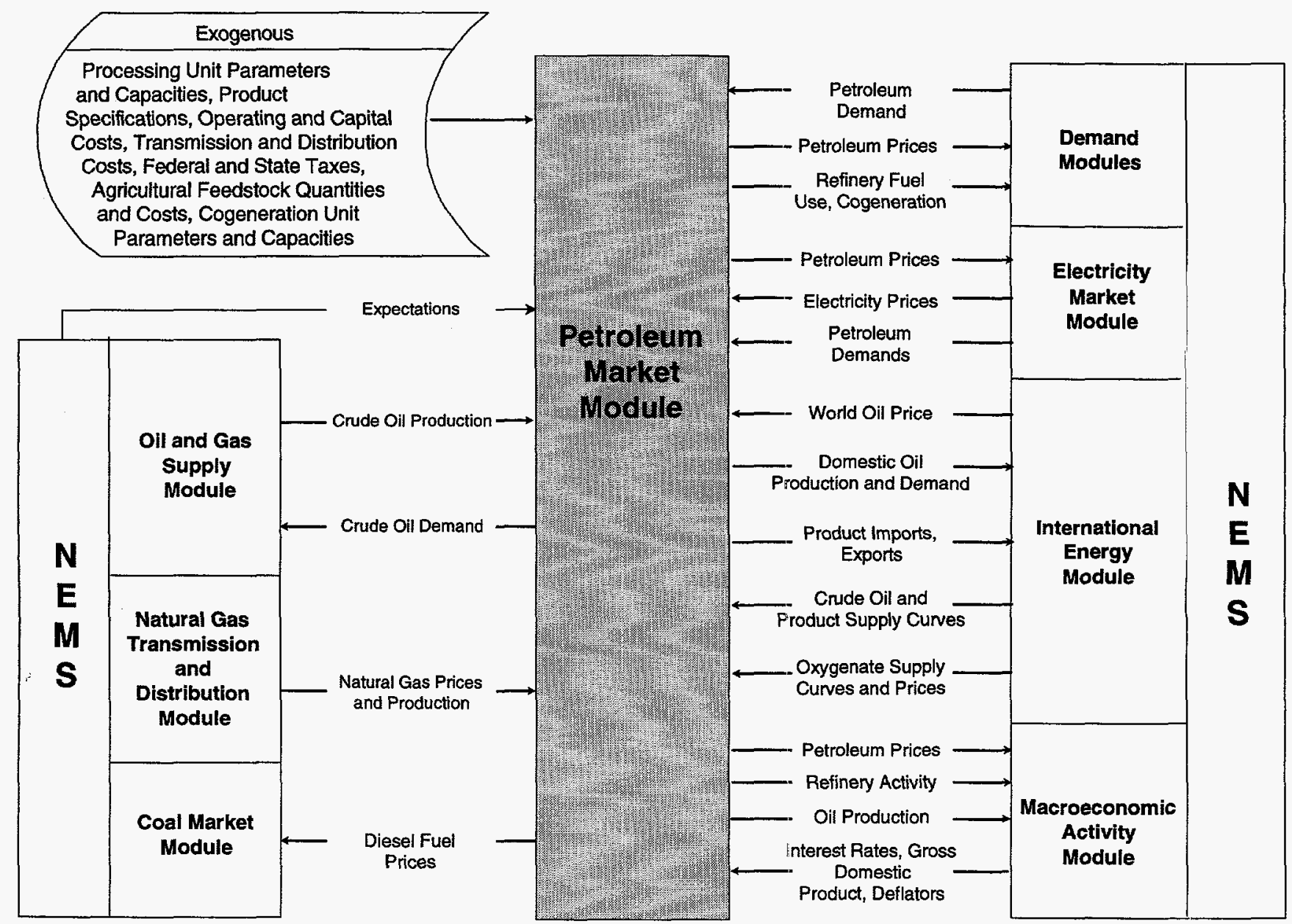

Figure 18. Petroleum Administration for Defense Districts

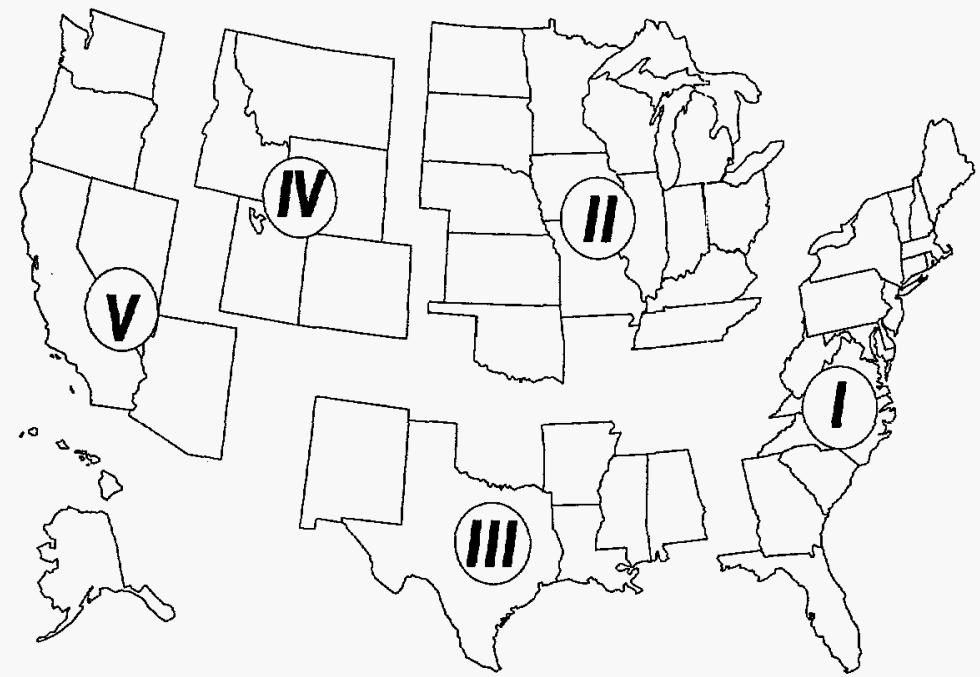




\section{Product Categories}

Product categories, specifications, and recipe blends modeled in PMM include the following:

Motor gasoline: traditional unleaded, oxygenated $(2.7 \%)$, reformulated $(2.0 \%)$, reformulated/high oxygen $(2.7 \%)$.

Jet fuels: kerosene-based.

Distillates: kerosene, heating oil, highway diesel.

Residual fuels: low-sulfur, high-sulfur.

Liquefied petroleum gas (LPG): propane, LPG mixes.

Petrochemical feedstocks: petrochemical naphtha, petrochemical gas oil, propylene, aromatics.

Others: asphalt and road oil, still gas, petroleum coke, lubricating products and waxes, special naphthas.

\section{Fuel Use}

PMM determines refinery fuel use by PADD for purchased electricity, natural gas, distillate fuel, residual fuel, liquefied petroleum gas, and other petroleum. The fuels (natural gas, petroleum, other gaseous fuels, and other) consumed within the refinery to generate electricity from cogeneration facilities are also measured.

\section{Crude Oil Categories}

Both domestic and imported crude oil are aggregated into five categories, as defined by the following ranges of gravity and sulfur:

\begin{tabular}{|l|c|c|}
\hline \multicolumn{1}{|c|}{ Category } & Sulfur & Gravity \\
\hline Low-sulfur light & $0-0.5 \%$ & $>24$ \\
Medium-sulfur heavy & $0.35-1.1 \%$ & $>24$ \\
High-sulfur light & $>1.1 \%$ & $>32$ \\
High-sulfur heavy & $>1.1 \%$ & $24-33$ \\
High-sulfur very heavy & $>0.7 \%$ & $<23$ \\
\hline
\end{tabular}

This aggregation of crude oil types allows the PMM to account for changes in crude oil composition over time. A "composite" crude with the appropriate yields and qualities is developed for each category by averaging characteristics of specific crude oil streams that fall into each category. While the domestic and foreign categories are the same, the composites for each type may differ, because different crude oil streams make up the composites.

\section{Natural Gas Plants}

The outputs of natural gas processing plants-ethane, propane, butane, isobutane, and natural gasoline-are modeled in the PMM. These products move directly into the market to meet demand or are inputs to the refinery.

\section{Refinery Processes}

Not every refinery processing unit is represented in PMM. The refinery processes represented were chosen because they have the most significant impact on production. The following distinct processes are represented:

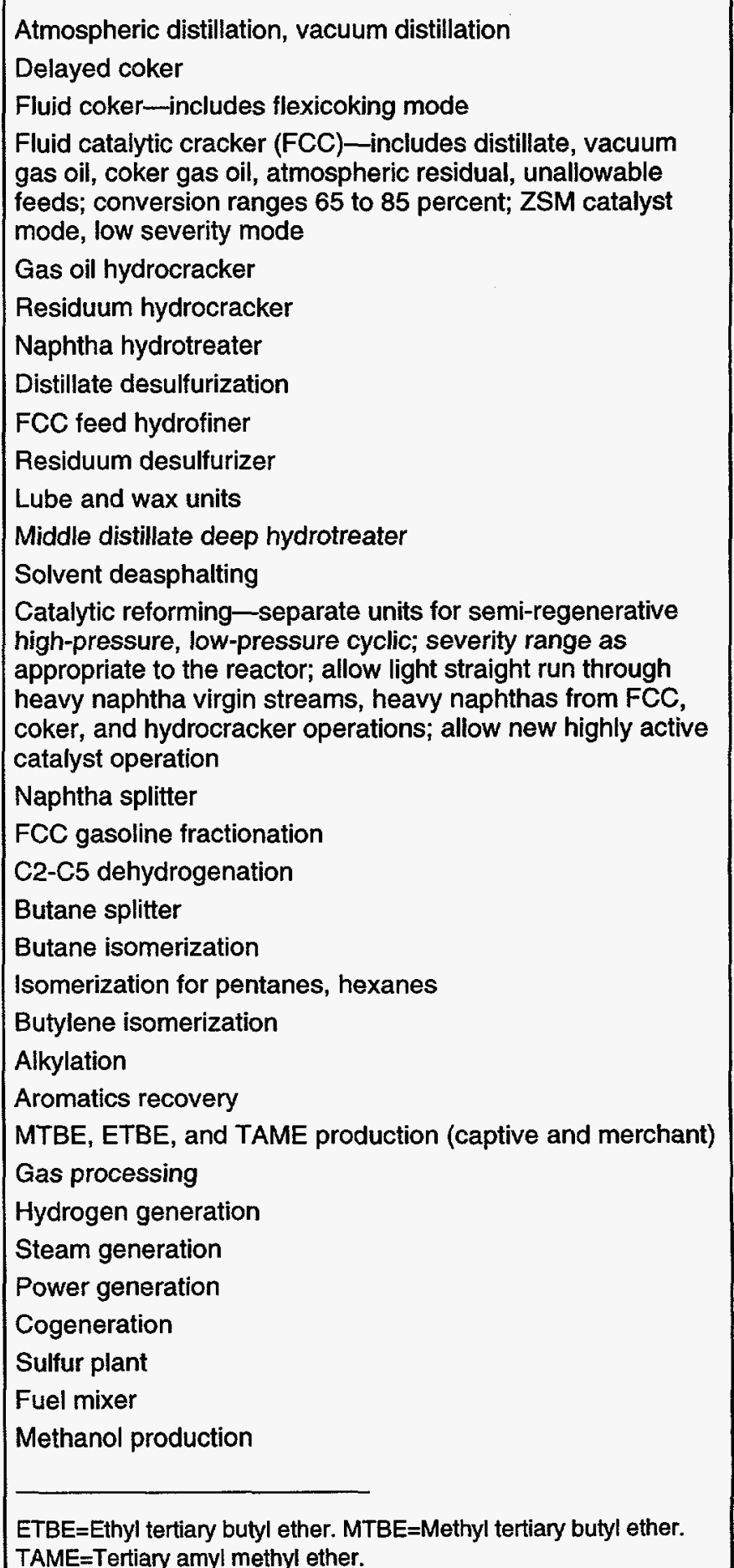




\section{Ethanol}

The biofuels supply submodule of the PMM provides the linear program with supply curves for corn-derived ethanol, allowing the PMM to forecast transportation ethanol demand. The supply curves take into account feedstock costs, feedstock conversion costs, and energy prices. Agricultural feedstock production quantities and costs are provided exogenously from a U.S. Department of Agriculture linear programming model, the Agricultural Resources Interregional Modeling System. ${ }^{12}$

\section{End-Use Markups}

The linear programming portion of the model provides unit prices of products sold in the refinery regions (refinery gate) and in the demand regions (wholesale). End-use markups are added to produce a retail price for each of the Census divisions. The markups are based on an average of historical markups, defined as the difference between the end-use prices by sector and the corresponding wholesale price for that product. The average is calculated using data from the past 12 years. Because of the lack of any consistent trend in the historical end-use markups, the markups remain at the historical average level over the forecast period.

State and Federal taxes are also added to transportation fuel prices to determine final end-use prices. Recent tax trend analysis indicated that State taxes increase at the rate of inflation, while Federal taxes do not. In the PMM, therefore, State taxes are held constant in real terms throughout the forecast while Federal taxes are deflated at the rate of inflation.

\section{Gasoline Types}

The Clean Air Act Amendments of 1990 resulted in the production of a number of new blends of gasoline. In November 1992, a wintertime requirement for oxygenated gasoline containing a minimum of 2.7 percent oxygen by weight went into effect in the 39 worst carbon monoxide emitting areas. The number of emitting areas requiring oxygenated gasoline has fluctuated from year to year. Currently, oxygenated gasoline represents about 4 percent of gasoline demand in the forecast. Since January 1995, gasoline sold year-round in the nine most severe ozone nonattainment areals has been "reformulated" according to U.S. Environmental Protection Agency specifications. A third type of gasoline, a higher oxygen reformulated blend, is sold in areas where the oxygenated and reformulated requirements overlap. In addition, California gasoline standards, which are more severe than the Federal reformulated standards, became effective for that State in March 1996. Gasoline production is modeled within NEMS to account for these requirements. Additional product specifications can be accounted for as policy analysis scenarios.

\footnotetext{
${ }^{12}$ B.C. English, E.G. Smith, J.D. Atwood, S.R. Johnson, and G.D. Oamek, "Resource Conservation Act Analysis: An Overview of the CARD Agricultural Resource Interregional Modeling System," The Center for Agricultural and Rural Development, Ames, Iowa (Technical Report 89-TR11, September 1989).
} 
The coal market module (CMM) represents the mining, transportation, and pricing of coal, subject to end-use demand. Coal supplies are differentiated by heat and sulfur content. The CMM also determines the minimum cost pattern of coal supply to meet exogenously defined U.S. coal export demands as a part of the world coal market. Coal supply is projected on a cost-minimizing basis, constrained by existing contracts. Twelve different coal types are differentiated with respect to thermal grade, sulfur content, and underground or surface mining. The domestic production and distribution of coal is forecast for 13 demand regions and 11 supply regions (Figures 19 and 20).

The solutions for the components of the CMM are found simultaneously. The sequence of solution among components can be summarized as follows. Coal supply curves are produced by the coal production submodule and input to the coal distribution submodule. Given the coal supply curves, distribution costs, and coal demands, the coal distribution submodule projects delivered coal prices. The module is iterated to convergence with respect to equilibrium prices to all demand sectors. The structure of the CMM is shown in Figure 21.

\section{Coal Production Submodule}

This submodule produces annual econometric coal supply curves, relating annual production to marginal prices. The supply curves are constructed from a regression analysis of production, prices, and costs. A separate supply curve is provided for surface and underground mining for all significant production by coal rank (bituminous, subbituminous and lignite), coal grade (steam or metallurgical), and sulfur level in each supply region. Constructing curves for the coal types available in each region yields a total of 34 curves that are used as inputs to the coal distribution submodule. A different set of supply curves is constructed for each year in the forecast period.
The factors accounted for in constructing the supply curves are labor productivity and the costs of factor inputs (mining equipment, mine labor, and fuel). Labor productivity projections are developed and applied to each supply curve, based on historical data. The projections incorporate an assumption that the rate of improvement will decline as the rate of technology penetration slows. Labor costs are tied to labor productivity and wage rates. It is assumed, in the reference case, that wage rates keep pace exactly with inflation.

\section{Coal Distribution Submodule}

The coal distribution submodule is a linear program that determines the least-cost supplies of coal for a given set of coal demands by demand region and sector, accounting for transportation costs from the different supply curves, coal heat and sulfur content, existing coal supply contracts, technical limitations of older boiler types, and sulfur allowance costs under the Clean Air Act Amendments of 1990 . Existing supply contracts between coal producers and utilities are incorporated in the model as minimum flows between specific supply curves and region-sulfur level combinations. The minimum flows are assumed to remain in effect for the duration of the contract and then be replaced by marketdetermined flows.

Coal transportation costs are simulated using interregional coal transportation costs derived by subtracting reported minemouth costs for each supply curve from reported delivered costs for each demand type in each demand region. Transportation rates are assumed to change in response to railroad labor productivity, diesel fuel costs, and equipment costs. In recent years, railroad rates have declined because of operating efficiencies from such measures as improved scheduling and lower fuel cost per ton-mile that have resulted from low crude oil prices, more efficient diesel engines, and larger and lighter aluminum cars.

\begin{tabular}{|l|l|l|}
\hline \multicolumn{1}{|c|}{ CMM Outputs } & \multicolumn{1}{|c|}{ Inputs from NEMS } & \multicolumn{1}{c|}{ Exogenous Inputs } \\
\hline Coal production and distribution & Coal demand & Interest rates \\
Minemouth coal prices & Price indices and deflators & Base year production, prices, and \\
End-use coal prices & coal quality parameters \\
Coal exports & Contract quantities \\
Transportation rates & & Labor productivity \\
Coal quality by source, destination, and end- & & Labor costs \\
use sector & & Labor cost escalators \\
World coal flows & & $\begin{array}{l}\text { Domestic transportation costs } \\
\text { International transportation costs } \\
\end{array}$ \\
& & $\begin{array}{l}\text { International supply curves } \\
\text { International coal import demands } \\
\text { Demand for U.S. coal imports }\end{array}$ \\
\hline
\end{tabular}




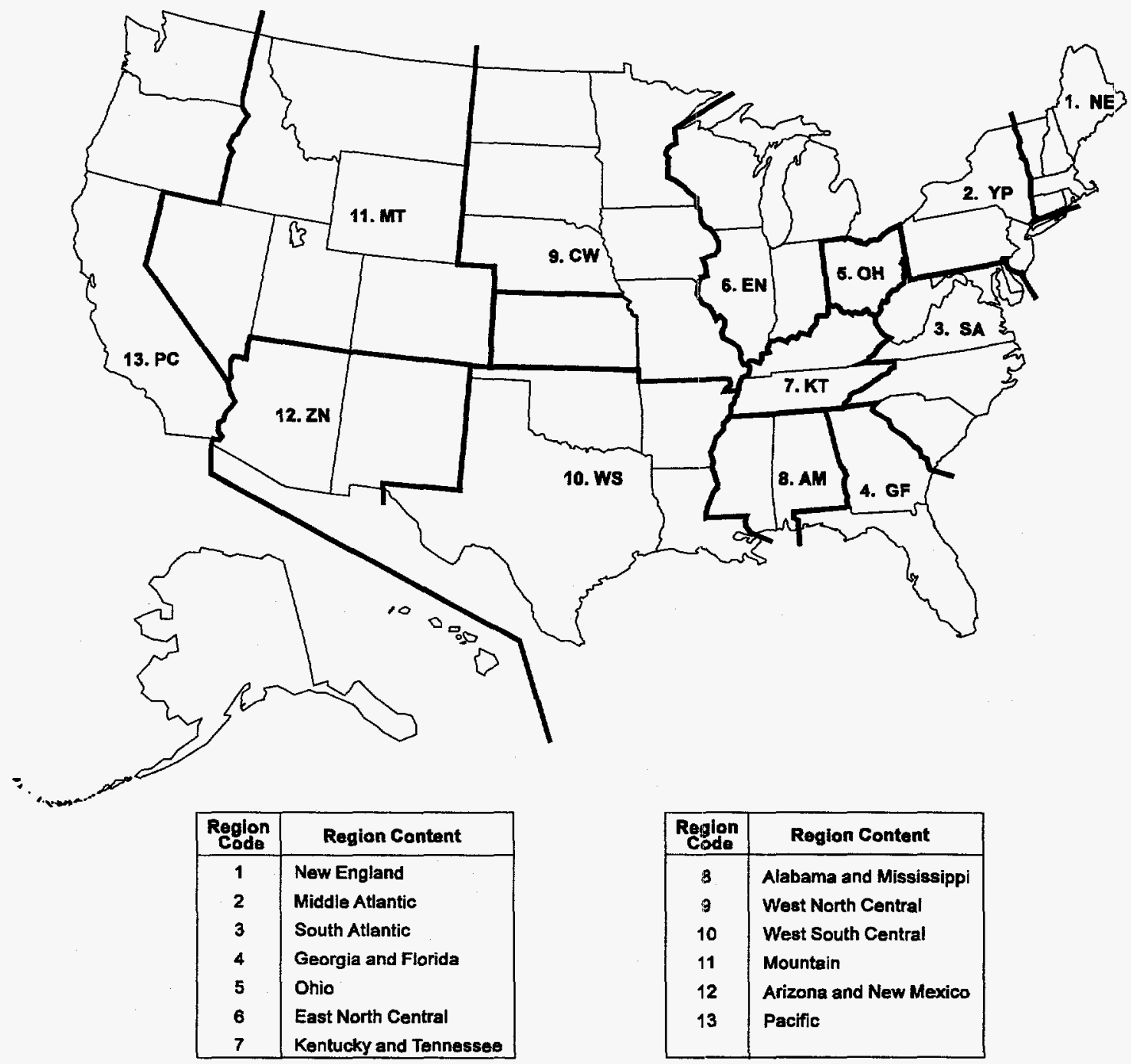

\section{Coal Export Component}

The coal export component of the coal distribution submodule projects quantities of coal imported and exported from the United States. The quantities are determined within a world trade context, based on userprovided characteristics of foreign coal supply and demand. The component disaggregates coal into 16 export regions and 20 import regions, as shown on the following page.

The export component is a part of the linear program that optimizes domestic coal supply. It determines world coal trade distribution by minimizing overall costs for coal, subject to U.S. coal supply prices and at number of constraints. Supply costs (mining and preparation plus transportation) for each coal export region, coal type, and end use compete in two demand sectors (coking and steam). The component also incorporates within the model structure supply diversity constraints that reflect the observed tendency of coal-importing countries to avoid excessive dependence upon one source of supply. 
Figure 20. Coal Market Module Supply Regions

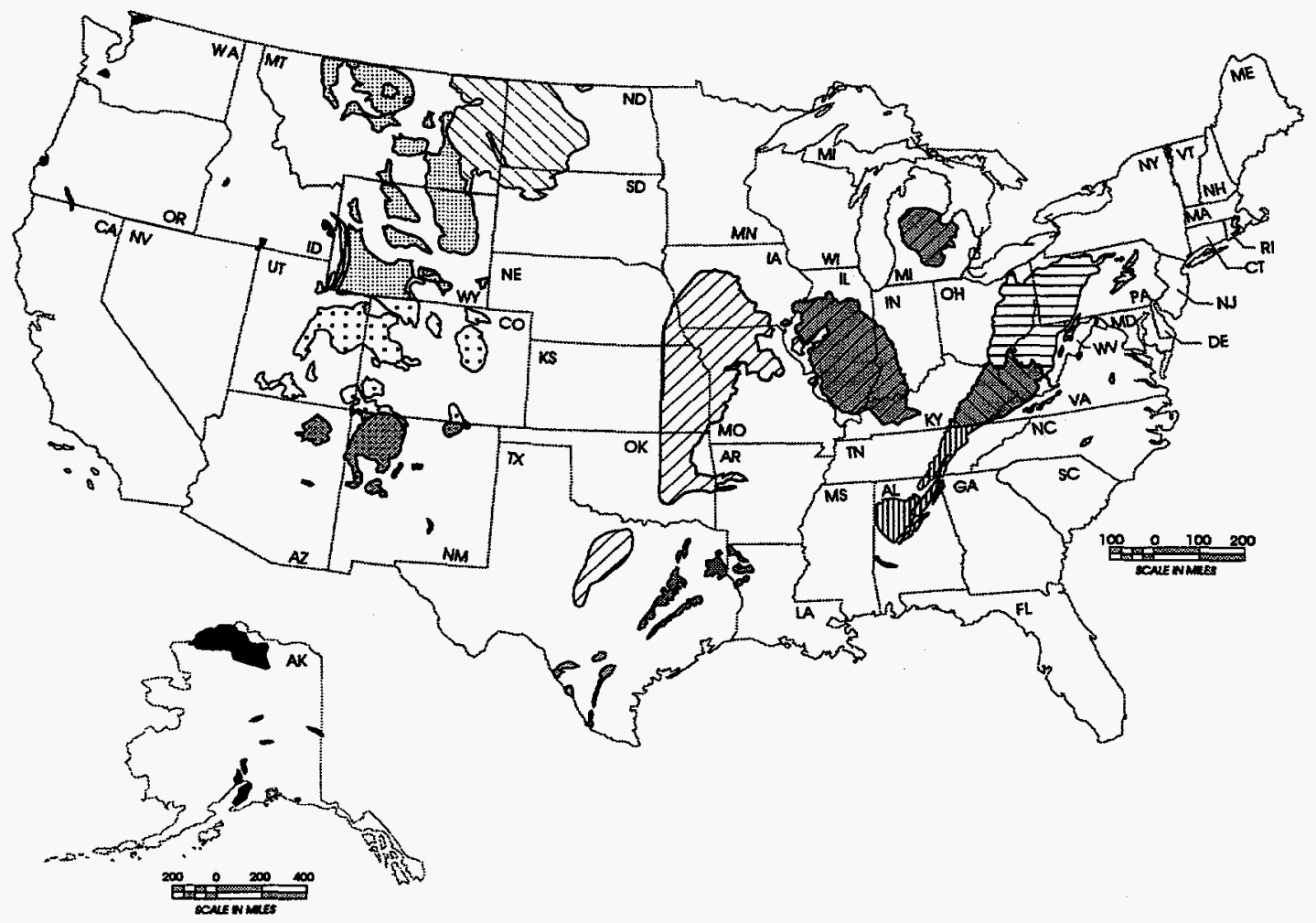

APPALACHIA

INTERIOR

NORTHERN GREAT PLAINS

OTHER WEST

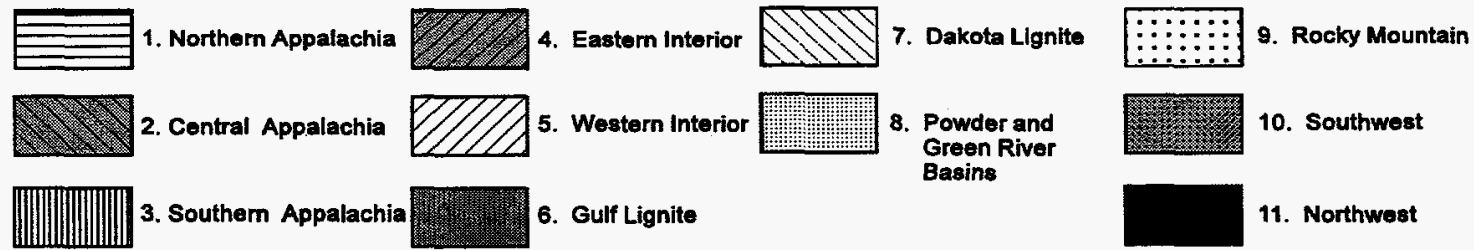

\begin{tabular}{|ll|ll|}
\hline \multicolumn{2}{|c|}{ Coal Export Regions } & \multicolumn{2}{c|}{ Coal Import Regions } \\
\hline U.S. East Coast & South Africa & U.S. East Coast & Iberia \\
U.S. Gulf Coast & Poland & U.S. Gulf Coast & Italy \\
U.S. Southwest and West & CIS (Europe) & U.S. Northern Interior & Mediterranean and Eastern Europe \\
U.S. Northern Interior & CIS (Asia) & U.S. Noncontiguous & Mexico \\
U.S. Noncontiguous & China & Eastern Canada & South America \\
Australia & Colombia & Interior Canada & Japan \\
Western Canada & Indonesia & Scandinavia & East Asia \\
Interior Canada & Venezuela & United Kingdom and Ireland & Hong Kong \\
& & Germany & ASEAN (Association of South East Asia Nations) \\
& & Other Northwestern Europe & India and South Asia \\
\hline
\end{tabular}


Figure 21. Coal Market Module Structure

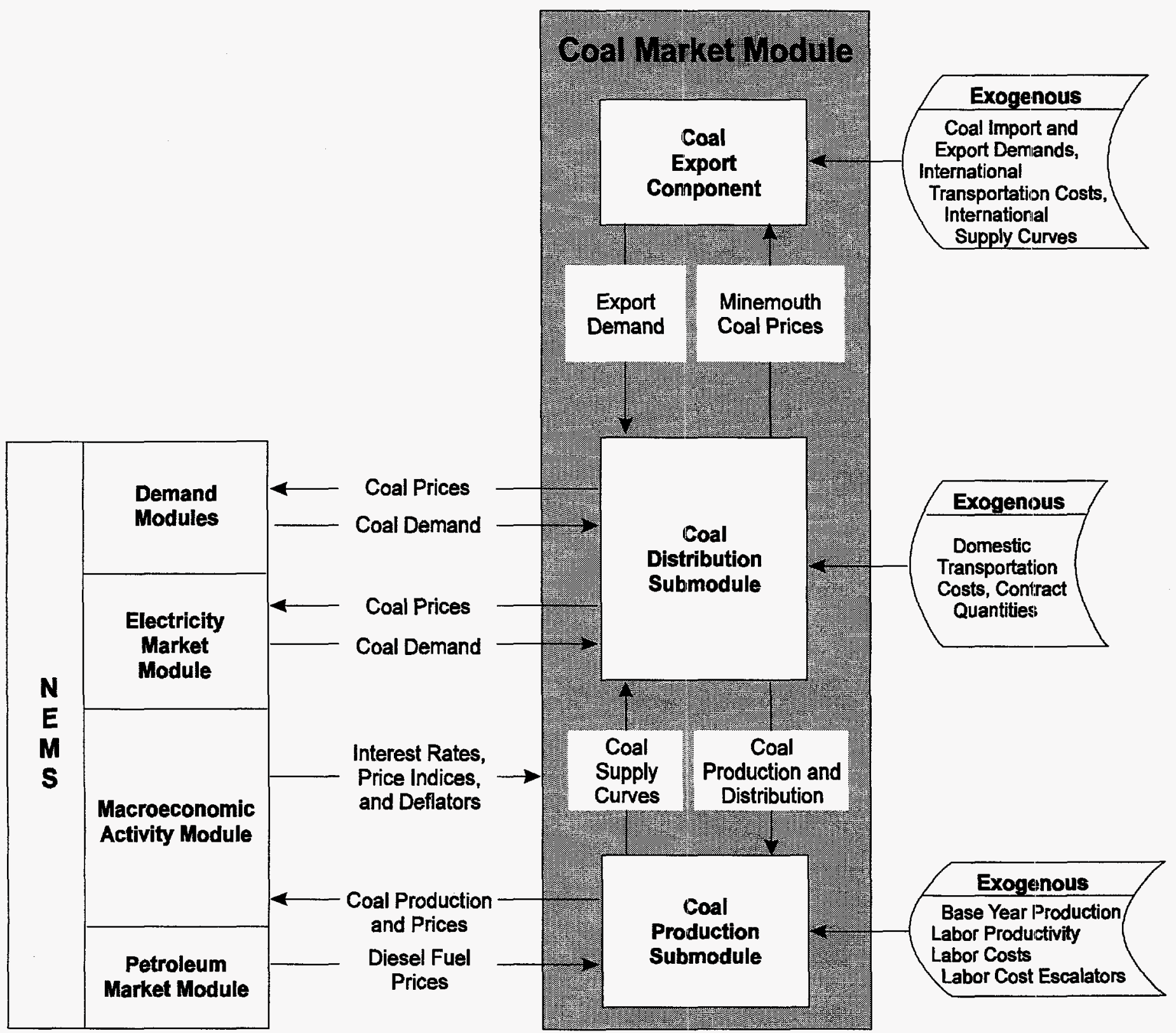


The National Energy Modeling System is documented in a series of model documentation reports, available by contacting the National Energy Information Center (202/586-8800).

Energy Information Administration, National Energy Modeling System Integrating Module Documentation Report, DOE/EIA-M057(97) (Washington, DC, May 1997).

Energy Information Administration, Model Documentation Report: Macroeconomic Activity Module (MAM) of the National Energy Modeling System, DOE/EIA-M065(97) (Washington, DC, December 1996).

Energy Information Administration, Model Developer's Appendix to the Model Documentation Report: NEMS Macroeconomic Activity Module, DOE/ELA-M065A (Washington, DC, July 1994).

Energy Information Administration, Documentation of the DRI Model of the U.S. Economy, DOE/ELA-M061 (Washington, DC, December 1993).

Energy Information Administration, NEMS International Energy Module, Model Documentation Report, DOE/EIA-M071 (Washington, DC, April 1994).

Energy Information Administration, EIA Model Documentation: World Oil Refining Logistics Demand Model, "World" Reference Manual, DOE/EIA-M058 (Washington, DC, March 1994).

Energy Information Administration, Model Documentation Report: Residential Sector Demand Module of the National Energy Modeling System, DOE/EIA-M067(98) (Washington, DC, January 1998).

Energy Information Administration, Model Documentation Report: Commercial Sector Demand Module of the National Energy Modeling System, DOE/EIA-M066(98) (Washington, DC, January 1998).

Energy Information Administration, Model Documentation Report: Industrial Sector Demand Module of the National Energy Modeling System, DOE/EIA-M064(98) (Washington, DC, January 1998).

Energy Information Administration, Model Documentation Report: Transportation Sector Model of the National Energy Modeling System, Volume I, DOE/EIA-M070(98)/1 (Washington, DC, January 1998).
Energy Information Administration, Model Documentation Report: Transportation Sector Model of the National Energy Modeling System, Volume II, DOE/EIA-M070(98)/2 (Washington, DC, January 1998).

Energy Information Administration, Model Developer's Report for the Transportation Module, DOE/ELA-M070A (Washington, DC, March 1995).

Energy Information Administration, Model Documentation: Electricity Market Module, Load and Demand-Side Management Submodule. Volume 1: Model Description, DOE/EIA-M068-A/1 (Washington, DC, March 1994).

Energy Information Administration, Model Documentation: Electricity Market Module, Load and Demand-Side Management Submodule. Volume 2: Model Code Listing, DOE/EIA-M068-A/2 (Washington, DC, March 1994).

Energy Information Administration, Model Documentation: Electricity Market Module, Electricity Capacity Planning Submodule, DOE/EIA-M068-B (Washington, DC, March 1994).

Energy Information Administration, Model Documentation: Electricity Market Module, Modifications to the Electricity Capacity Planning Submodule, DOE/ELA-M068-B/1 (Washington, DC, April 1995).

Energy Information Administration, Electricity Market Module, Electricity Capacity Planning Submodule Updates for the Annual Energy Outlook 1996, DOE/EIAM068-B/2 (Washington, DC, June 1996).

Energy Information Administration, Model Documentation: Electricity Market Module, Modeling Renewable Portfolio Standards for the Annual Energy Outlook 1998, DOE/EIA-M068-B/3 (Washington, DC, February 1998).

Energy Information Administration, Model Documentation: Electricity Market Module, Electricity Finance and Pricing Submodule, DOE/EIA-M068-C (Washington, DC, April 1994).

Energy Information Administration, Model Documentation: Electricity Market Module, Modifications to Incorporate Competitive Electricity Prices in the Annual Energy Outlook 1998, DOE/EIAM068-C/1 (Washington, DC, February 1998). 


\section{BIBLIOGRAPHY}

Energy Information Administration, Model Documentation: Electricity Market Module, Electricity Fuel Dispatch Submodule, DOE/ELA-M068-D(97) (Washington, DC, January 1997).

Energy Information Administration, Documentation of the Electricity Market Module (EMM). Appendix: Model Developer's Report, DOE/EIA-M068 Appx (Washington, DC, February 1995).

Energy Information Administration, Documentation of the Oil and Gas Supply Module (OGSM), DOE/EIAM063(98) (Washington, DC, January 1998).

Energy Information Administration, Documentation of the Oil and Gas Supply Module (OGSM). Appendix: Model Developer's Report, DOE/EIA-M063A (Washington, DC, July 1994).

Energy Information Administration, Model Documentation: Natural Gas Transmission and Distribution Model of the National Energy Modeling System. DOE/EIA-M062/1(98) (Washington, DC, January 1998).

Energy Information Administration, Model Documentation: Natural Gas Transmission and Distribution Model (NGTDM) of the National Energy Modeling System: Model Developer's Report, DOE/EIAM062/2 (Washington, DC, July 1995).
Energy Information Administration, EIA Model Documentation: Petroleum Market Model of the National Energy Modeling System, DOE/ELA-M059(98) (Washington, DC, December 1997).

Energy Information Administration, Documentation of the Petroleum Market Model (PMM). Appendix: Model Developer's Report, DOE/ELA-M059/A (Washington, DC, December 1994).

Energy Information Administration, Model Documentation: Coal Market Module of the National Energy Modeling System, DOE/ELA-M060(98) (Washington, DC, January 1998).

Energy Information Administration, Model Documentation: Renewable Fuels Module of the National Energy Modeling System, DOE/ELA-M069(98) (Washington, DC, January 1998).

Energy Information Administration, Model Documentation: Renewable Fuels Module of the National Energy Modeling System. Appendix: Model Performance, DOE/ELA.M069/A (Washington, DC, September 1994). 